\title{
The Behavior of
}

Large Particles

Falling in Quiescent Liquids

GEOLOGICAL SURVEY PROFESSIONAL PAPER 562-C

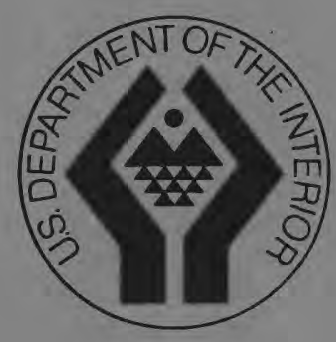




\section{The Behavior of}

Large Particles

Falling in Quiescent Liquids

By G. E. STRINGHAM, D. B. SIMONS, and H. P. GUY

SEDIMENT TRANSPORT IN ALLUVIAL CHANNELS

GEOLOGICAL SURVEY PROFESSIONAL PAPER 562-C

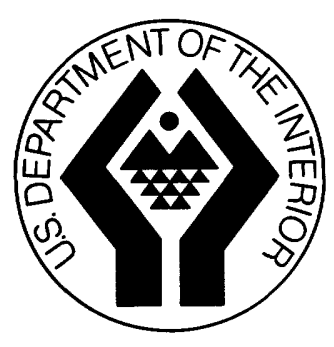

UNITED STATES GOVERNMENT PRINTING OFFICE, WASHINGTON : 1969 
UNITED STATES DEPARTMENT OF THE INTERIOR

STEWART L. UDALL, Secretary

GEOLOGIGAL SURVEY

William T. Pecora, Director

For sale by the Superintendent of Documents, U.S. Government Printing Office

Washington, D.C. 20402 - Price 55 cents (paper cover) 


\section{CONTENTS}

Abstract_-

Introduction

Drag concepts.

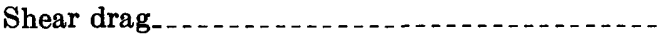

Pressure drag . . . . . .

Total drag-

Historical development of drag concepts. . . . . . . .

Mathematical development. ..............

Experimental development

Acknowledgments.

Fall behavior parametess

Variables affecting particle behavior..............

Fluid variables...............................

Variables associated with particle motion. ......

Geometric variables...........................

Dimensional analysis.........................

Coefficient of drag versus Reynolds number...-

Shape factor.

Frequency numbers

Stability numbers

Force number

\begin{tabular}{r|} 
Page \\
C1 \\
1 \\
1 \\
2 \\
2 \\
2 \\
2 \\
3 \\
3 \\
3 \\
5 \\
5 \\
5 \\
5 \\
5 \\
7 \\
7 \\
8 \\
9 \\
9 \\
9 \\
10
\end{tabular}

Fall behavior parameters-Continued

Choice of characteristic diameters and velocities_. _. $\quad$ C10

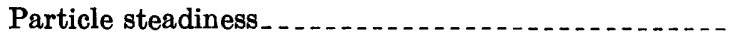

Particles, liquids, equipment, and procedure

Particles

Equipment.

Procedure

Experimental results

Description of findings.

Spheres............ 16

Disks_.................... 17

Oblate spheroids_............. 27

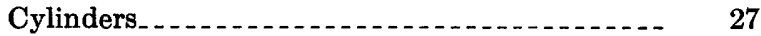

Prolate spheroids .

Comparison of behavior among all particles....... 31

Interpretation of results.

Parametric relationships........ 32

Patterns of fall

Shape factors._... 33

Summary and conclusions........ 35

References cited. 36

\section{ILLUSTRATIONS}

Figure

1. Sketches showing vortex pattern of an oscillating disk

Page

2. Sketches of circular fluid flow around a particle

3. Graph showing coefficient of drag as a function of Reynolds number for fixed disks,

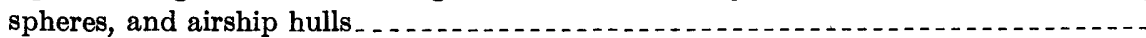

4. Sketch showing forces on a falling disk

5. Photographs of particles used in experiments

6. Graph of kinematic viscosity of glycerine-water mixtures as a function of temperature.-

7. Graph of density of glycerine-water mixtures as a function of temperature.........

8. Schematic diagram of fall column

9. Sketch showing distortion of light rays caused by fluid refraction and the curved surface of the fall column

10. Graph of coefficient of drag as a function of Reynolds number and force number for

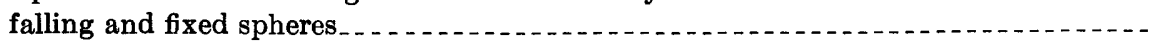

11-15. Sketches showing fall pattern of a disk:

11. Steady

12. Regular oscillation...

13. Entering glide-tumble-_.

14. Leaving glide-tumble. . .

15. Tumble.

16. Graph showing regimes of fall for a free-falling disk

17-19. Graphs showing velocity-time relationship of falling disk for-

17. Aluminum in an oscillatory pattern.

18. Aluminum in a glide-tumble pattern

19. Lead in a tumbling pattern. 
Figures 20-21. Graphs showing comparison of maximum and nominal particle diameter for coefficient of drag as a function of Reynolds number for falling disks, $S F_{c}=0.1$, based on-

20. Path velocity..-

21. Vertical velocity

22. Graph showing coefficient of drag as a function of frequency number for falling disks, $S F_{c}=0.1$

23-24. Graphs showing coefficient of drag as a function of Reynolds number, $S F_{c}=0.5$, for-

23. Falling oblate spheroids

24. Falling cylinders

25. Graph showing coefficient of drag as a function of frequency number for falling cylinders, $S F_{c}=0.5$

26. Graph showing coefficient of drag as a function of Reynolds number for falling prolate spheroids, $S F_{c}=0.71_{\ldots} \ldots$

27. Composite graphs of coefficient of drag as a function of Reynolds number for falling spheres, disks, oblate spheroids, cylinders, and prolate spheroids based on maximum and nominal particle diameter and path velocity

\section{TABLES}

TABLE

1. Particle properties, measured and computed.

2. Spheres

3. Disks.

5. Cylinders

6. Prolate spheroids.

7. Frequency of oscillation of unstable particles falling in water-glycerine mixtures......

\section{SYMBOLS}

A characteristic area of the particle $\left(\mathrm{cm}^{2}\right)$. In this paper it is the maximum projected area of the particle.

$A_{n} \quad$ The area projected on the basis of the nominal diameter $\left(\mathrm{cm}^{2}\right)$.

$C_{1}$... Dimensionless coefficients.

$C_{D} \quad$ Coefficient of drag.

$C_{L} \quad$ Coefficient of lift.

$D \quad$ Drag forces (dynes).

$F \quad$ Driving force defined by $\left(\rho_{p}-\rho_{f}\right) \forall g$ (dynes).

I Moment of inertia of the particle (dyne-cm-sec ${ }^{2}$ ).

$L \quad$ Lift force (dynes).

$M \quad$ Virtual mass (dyne-sec $2 / \mathrm{cm}$ ).

$N_{c} \quad$ Number of corners.

$O$. Volume of a sphere circumscribing a particle $\left(\mathrm{cm}^{3}\right)$.

$O_{c} \quad$ Circumference of a circle of area equal to the plane area of the particle $(\mathrm{cm})$.

$O_{p} \quad$ Circumference of a particle $(\mathrm{cm})$.

$\mathbf{R}$ Reynolds number based on particle size $\left(\rho_{f} \omega d / \mu\right)$.

$R_{p} \quad$ Resistance due to pressure.

$R_{s} \quad$ Resistance due to shear.

$R_{t} \quad$ Total resistance.

$S \quad$ Surface area of the particle $\left(\mathrm{cm}^{2}\right)$.

$S F \quad$ Shape factor.

$S F_{c} \quad$ Corey shape factor $(c / \sqrt{a h})$.

$S F_{c a} \quad$ Corey shape factor modified by Alger.

$S F_{d} \quad$ Dynamic shape factor $\left(\omega / \omega_{n}\right)^{2}$.

$S_{\boldsymbol{r}} \quad$ Surface roughness.

$¥ \quad$ Volume $\left(\mathrm{cm}^{3}\right)$. 


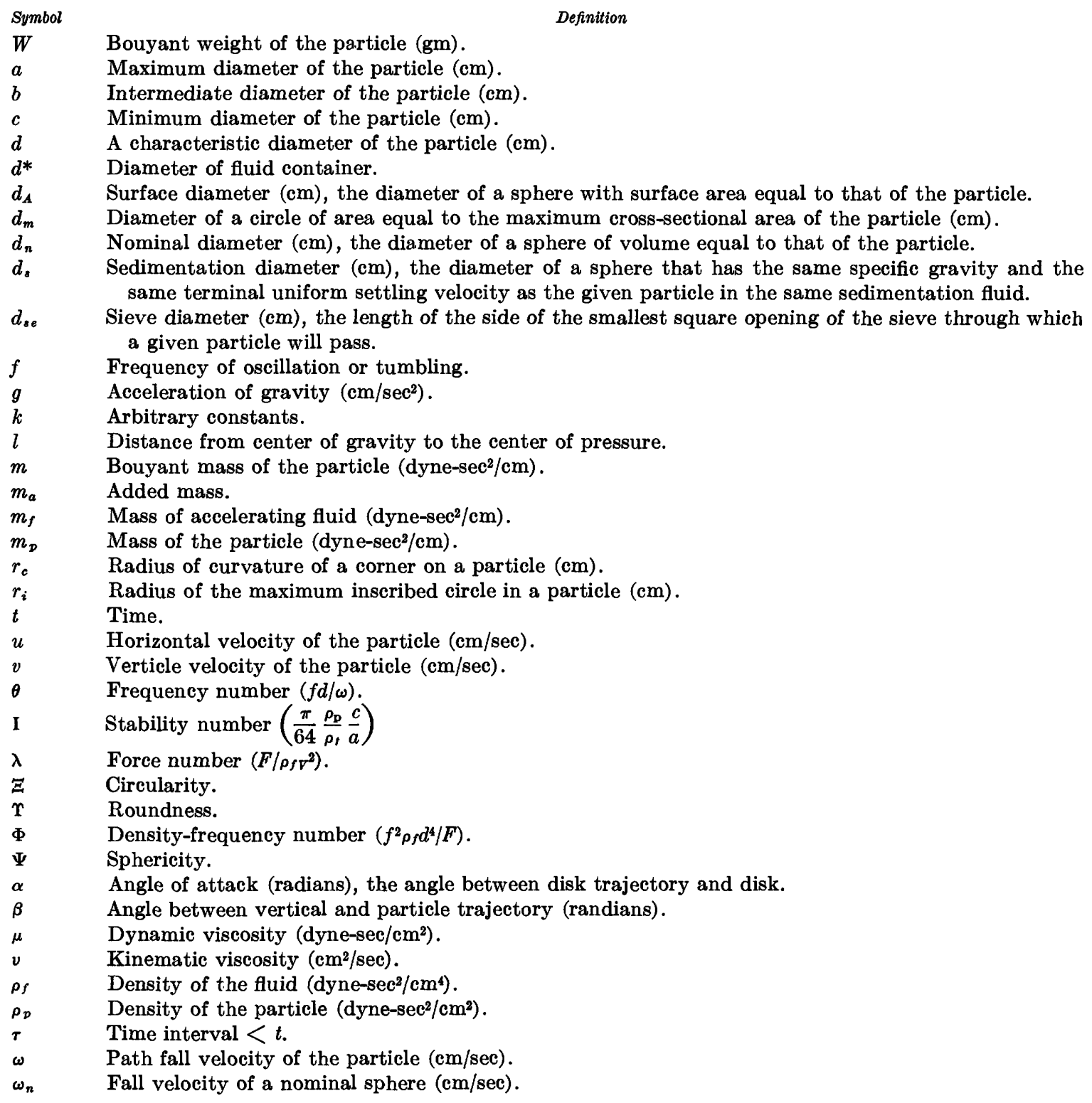





\title{
SEDIMENT TRANSPORT IN ALLUVIAL CHANNELS
}

\section{THE BEHAVIOR OF LARGE PARTICLES FALLING IN QUIESGENT LIQUIDS}

\author{
By G. E. Stringham, D. B. Simons, and H. P. Guy
}

\begin{abstract}
The free-fall behavior patterns of specific idealized particles falling singly in quiescent liquids were observed with respect to fall patterns, fall velocity, and travel path. Particle shapes and densities were chosen to represent the limiting conditions of natural gravel-sized sediment found in alluvial channels. The liquids used in the fall column were water, various mixtores of water and glycerine, and pure glycerine.

The particles were dropped in a vertical clear plexiglass falli
\end{abstract} column 3 meters high and $40 \mathrm{~cm}$ in diameter. Two $16-\mathrm{mm}$ movie cameras set at right angles to each other and focused on a timer and a 1-meter test section of the column recorded the particle behavior. The horizontal and vertical coordinates of the particles were established by projecting the image of the particles moving through the test section onto a grid.

The spheres usually fell in a straight vertical path, but sometimes the nylon or teflon spheres falling in pure water exhibited small erratic horizontal movements. Disks, on the other hand, exhibited four types of fall behavior: (1) steady-flat fall-maximum projected area perpendicular to the axis of the fall when the Reynolds number $\mathbf{R}<100$; (2) regular oscillation-oscillation occurred about a diameter perpendicular to the direction of fall, and there was very little horizontal translation; (3) glidetumble-the frequency of oscillation was less than regular oscillation, the amplitude increased until the disks fell vertically on edge part of the time, and sometimes tumbling occurred at the end of each glide; and (4) tumble-the axis of the fall path was virtually a straight inclined line, the disk continually rotated, and the frequency of rotation approached the frequency of oscillation in the oscillation behavior pattern.

The steadiness of a falling particle is dependent upon the stability of the resultant of the pressure forces in the wake of the particle. Shape of the particle and the Reynolds number both affect the distribution of the pressure forces in the wake with extremes in shape and high $\mathbf{R}$ causing the resultant force to be the least stable. Thus, the fall pattern of a disk, which is in effect a two-dimensional particle, is much less steady than the fall pattern of a three-dimensional sphere. The ratio of the path length to vertical distance through which the particle falls is also related to the steadiness of the particle, the more unsteady the particle, the greater the path length.

The effect of particle-fluid density ratio and the thicknessdiameter ratio of the particle on its fall velocity and steadiness can be expressed by a dimensionless stability number I. The frequency of oscillation can be related to the fall velocity and particle diameter by a dimensionless frequency number $\theta$.

\section{INTRODUCTION}

The fall velocity of a sediment particle, defined as the rate at which the particle settles through a fluid, is one of the most important factors affecting the erodibility and movement of earth material, the time that a particle will remain in suspension in streamflow, and the nature of deposition and bed roughness formed in moving and quiet waters.

The fall velocity for a given particle depends on its shape, size, and density as well as on the physical properties of the fluid. All these factors, individually or in combination, may affect the stability and the fall path of the particle. Other properties, such as roughness, roundness, or concentration of particles, and turbulence in the fluid, may also be important.

\section{PROBLEM AND SCOPE}

A particle moving relative to a fluid is acted upon by a drag force whose magnitude is a function of the relative velocity between fluid and particle, fluid density, and particle size and shape. The drag force is usually expressed as a function of the particle velocity and size and in terms of the fluid properties. The relationship is not unique, however, and must be correlated by means of a coefficient of drag $C_{D}$. The coefficient of drag is, in turn, related to the Reynolds number $\mathbf{R}$. The relationship between $C_{D}$ and $\mathbf{R}$ can be shown graphically by plotting $C_{D}$ as a function of $\mathbf{R}$ on logarithmic paper. Such a diagram will be referred to as the $C_{D}-\mathbf{R}$ diagram.

For some idealized cases, the relationship between $C_{D}$ and $\mathbf{R}$, at small values of $\mathbf{R}$, can be determined mathematically. Generally, however, it must be established experimentally.

The relationship between the coefficient of drag and the Reynolds number is often established with the particles rigidly mounted in a moving fluid. Different and more complicated is the case of freely moving 
particles in either a quiescent or a moving fluid. The resistance forces on a free particle cannot be measured directly but must be estimated from limited mathematical theory and from tests on mounted particles. Thus, the effects of rotation, density, and inertia in the unsteady fall path of a particle cannot be considered if the particle is not free to respond to the unbalanced forces which may develop around it. This paper is a report of a study made to investigate some aspects of free-fall phenomena.

The scope of the study was limited to the examination of the free-fall behavior patterns of specific idealized particles falling singly in quiescent liquids. Its purpose was to evaluate the steadiness of particles with respect to orientation, fall velocity, and path of travel at Reynolds numbers greater than 10. The particles used were spheres, oblate and prolate spheroids, cylinders, and disks. The specific gravity of the spheres ranged from 1.14 to 14.95 . The specific gravities of the other shapes ranged from 2.81 to 10.15 . These shapes and specific gravities were chosen because they represent limiting conditions of natural gravel-sized sediment particles commonly found in alluvial channels. In addition, the liquids used were water, various mixtures of water and glycerine, and pure glycerine with kinematic viscosities ranging from 0.010 to $3.59 \mathrm{sq} \mathrm{cm}$ per sec, respectively.

\section{DRAG CONCEPTS}

The energy imparted to a fluid by a particle falling in the fluid is either transmitted to the boundaries of the fluid or is dissipated in heat. The internal resistance within the fluid to fluid motion is transmitted to the particle, in accordance with Newton's third law of motion, and is called drag. According to Albertson, Barton, and Simons (1960), this drag, or fluid resistance, is of two general types: shear drag, the tangential component of the resistance, and pressure drag, the normal component of resistance.

\section{SHEAR DRAG}

A shearing force related to the viscosity of the fluid occurs within the fluid as the molecules attracted to the particle move past those of the surrounding fluid. The magnitude of the resistance due to shear can be defined by

$$
R_{s}=C_{1} S \frac{\rho_{f} \omega^{2}}{2},
$$

where

$$
\begin{aligned}
C_{1} & =\text { a dimensionless coefficient } \\
S & =\text { surface area of particle }\left(\mathrm{cm}^{2}\right), \\
\rho_{f} & =\text { density of the fluid }(\text { dyne-sec } \\
\omega & =\text { path fall velocity of the particle }(\mathrm{cm} / \mathrm{sec})
\end{aligned}
$$

Equation 1 is a function of the Reynolds number

$$
\mathbf{R}=\frac{\omega d}{v},
$$

which can be defined as the ratio of the fluid inertia forces to the fluid viscous forces and where

$$
\begin{aligned}
& d=\text { characteristic length of the particle }(\mathrm{cm}) \text { and } \\
& v=\text { kinematic viscosity }\left(\mathrm{cm}^{2} / \mathrm{sec}\right) .
\end{aligned}
$$

At very small $\mathbf{R}$, the shear force is the result of the shear stress acting over the entire surface of the particle and is distributed throughout the fluid. If the fluid is of finite extent, the stress is transferred to its outer boundaries. On the other hand, at large $\mathbf{R}$, separation occurs on the lee side of the particle, causing a wake to develop. The formation of the wake decreases the surface area over which the shear force acts. At the same time, the velocity around the particle increases, which tends to increase the shear drag. Then, at large $R$, the most concentrated stresses are confined to the boundary layer near the surface of the particle and to the wake of the particle. Most of the energy imparted to the fluid is dissipated in the wake.

\section{PRESSURE DRAG}

The resistance to movement of the mass of fluid in the path of a particle causes a positive pressure in front of, and a negative pressure behind, the particle. This pressure differential is the resistance to fall due to pressure drag and can be defined by

$$
R_{p}=C_{2} A \frac{\rho_{f} \omega^{2}}{2},
$$

where

$$
\begin{aligned}
& C_{2}=\text { a dimensionless coefficient and } \\
& A=\text { the projected area of the particle }\left(\mathrm{cm}^{2}\right) .
\end{aligned}
$$

At small $\mathbf{R}$, the pressure changes systematically around the particle in accordance with the relative acceleration and deceleration of the fluid. The pressure force is distributed throughout the fluid. On the other hand, at large $\mathbf{R}$, a wake develops behind the particle. The pressure in the wake is virtually that found in the boundary layer at the point of separation. As in shear drag at large $\mathbf{R}$, the pressure forces are confined to the boundary layer and the wake of the particle.

\section{TOTAL DRAG}

The surface area of a particle $S$, used in equation 1 , can be expressed as the product of some constant and the projected area of the particle $A$ used in equation 3 . When the total resistance $R_{t}$ of a freely falling particle becomes equal to the buoyant weight or total driving 
force $F$ of the particle, equations 1 and 3 may be written in the form

$$
R_{t}=F=C_{D} A \frac{\rho_{f} \omega^{2}}{2},
$$

where

$C_{D}=C_{1}$ (constant) $+C_{2}=$ coefficient of drag,

$F=\forall g\left(\rho_{p}-\rho_{f}\right)$ in dynes,

$g=$ acceleration of gravity in $\mathrm{cm} / \mathrm{sec}^{2}$,

$¥=$ particle volume in $\mathrm{cm}^{3}$,

$\rho_{f}=$ fluid density in dyne- $\mathrm{sec}^{2} / \mathrm{cm}^{4}$, and

$\rho_{p}=$ particle density in dyne- $\mathrm{sec}^{2} / \mathrm{cm}^{4}$.

This is the general form of the law of resistance to motion of solids in a fluid as expressed first by Newton (Prandtl and Tietjens, 1934).

At small $\mathbf{R}$ (less than 0.5), Stokes' solution (Lamb, 1932) for resistance to flow around spheres shows that two-thirds of the total resistance is due to shear, and one-third is due to pressure. The drag at small $\mathbf{R}$ is sometimes called deformation drag because the shear and the pressure forces are distributed throughout the fluid and thus "deform" the fluid.

At large $\mathbf{R}$, the shear drag becomes insignificant, and the total drag becomes predominantly pressure drag.

\section{HISTORICAL DEVELOPMENT OF DRAG CONCEPTS}

The present knowledge of resistance to motion experienced by a solid particle falling through a fluid has been developed largely within the past 125 years. Both mathematical and experimental studies have contributed to this fund of knowledge.

\section{MATHEMATICAL DEVELOPMENT}

From the Navier-Stokes equations, rather concise equations have been developed that define the nature of flow around particles for Reynolds number $\mathbf{R}$ less than about 0.5. However, solutions to the NavierStokes equations have not been found for flow conditions where $\mathbf{R}>>0.5$ as in this study; hence, the Navier-Stokes equations are not applicable hereir.

For values of $\mathbf{R}$ greater than the Stokes range, concepts will be based on the Lagrangian description of flow phenomenon, or from the point of view of an observer traveling with the particle through a stationary fluid. For unsteady motion of a particle in a fluid, Stelson and Mavis (1957) show that the force required to cause acceleration is greater than the force required to accelerate the mass of the particle $m_{p}$, and that the mass of the displaced fluid $m_{f}$ must be considered. The mass of the fluid that must be considered is related to the shape as well as the size of the particle. The total mass, or virtual mass $M$ is, therefore, the sum of the particle mass and an appropriate fluid mass.
The character of the resistance of an accelerating particle is defined by Brush (1964) on the basis of Basset's equations. When the nonlinearity of the resistance term, for motion beyond the Stokes range, is accounted for, the equation becomes:

$M \frac{d \omega}{d t}=\left(m_{p}-m_{f}\right) g-C_{D} \frac{\pi d^{2} \rho_{f}}{8}|\omega| \omega-\frac{3}{2} d^{2} \sqrt{\pi \rho_{f} u} \int_{0}^{t} \frac{\frac{d \omega}{d t} d \tau}{\sqrt{t-\tau}}$

where

$$
\begin{aligned}
g & =\text { acceleration of gravity }\left(\mathrm{cm} / \mathrm{sec}^{2}\right) \\
d & =\text { a characteristic diameter of the particle }(\mathrm{cm}), \\
\mu & \left.=\text { dynamic viscosity (dyne-sec } / \mathrm{cm}^{2}\right) \\
t & =\text { time (sec), } \\
\tau & =\text { time interval } \leq t \\
M & =\text { virtual mass }(\text { dyne-sec } / \mathrm{cm}), \\
m_{p} & =\text { mass of the particle }\left(\mathrm{dyne}-\mathrm{sec}^{2} / \mathrm{cm}\right), \text { and } \\
m_{f} & =\text { mass of the accelerating fluid }\left(\mathrm{dyne}-\mathrm{sec}^{2} / \mathrm{cm}\right)
\end{aligned}
$$

For steady motion, equation 5 reduces to equation 4 . A solution to equation 5 was presented by Brush in the form of series expansions, which is suitable for computer analysis.

Odar and Hamilton (1964) also worked with Basset's equation. They expanded its range of applicability into the nonlinear zone by accounting for the ratio of the convective to local acceleration.

\section{EXPERIMENTAL DEVELOPMENT}

The flow characteristics around a particle become so complex when $\mathbf{R}>1$ that resistance to motion and the behavior of the falling particle must be determined experimentally. Thus, Newton's law of resistance, equation 4, has been used as the basis of experimental development. The experimental development has been achieved by determining $C_{D}$ from measurements of the fluid and particle properties as needed in equation 4 and from measurement of the particle velocity relative to that of the fluid.

Pernolet (Wadell, 1934), a French engineer, made some of the first experiments on fall velocity in 1851 . He discovered that the fall velocity of lead particles of similar weight varied with shape. Among the first contributors to use a systematic approach to determine the effect of shape on fall velocity of a particle included Rubey (1933) Zergrzda (Schulz and others, 1954) and Wadell (1932). Included in Wadell's (1932, 
$1933,1934)$ work were the following particle descriptive parameters:

1. The nominal diameter $d_{n}$, the diameter of a sphere having a volume equal to the volume of the particle $¥$,

$$
d_{n}=\left|\frac{6 \mp}{\pi}\right|^{1 / 3} .
$$

2. The degree of sphericity $\Psi$, the cube root of the ratio of the volume of the particle to the volume of the circumscribing sphere $O_{v}$,

$$
\Psi=\left|\frac{¥}{O_{v}}\right|^{1 / 3} \text {. }
$$

3. The degree of roundness $\boldsymbol{\Upsilon}$, in a plane with respect to the particle, the ratio of the sum of the ratio of the radius of curvature of the corner $r_{c}$ to the radius of the maximum inscribed circle $r_{i}$ to the number of corners $N_{c}$,

$$
\Upsilon=\frac{\sum \frac{r_{c}}{r_{i}}}{N_{c}}
$$

4. The degree of circularity $\Xi$, the ratio of the length of the circumference of a circle of area equal to the plane area of the particle $O_{c}$ to the length of the circumference of the particle $O_{p}$,

$$
\Xi=\frac{O_{c}}{O_{p}}
$$

Of these four shape parameters, the nominal diameter has greatest application because of the relative ease of making the necessary measurements. It is used extensively as the characteristic length in computations of the Reynolds number.

In addition to Wadell's nominal diameter, two other particle diameter concepts are commonly used and defined by B. C. Colby (in U.S. Inter-Agency Comm. Water Resources, 1957).

1. The sedimentation diameter $d_{s}$ is the diameter of a sphere that has the same specific gravity and same terminal uniform settling velocity as the given particle in the same sedimentation fluid. The sedimentation diameter varies with the viscosity of the fluid. Chatuthasry (1961) studied the sedimentation diameter as a function of the nominal diameter and found that the ratio $d_{s} / d_{n}$ tended to decrease when $\mathbf{R}$ increased beyond 100 .

2. The sieve diameter $d_{s e}$ is the length of the side of the smallest square opening of the sieve through which the given particle will pass. Serr (1948) proposed that the ratio $d_{s e} / d_{s}$ be used as a measure of particle shape.

Shape description was advanced independently by Corey (1949) and McNown and Malaika (1950) with an expression of the ratio of the three mutually perpendicular axis lengths,

$$
S F_{c}=\frac{c}{\sqrt{a b}}
$$

where

$a=$ maximum diameter of the particle $(\mathrm{cm})$,

$b=$ intermediate diameter of the particle $(\mathrm{cm})$, and

$c=$ minimum diameter of the particle $(\mathrm{cm})$.

It was soon learned that this relationship did not adequately relate the fall velocity of all sizes and shapes of particles to that of the fall velocity of a sphere. Alger (1964) used the ratio of the diameter of a sphere whose surface area is equal to that of the particle to the nominal diameter of the particle, $d_{A} / d_{n}$, to modify equation 10.

In a study of the various shape parameters affecting fall velocity, Wilde (1952) found that the maximum projected area of a particle could be closely approximated by the product of the lengths of the major and intermediate axes. He also found that the fall velocity increased greatly with the roundness of a particle. Roundness has not been used extensively because it is difficult to measure.

A dynamic shape factor $S F_{d}$ has been derived by Briggs, McCullock, and Moser (1962) by solving equation 4 for $\omega^{2}$, dividing both sides by the square of the fall velocity of a nominal sphere $\omega_{n}$ and combining terms to obtain

$$
S F_{d}=\frac{\omega^{2}}{\omega_{n}^{2}}=\frac{8}{\pi} \frac{F}{\rho_{f} v} \frac{1}{C_{D} \mathbf{R}^{2}} .
$$

At large $\mathbf{R}$, the fall pattern of particles is usually irregular. Wilmarth, Hawk, and Harvey (1964) studied the fall pattern of disks in various fluids and found that the dimensionless mass moment of intertia $I$ of disks correlated with particle stability. The inertia term "I," referred to in this paper as the "stability number," is defined by:

$$
\mathrm{I}=\frac{I}{\rho_{f} a^{5}}=\frac{\pi}{64} \stackrel{\rho_{p}}{\rho_{f}} \frac{c}{a}
$$

where $I=$ the mass moment of inertia of the particle (dyne-cm-sec ${ }^{2}$ ). Experimentally, I determines a poimt on the $C_{D}-\mathbf{R}$ diagram at which a particle would no longer be steady in orientation. Disks, for example, were found to be stable with the maximum area perpendicular to the fall line when $R$ is less than 100 . At 
$\mathbf{R}>100$ the orientation of the disk and its path of travel were no longer constant.

Once oscillation of the particle began, Wilmarth, Hawk, and Harvey found that I could be correlated with a dimensionless "frequency number" defined by

$$
\theta=\frac{f a}{\omega}
$$

where $f$ is the frequency of oscillation or tumbling. The relation between $I$ and $\theta$ is linear for a given $\mathbf{R}$.

It is evident from this summary of previous work on particle behavior that parameters controlling stability of the free falling particle have received too little attention, and therefore, should receive further attention in this paper.

\section{ACKNOWLEDGMENTS}

This report is a modification of a $\mathrm{Ph}$. $\mathrm{D}$. dissertation presented to Colorado State University by the senior writer (Stringham, 1965) while employed by the U.S. Geological Survey. Notable among those giving counsel and guidance during the study were Professors M. L. Albertson, R. S. Creely, and E. J. Plate, of Colorado State University, and E. V. Richardson, of the U.S. Geological Survey. Ashok Kumar, Anwiya Andrews, Reinhard Weiss, and Darell Zimbelman assisted with data collection and the reduction of voluminous raw data to a usable form.

Appreciation is extended to P. C. Benedict, R. W. Carter, B. C. Colby, B. R. Colby, J. V. Skinner, G. P. Williams, and F. Witzigman in connection with review of this paper.

\section{FALL BEHAVIOR PARAMETERS}

In accordance with the scope of this paper, it is necessary to understand how the various parameters involved in fall velocity phenomenon at $\mathbf{R}>10$ operate. A discussion of the major fall velocity parameters as deduced from dimensional analysis is presented. The general form of the resistance equation is that of equation 4.

\section{VARIABLES AFFECTING PARTICLE BEHAVIOR}

The three major kinds of variables which affect the behavior of a freely falling particle are fluid properties, particle motion characteristics, and particle characteristics. Acceleration or deceleration, as expressed in equation 5 , occurs if the drag forces do not balance the buoyant weight. When drag and buoyant weight balance, the motion is steady and is governed by equation 4. It should, therefore, be possible to define all types of falling particle behavior, including fall velocity, acceleration, and pattern of fall, in terms of the force balance between buoyant weight and drag.

\section{FLUID VARIABLES}

Fluid variables of concern are density and viscosity. The density ratio between particle and fluid $\rho_{p} / \rho_{f}$, is a measure of the driving force and hence the fall velocity of the particle. The fall velocity increases with the density ratio. The coefficient of drag $C_{D}$, the Reynolds number $\mathbf{R}$, and the stability number I are also functions of fluid density.

Both shear and pressure forces are dependent upon the viscosity of the fluid. The magnitude of the shear force is a direct function of viscosity. Viscosity controls the pressure force to the extent that it affects the nature of the boundary layer and the point at which the boundary layer separates from the particle. As discussed earlier, the point of separation affects the pressure within the wake behind the particle, and hence affects the pressure drag.

It has been noted, as will be discussed later, that patterns of fall for some particles are dependent upon their fall velocity. It is probable that changes in the fall velocity, because of viscous changes in the fluid (brought about usually by temperature changes), can significantly affect the fall pattern of the particle.

As mentioned in the introduction, the fall velocity of sediment particles found in the bed of an alluvial channel is one of the factors which control the bed form of the channel. Fahnestock and Maddock (1964) note that the bed form of the Rio Grande near El Paso, Tex., changes with the annual fluctuation of the water temperature and the corresponding change in viscosity.

\section{VARIABLES ASSOCIATED WITH PARTICLE MOTION}

Velocity, vortex formation and shedding, and circulation are the variables considered which affect fall pattern. In accordance with equation 5 , resistance to motion is a function of the square of the velocity. Both shear and pressure drags increase with increasing velocity.

\section{Vortex formation and shedding}

When separation occurs behind an object moving in a fluid, vorticies form in the wake. The vorticies remain bound to the particle under certain conditions, and under other conditions they are shed. Prandtl and Tietjens (1934) have shown that in a two-dimensional flow around a cylinder, at a certain value of $\mathbf{R}$, the vorticies are alternately shed, first from one side of the cylinder, and then the other, at regular periodic intervals. At greater $\mathbf{R}$, the periodicity disappears, but the shedding continues. This process of vortex shedding, radically changes the pressure distribution in the wake, which, in turn, may cause oscillation of the cylinder.

Wilmarth, Hawk, and Harvey (1964) painted some of their disks with a water-soluble dye. As the disk 
dropped through the water, the dye in the wake remained giving a visible trace of the wake and its associated vorticies, which they photographed. Pictorial conception of those photographs is given in figure 1 . At small $\mathbf{R}$ where the disk orientation was stable, the wake formed a straight streak behind the particle. When oscillation first began, (for $R \approx 100$ ), and motion was close to vertical with very little lateral translation, a complete horseshoe-shaped vortex ring was shed at the end of each swing (fig. $1 A$ ). At greater $\mathbf{R}$, when lateral translation was associated with the oscillation, vortex trails formed on the edges of the disk on the ends of a diameter perpendicular to the direction of motion much the same as occur on wing tips of aircraft (fig. $1 B)$. At the apex of each swing, a vortex was shed from each end of the perpendicular diameter.

Particles of other shapes will have different vortex patterns. The vortex pattern and the associated pressure distribution is one of the major factors controlling particle orientation and path of travel.

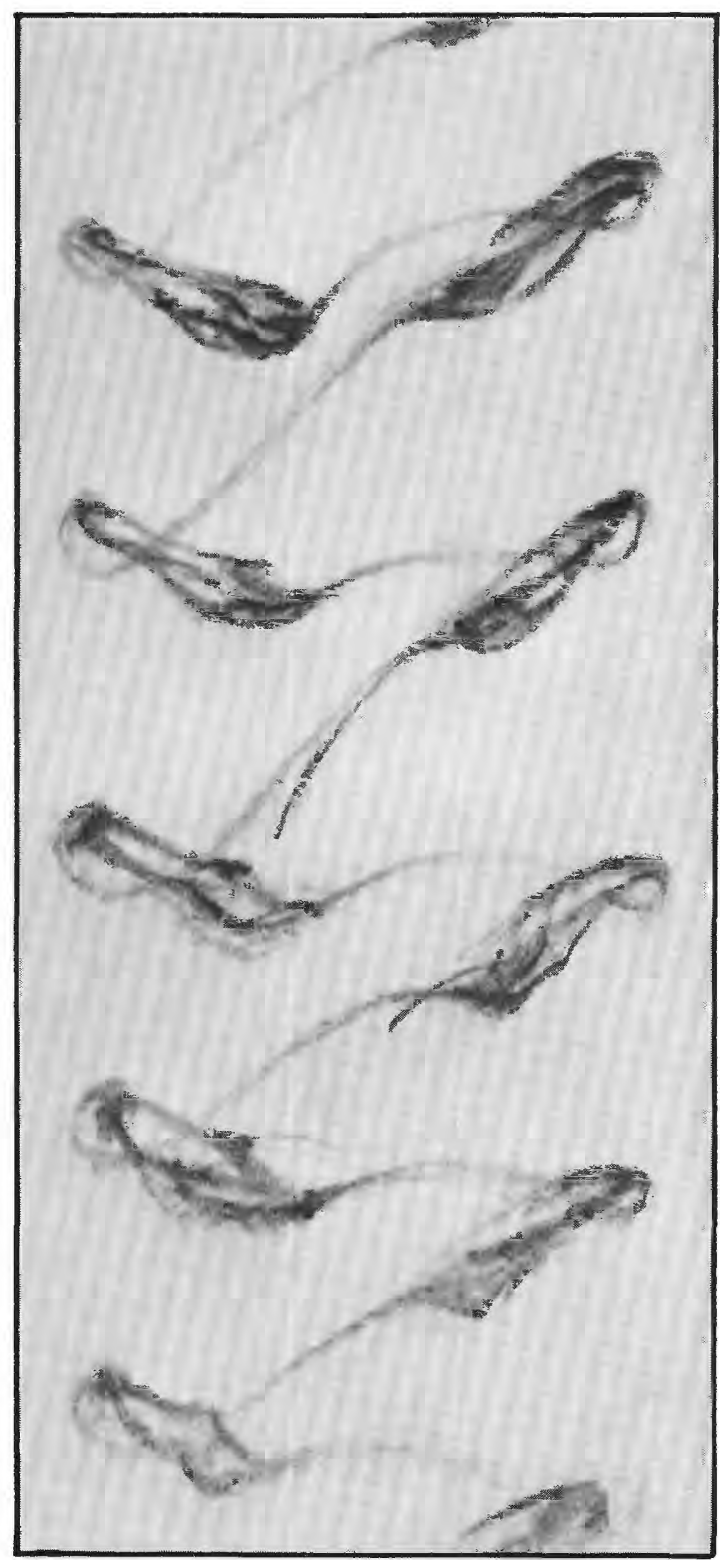

$A$

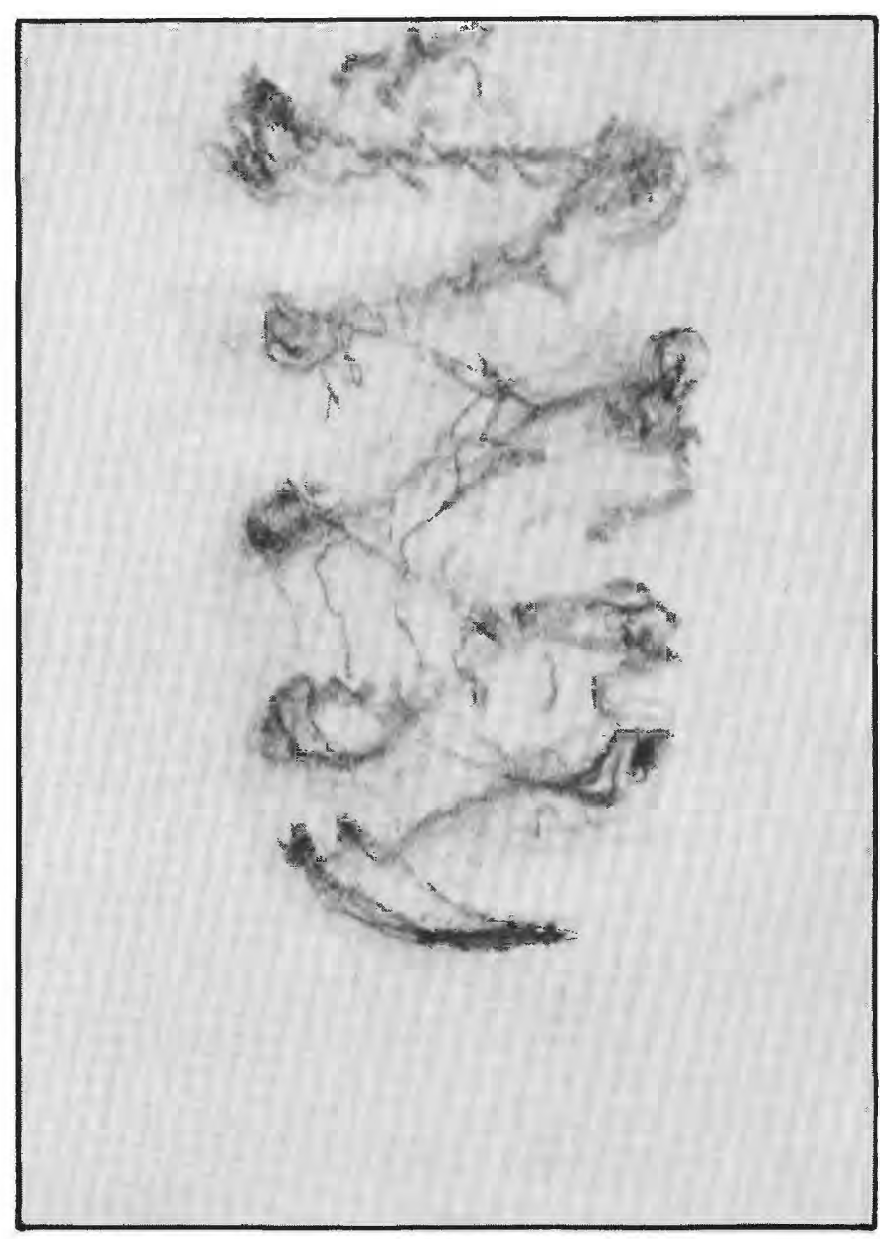

$B$

Figure 1.-Vortex pattern of an oscillating disk. After Wilmarth, Hawk, and Harvey, 1964. A, Oscillation accompained by very little horizontal translation, path of travel almost vertical. $B$, Oscillation accompanied by horizontal translation, path of travel almost parallel to disk face. 
Clrculation

Circulatlon can be considered as a circular fluid flow around a submerged particle (fig. $2 A$ ). If circular flow is superimposed on the steamline flow (fig. $2 B$ ), the streamlines will be distorted (fig. $2 C$ ). This distortion of the flow pattern causes a nonsymmetrical pressure distribution around the particle and gives rise to lateral thrust and a lift force, which combines with the drag force to resist motion.

Wilmarth, Hawk, and Harvey (1964) also show that circulation exists around the disk when lateral translation occurs. The combination of circulation of the fluid and translation of the particle is the cause of the vortex trails mentioned in the preceding section. The circulation produces a lift force on the particle similar to that associated with the aerodynamic effects upon which atmospheric flight depends. Thus, through at least part of the oscillation of the disk, its motion is controlled by a force system similar to the system which controls flight. Circulation may have some small effect on the shear drag, but this effect would be small in comparison to its effect on pressure drag.

\section{GEOMETRIC VARIABLES}

The geometric variables that affect particle behavior are shape, roundness, surface roughness, and orientation with respect to the direction of motion. The density of the particle affects the buoyant weight as indicated in the discussion of fluid density.

The relative lengths of the three mutually perpendicular axes of a particle are used as an index of the particle shape. The shape of the particle controls the geometry of fluid flow. The fluid flow geometry affects the shear and pressure drag by controlling the contact area between the fiuid and particle, the pressure distribution around it, and the point of separation of the wake.

If a particle is not symmetrical, the shape, with reference to the direction of motion, will vary with variation in the orientation of the maximum cross- sectional area. Resistance will be controlled by the geometry of flow as discussed in the preceding section.

The roundness of a particle modifies the effect of shape on the point of separation. Sharp corners cause separation at smaller Reynolds numbers than rounded ones, and a wake develops at lower velocities. The development of the wake increases the pressure drag. Rounded particles, therefore, will have less resistance to motion; hence greater free-fall velocities than sharpcornered ones with similar characteristics such as size.

Surface roughness of a particle may increase or decrease the resistance to motion. Shear drag will be increased by roughness if the roughness protrudes beyond the laminar boundary layer. Prandtl and Tietjens (1934) show that separation around a sphere is controlled by flow conditions in the boundary layer. When the flow in the boundary layer changes from laminar to turbulent, the point of separation moves from the upstream to the downstream side of the sphere. This reduces both the size of the wake and the pressure drag. The total drag will be affected to the extent that the balance between shear and pressure drag is affected.

\section{DIMENSIONAI ANAL YSIS}

Measurable variables pertaining to the resistance to motion of a single particle falling at a uniform velocity in a quiescent fluid include:

$\omega=$ fall velocity $(\mathrm{cm} / \mathrm{sec})$, $\rho_{f}=$ fluid density $\left(\right.$ dyne- $\left.\mathrm{sec}^{2} / \mathrm{cm}^{4}\right)$,

$\mu=$ dynamic viscosity of the fluid (dyne-sec $/ \mathrm{cm}^{2}$ ), $\rho_{p}=$ particle density (dyne- $\left.\mathrm{sec}^{2} / \mathrm{cm}^{4}\right)$,

$a=$ major axis of the particle $(\mathrm{cm})$,

$b=$ intermediate axis of the particle $(\mathrm{cm})$,

$c=$ minor axis of the particle $(\mathrm{cm})$,

$F=$ driving force (dynes),

$f=$ frequency of oscillation or tumbling (cycles/ sec),

$S_{r}=$ surface roughness $(\mathrm{cm})$, and

$S=$ surface area $\left(\mathrm{cm}^{2}\right)$.

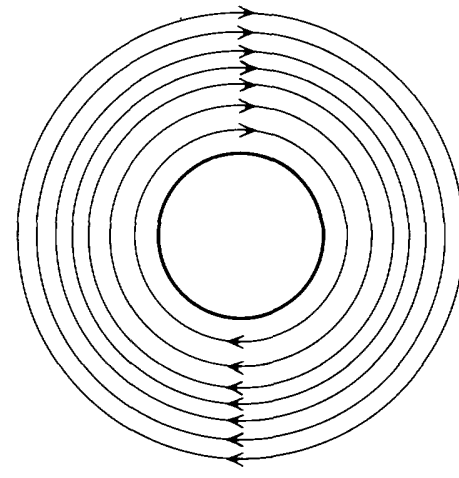

A

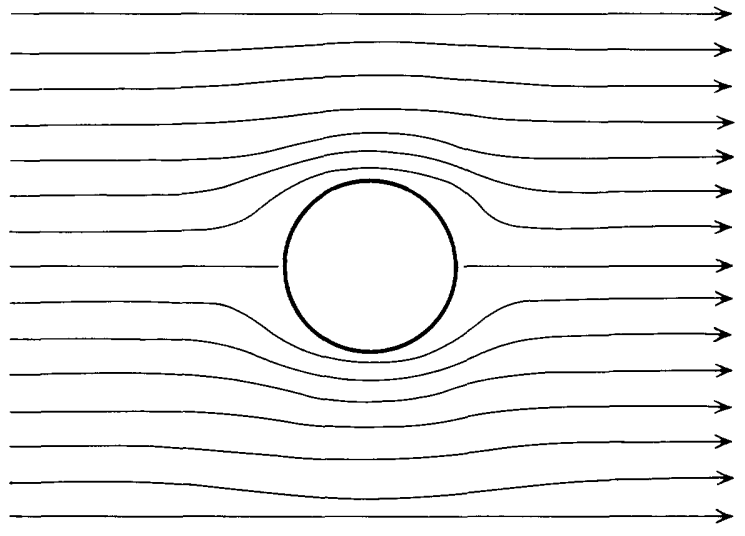

B

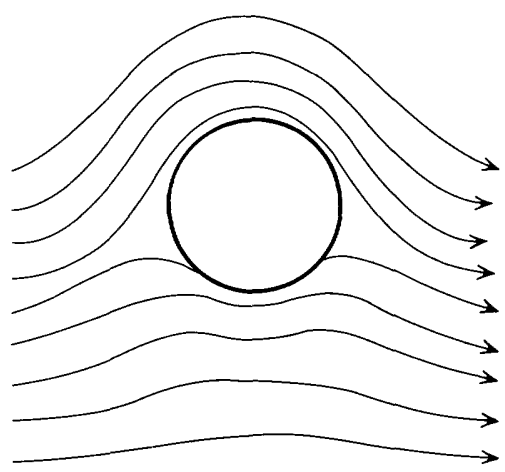

C

Figure 2.-Circular fluid flow around a particle. $A$, Pure circulation. $B$, Pure translation. $C$, Circulation and translation. 
These variables can be expressed in the functional $\mid$ and equation:

$$
\phi_{1}\left(\omega, \rho_{f}, \mu, \rho_{p}, a, b, c, F, f, S_{r}, S\right)=0 .
$$

Selecting $\omega, a$, and $\rho_{f}$ as the repeating variables, the following groupings can be established:

$$
\phi_{2}\left|\frac{\rho_{f} \omega a}{u}, \frac{F}{a^{2} \rho_{f} \omega^{2}}, \frac{\rho_{p}}{\rho_{f}}, \frac{\mathrm{c}}{a}, \frac{b}{a}, \frac{S_{r}}{a}, \frac{S}{a^{2}}, \frac{f a}{\omega}\right|=0 .
$$

Because surface roughness will not be considered now, $\frac{S_{r}}{a}$ can be neglected.

Then, combining:

$$
\begin{aligned}
& \frac{\rho_{p}}{\rho_{f}} \text { and } \frac{c}{a} \text { to obtain } \frac{\rho_{p}}{\rho_{f}} \text { and } \frac{c}{a} \\
& \frac{c}{a} \text { and } \frac{b}{a} \text { to obtain } \frac{c b}{a^{2}} \text { and } \frac{c}{a}
\end{aligned}
$$

results in:

$$
\phi_{3}\left|\frac{\rho_{f} \omega a}{\mu}, \frac{F}{a^{2} \rho_{f} \omega^{2}}, \frac{\rho_{p}}{\rho_{f}} \frac{c}{a}, \frac{c b}{a^{2}}, \frac{c}{a}, \frac{S}{a^{2}}, \frac{f a}{\omega}\right|==0 .
$$

If the repeating variables used are $a, \rho_{f}$, and $F$, a functional equation similar to equation 16 results and and is expressed as:

$$
\phi_{4}\left|\frac{F \rho_{f}}{\mu^{2}}, \frac{F}{a^{2} \rho_{f} \omega^{2}}, \frac{\rho_{p}}{\rho_{f}}, \frac{c}{a}, \frac{c b}{a^{2}}, \frac{S}{a^{2}}, \frac{f^{2} \rho_{f} a^{4}}{F}\right|=0 .
$$

Because $\frac{c b}{a^{2}}, \frac{c}{a}$, and $\frac{S}{a^{2}}$ are functions of the geometry of the particle, they can be combined into a term called the shape factor $S F$.

Assuming terminal fall velocity:

$$
\begin{aligned}
& \frac{\rho_{f} \omega a}{\mu} \propto \mathbf{R}-\text { Reynolds number } \\
& \frac{F}{a^{2} \rho_{f} \omega^{2}} \propto C_{D} \text {-coefficient of drag }
\end{aligned}
$$

$\frac{\rho_{p}}{\rho_{f}} \frac{c}{a} \propto \mathrm{I}-$ Wilmarth's stability number

$$
\begin{aligned}
& \frac{F \rho_{f}}{\mu^{2}}=\frac{F}{\rho v^{2}} \propto \lambda \text {-force number } \\
& \frac{f a}{\omega} \propto \theta \text {-frequency number }
\end{aligned}
$$

$$
\frac{f^{2} \rho_{f}^{a^{4}}}{F} \propto \Phi \text {-density-frequency number }
$$

and equations 16 and 17 reduce to:

$$
\phi_{5}\left(\mathbf{R}, C_{D}, \mathrm{I}, S F, \theta\right)=0,
$$

$$
\phi_{6}\left(\lambda, C_{D}, \mathrm{I}, S F, \Phi\right)=0 .
$$

From equations 18 and $19, C_{D}$ can be expressed as:

and

$$
C_{D}=\phi_{7}(\mathbf{R}, \mathrm{I}, S F, \theta)
$$

$$
C_{D}=\phi_{8}(\lambda, \mathbf{I}, S F, \Phi) \text {. }
$$

Equations 20 and 21 indicate that $\mathbf{R}, \lambda, \mathrm{I}, S F, \theta$, and $\Phi$ are parameters of major importance governing the resistance of a particle falling at a constant velocity in a quiescent fluid. Although they are all used for clarification of certain concepts, these parameters are not independent of each other because $\lambda$ can be shown to be a function of $\mathbf{R}$, and $\Phi$ is a function of $\theta$.

\section{COEFFICIENT OF DRAG VERSUS REYNOLDS NUMBER}

The coefficient of drag and the Reynolds number have been defined in previous discussions. Experimental evidence and theoretical solutions of the equations of motion for small Reynolds numbers clearly indicate that the coefficient of drag is a function of the Reynolds number. It has, therefore, become a "universal" procedure to express the relationship between $C_{D}$ and $\mathbf{R}$ by means of a logarithmic plot (fig. 3 ) that is further described as a $C_{D}-\mathbf{R}$ diagram. The curves show how $C_{D}$ varies with $\mathbf{R}$ when a disk, sphere, and an airship hull are held stationary in the flow of a wind or water tunnel. When a disk is mounted with its maximum cross-sectional area perpendicular to the direction of flow, the coefficient of drag becomes nearly independent of Reynolds numbers at $\mathbf{R}>1,000$ (fig. 3, upper curve). The curve for fixed disks represents an extreme condition in which the drag force is almost entirely pressure drag; it occurs when the size and shape of the wake are fixed by separation of the fluid from the boundary of the

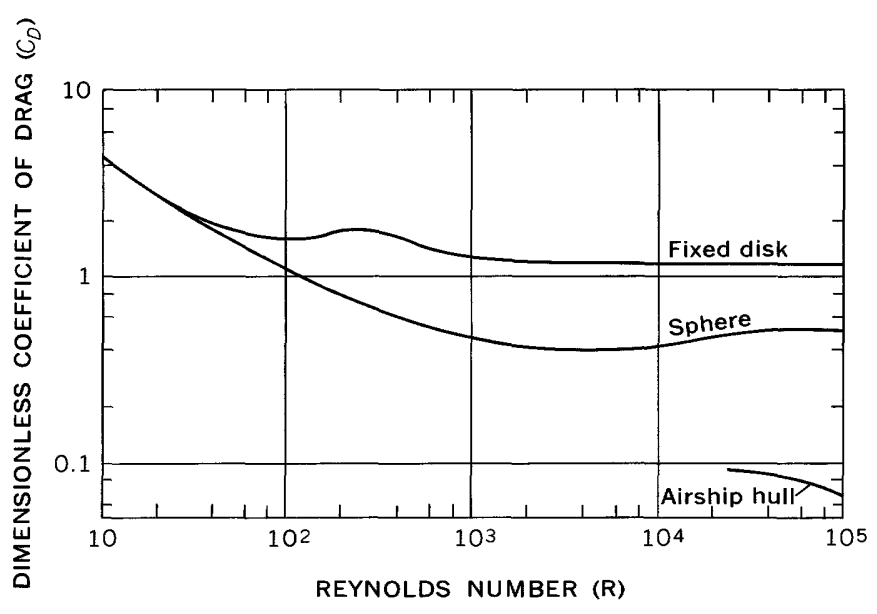

Figure 3.- Coefficient of drag as a function of Reynolds number for fixed disks, spheres, and airship hulls. After Rouse, 1946. 
particle at a fixed place around the particle periphery. Because shear drag is a function of velocity, as is the Reynolds number, the fact that $C_{D}$ does not increase with $\mathbf{R}$ indicates the minor role played by the shear in the total drag on a disk at high Reynolds numbers.

The relationship of $C_{D}$ to $\mathbf{R}$ for a smooth sphere (fig. 3 , lower curve) is typical for flow conditions around a particle where a combination of both shear and pressure forces are significant for greater Reynolds numbers than for conditions previously discussed. Here, the place of separation is affected by flow conditions in the boundary layer as well as by shape.

The relationship of $C_{D}$ to $\mathbf{R}$ for an airship hull (fig. 3, lower right corner) mounted with the long axis parallel to the flow may be considered a case where the resistance to flow is due almost entirely to shear drag on the surface of the hull for all ranges of $\mathbf{R}$. The hull is a streamline shape, and separation does not occur except at the extreme downstream end.

\section{SHAPE FACTOR}

The shape factor combines the lenghts of the three mutually perpendicular axis into one parameter. The particular form that will be used in this study is the Corey shape factor as defined previously (equation 10).

\section{FREQUENCY NUMBERS}

Two numbers which are functions of frequency of oscillation or rotation are deduced from the dimensional analysis. The frequency number $\theta$ has been used by Wilmarth, Hawk, and Harvey (1964) and others in studies of resistance to motion. This number is a significant factor only when cyclic oscillations or complete rotation occurs.

The density-frequency number $\Phi$ reflects the density ratio between the fluid and the particle. Logically, density should affect the frequency of oscillation through the inertial forces; this number, therefore, may be significant.

\section{STABILITY NUMBERS}

The steadiness of a particle does not influence resistance to motion in studies on rigidly mounted particles, nor on particles which maintain a stable orientation during free fall. For freely falling disks, the stability number I can be used in conjunction with the Reynolds number to define a region of stable fall, and hence is termed a "stability number" (Wilmarth and others, 1964). Since particles with shapes other than disks are used in this study, the number will be specifically defined for each shape on the basis of the definition for disks as a pattern.

The stability number for disks, as defined by Wilmarth, Hawk, and Harvey, is the ratio of the mass moment of inertia of a thin disk about its diameter to a quantity proportional to the mass moment of inertia of a rigid sphere of fluid of the same diameter as that of the disk about its diameter. Or, in equation form:

$$
\mathrm{I}=\frac{I}{\rho_{f} a^{5}}
$$

where

$$
I=\rho_{p} \nsucc \frac{a^{2}}{16}=\frac{\pi}{64} \rho_{p} a^{4} c
$$

then

$$
\mathrm{I}=\frac{\pi}{64} \frac{\rho_{p}}{\rho_{f}} \frac{c}{a} .
$$

Thus, it can be seen that $I$ is a constant multiplied by the density ratio of the disk and the fluid in which the particle is submerged and by the thickness-diameter ratio of the disk.

The stability number for oblate spheroids is defined in the same way as for disks. Therefore, with:

$$
I=\rho_{p} ¥ \frac{a^{2}+c^{2}}{20},
$$

the stability number becomes:

$$
\mathrm{I}=\frac{¥}{a^{5}} \frac{a^{2}+c^{2}}{20} \frac{\rho_{p}}{\rho_{f}}
$$

The stability number for cylinders is defined as the ratio of the mass moment of inertia of a cylinder about an axis perpendicular to its major axis to a quantity proportional to the mass moment of inertia of a rigid disk of fluid whose diameter is equal to the length of the cylinder about an axis perpendicular to the diameter of the fluid disk.

Therefore, with:

$$
I=\rho_{p} ¥\left|\frac{c^{2}}{16}+\frac{a^{2}}{12}\right|,
$$

the stability number is:

$$
\mathrm{I}=\frac{¥}{a}\left|\frac{c^{2}}{16}+\frac{a^{2}}{12}\right| \frac{\rho_{p}}{\rho_{f}} .
$$

The stability number for prolate spheroids is defined in a manner similar to the stability number for cylinders. The moment of inertia is:

$$
I=\rho_{p} ¥ \frac{c^{2}+a^{2}}{20},
$$

and the stability number becomes:

$$
\mathrm{I}=\frac{¥}{a^{5}} \frac{c^{2}+a^{2}}{20} \frac{\rho_{p}}{\rho_{f}} .
$$


The stability number for spheres, if defined in terms of the moment of inertia of the sphere and the moment of inertia of the associated fluid sphere of the same diameter, is the density ratio of the sphere and the fluid.

\section{FORCE NUMBER}

The force number, known as a size coefficient by other investigators, has been used to estimate fall velocity of a nominal sphere in fall-velocity studies. Not only does it come from the dimensional analysis, but it can be derived from Newton's drag equation. By proper manipulation of equation 4, and assuming the area term $A$ can be written as some constant $k$ times a characteristic diameter, the drag equation can be written as:

$$
F=\frac{k_{1} v^{2} \rho_{f}}{2} C_{D} \mathbf{R}^{2}
$$

or

$$
\frac{F}{\rho_{f} v^{2}}=k C_{D} \mathbf{R}^{2}
$$

where $k$ is $k_{1} / 2$.

Since $F$ is the buoyant weight of the particle, for any discrete particle falling in a fluid of constant density and viscosity, the force number $\lambda$ is unique. This indicates that the product $C_{D} \mathbf{R}^{2}$ is constant, and that a line of constant $\lambda$ on the $C_{D}-\mathbf{R}$ diagram should have a slope of -2 .

The unique nature of the relationship among $\lambda, C_{D}$, and $\mathbf{R}$ indicates to some extent the influence that shape, diameter, and velocity have on the position on the $C_{D}-\mathbf{R}$ diagram for any discrete particle. If for any given value of $\lambda$ equation 32 is rewritten as:

$$
k=C_{D} \mathbf{R}^{2}
$$

$C_{D}$ is replaced by its definition as derived from equation 4 , and the Reynolds number is written in accordance with its definition, then $k$ is:

$$
k=\frac{2 F}{A \rho_{f}} \frac{1}{\omega^{2}} \frac{(\omega d)^{2}}{v^{2}},
$$

or by letting $A=k_{1} d^{2}$, then

$$
k=\frac{2 F}{k_{1} \rho_{f}} \frac{1}{(\omega d)^{2}} \frac{(\omega d)^{2}}{v^{2}} .
$$

In equation 35 , note that $\omega d$ is common to both the Reynolds number and the coefficient of drag. Therefore, any factor which affects either $\omega$ or $d$ affects both $C_{D}$ and $\mathbf{R}$, changing the individual terms, but not the constant-product relationship. If by some means the shape of a particle could be changed while maintaining the same buoyant weight, the relationship of $C_{D}$ to $\mathbf{R}$ for the particle would shift on the $C_{D}-\mathbf{R}$ diagram to a new position along the line of constant $\lambda$. Any other parameter which might affect velocity, such as roughness or roundness, would also simply change its position along the line of constant $\lambda$.

In the literature, the question as to what diameter should be used in computing $C_{D}$ and $\mathbf{R}$ for irregularly shaped particles is discussed. Equation 35 indicates that the only effect of picking one particular diameter over another would be to shift position on the $C_{D}-\mathbf{R}$ diagram on a line of constant $\lambda$. To be specific, because the area associated with the nominal diameter of a nonspherical particle is less than the maximum projected area of the particle, its characteristic diameter is the smaller for the same particle. Hence, the point based on the nominal diameter plots at a greater value of $C_{D}$ and a lesser value of $\mathbf{R}$ than the point based on the characteristic diameter associated with the maximum projected area, but both points are on the same $\lambda$ line.

\section{CHOICE OF CHARACTERISTIC DIAMETERS AND VELOCITIES}

The computations for $C_{D}$ and $\mathbf{R}$ require the use of a characteristic length and velocity. Two characteristic diameters and two characteristic velocities are used in this report.

The characteristic lengths are the maximum diameter $d_{m}$ and the nominal diameter $d_{n}$. The diameter $d_{m}$ is the diameter of a circle which has an area equal to the maximum projected area of the particle. When $10<\mathbf{R}<$ 100 , the particle falls along a straight vertical path, and does not oscillate or rotate; the maximum area of the particle is perpendicular to the direction of fall. Under these circumstances, according to Newton's law of resistance, the resistance is a function of the maximum projected area; hence $d_{m}$ is used. To maintain consistency throughout the entire range of Reynolds numbers, $d_{m}$ is used even when the particle does oscillate and rotate and when the path of fall is not vertical. The nominal diameter $d_{n}$ is used as a basis of comparison with the work of others because fall velocity is usually expressed in terms of $d_{n}$ in the literature.

In a following section, the data for each diameter are plotted separately on the $C_{D}-\mathbf{R}$ diagram. However, if the data for both diameters, $d_{n}$ and $d_{m}$, were plotted on the same diagram, points could be moved from one curve to the other simply by moving them along lines of constant force number $\lambda$.

The characteristic velocities are the path velocity, or the time-rate of change in distance along the path 
of the particle, and the vertical velocity or the timerate of ehange of distance in a vertical direction. When the difference between path and vertical velocities is not significant, only the relationship of $C_{D}$ to $\mathbf{R}$ using path velocity will be given.

\section{PARTICLE STEADINRSS}

The forces affecting the steadiness of a particle need to be discussed because the steadiness has a large effect on its fall pattern. The forces acting on a disk when $\mathbf{R}>100$ will be used as an example (fig. 4).

When the plane of the disk face is neither perpendicular nor parallel to the direction of motion, the resultant pressure force opposing motion acting normal to the face of the disk has both horizontal and vertical

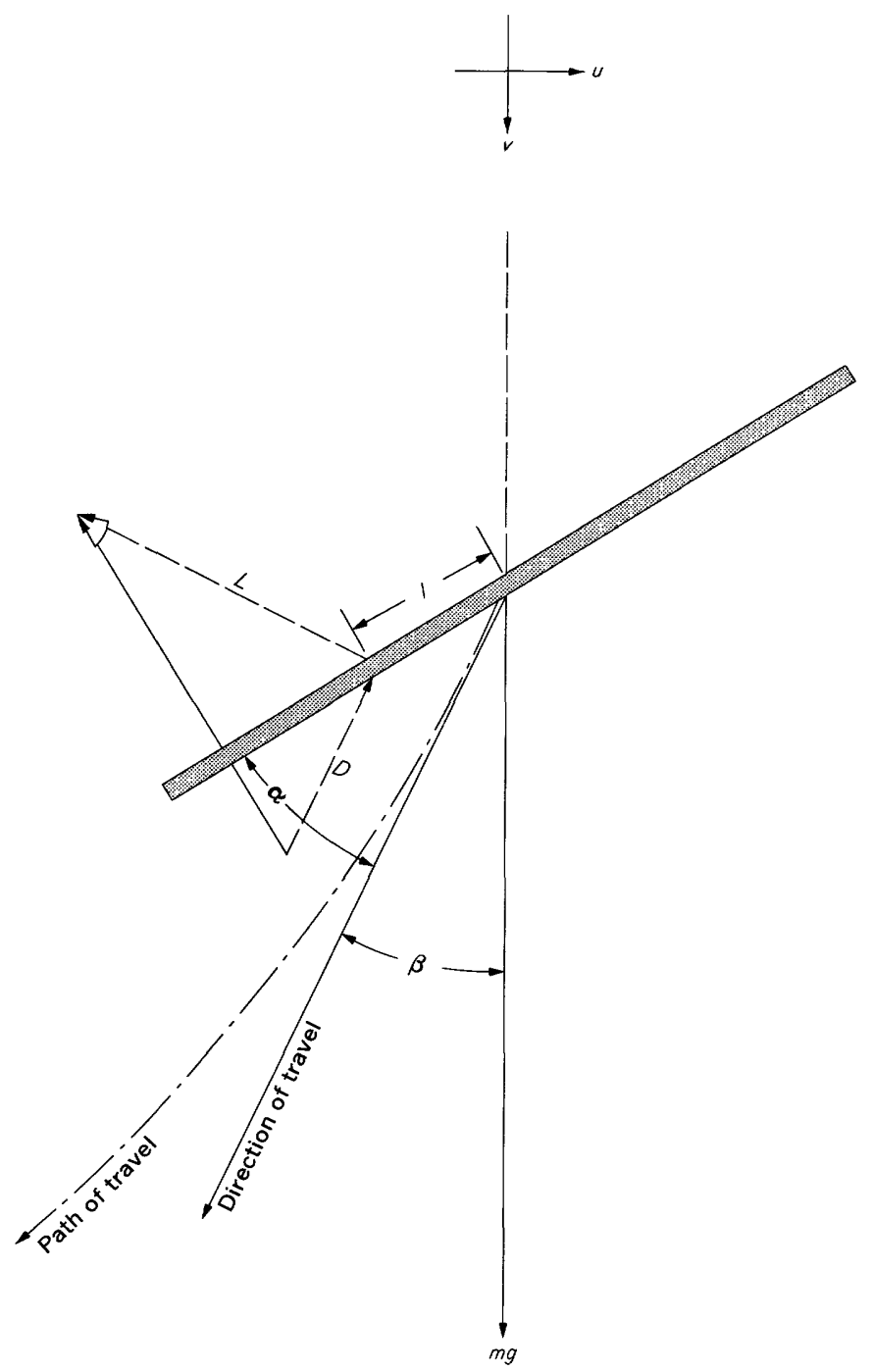

Figure 4.-Forces on a falling disk. Component $L$ is the lift force normal to the drag, and component $D$ is the drag force parallel to the direction of travel. See text for description of symbols.

$307-9650-69-3$ components. The vertical component resists the vertical fall of the disk, whereas the horizontal component causes its horizontal movement. If, as a result of circulation or the nonsymmetrical formation of the trailing vortex, the center of pressure does not act through the center of gravity of the disk, a torque will be exerted on the disk. The magnitude of the torque will be equal to the product of the magnitude of the resultant pressure force and the distance along the disk between the center of pressure and the center of gravity (fig. 4). The plane of the disk face must continually change because there is no movement to counterbalance the torque. This change in the angle of inclination is the reason that an oscillating disk swings through curvilinear arcs.

With reference to figure 4 :

$$
\begin{aligned}
m g & =\text { buoyant weight of the particle, } \\
D & =\text { drag force, } \\
L & =\text { lift force, } \\
l & =\text { distance between the center of gravity and } \\
& \quad \text { center of pressure, } \\
u & =\text { horizontal velocity of the particle }(\mathrm{cm} / \mathrm{sec}), \\
v & =\text { vertical velocity of the particle }(\mathrm{cm} / \mathrm{sec}), \\
\alpha & =\text { angle of attack or the angle between the plane } \\
& \text { of the disk face and direction of travel, and } \\
\beta & =\text { angle between direction of travel and the } \\
& \text { vertical. }
\end{aligned}
$$

By appropriate substitutions, the differential equations of motion for a freely falling disk can be written:

$$
\begin{gathered}
m \frac{d v}{d t}-m g+D \cos \beta+L \sin \beta=0, \\
m \frac{d u}{d t}+D \sin \beta-L \cos \beta=0, \text { and } \\
l A \frac{\rho_{f} \omega^{2}}{2}\left(C_{D} \sin ^{2} \alpha+C_{L} \cos ^{2} \alpha\right)-I \frac{d^{2} \alpha}{d t^{2}}=0 .
\end{gathered}
$$

At the instant an oscillating disk stops at the apex on one of the arcs, the plane of the face is inclined with the horizontal, and the disk weight is the only force acting on it. Once motion begins, the horizontal component of the resultant pressure changes the horizontal position, the vertical component opposes the motion, and the torque changes the angle of inclination, turning the disk towards the horizontal. This process continues until the apex at the opposite end of the arc is reached. This apex is reached rather abruptly once the angle of inclination is upward, because the resultant force and the weight of the particle combine to reduce the velocity of the disk and cause it to stall. It is then in a position to begin its next arc of motion.

The net result of all the forces acting on a disk is a dynamic situation involving the momentum of the 
disk, and the horizontal, vertical, and torque components of force acting on it. All these variables continually change with time.

\section{PARTICles, LIQUid,, EQUiPMENT, AND PROCEDURE \\ PARTICLES}

The particles studied included spheres, cylinders, disks, and oblate and prolate spheroids. Oblate spheroids are solids of revolution generated when an ellipse is rotated about its minor axis. The maximum projected area of an oblate spheroid is circular. Prolate spheroids are solids of revolution generated when an ellipse is rotated about its major axis. The maximum projected area of a prolate spheroid is elliptical. Nylon spheres, teflon spheres, and steel spheres, of three sizes and one tungsten carbide sphere were used (fig. 5). The diameters of the nylon, teflon, and steel spheres were 1.91, 2.54, and $3.81 \mathrm{~cm}$, respectively. The tungsten carbide sphere was $2.54 \mathrm{~cm}$ in diameter. In all, there were 10 spheres, no two being alike in both material and size. The other dimensions and properties of the spheres are given in table 1.

Three sizes of cylinders, disks, oblate and prolate spheroids were machined from lead and aluminum, making a total of 24 nonspherical particles, no two being the same size, shape, and density. The lengths of the major axes were $1.91,2.54$, and $3.81 \mathrm{~cm}$. The thickness to diameter ratio was 0.1 for the disks and 0.5 for the colate spheroids. The length to diameter ratio was 4.0 for the cylinders and 2.0 for the prolate spheroids. Arlditional properties of these particles are also summarized in table 1 .

\section{IIQUIDS}

Seven diff $\cdot r e n t$ liquids, pure glycerine, water, and five different mixtures of glycerine and water were used in the experiment. Percentages of glycerine used to

TABLE 1.-Particle properties, measured and computed

Measured

\begin{tabular}{|c|c|c|c|c|c|c|c|c|c|c|}
\hline \multirow{2}{*}{ Particle No. } & \multirow{2}{*}{$\begin{array}{l}\text { Material and } \\
\text { shape 1 }\end{array}$} & \multirow{2}{*}{ Specific gravity } & \multirow{2}{*}{$\underset{(\mathrm{g})}{\text { Weight }}$} & \multicolumn{2}{|c|}{ Length } & \multirow{2}{*}{$\underset{c / a}{R a t i o}$} & \multirow{2}{*}{ 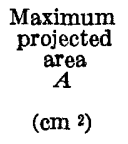 } & \multirow{2}{*}{$\begin{array}{c}\text { Maximum } \\
\text { projected } \\
\text { diameter } \\
d_{m} \\
(\mathrm{~cm})\end{array}$} & \multirow{2}{*}{$\begin{array}{c}\underset{V}{\text { Volume }} \\
\quad\left(\mathrm{cm}^{3}\right)\end{array}$} & \multirow{2}{*}{$\begin{array}{c}\text { Surface area } \\
\qquad \\
\left(\mathrm{cm}^{2}\right)\end{array}$} \\
\hline & & & & $\begin{array}{c}\underset{a}{\text { Maximum }} \\
(\mathrm{cm})\end{array}$ & $\begin{array}{c}\underset{c}{\text { Minimum }} \\
(\mathrm{cm})\end{array}$ & & & & & \\
\hline $\begin{array}{l}1 \\
2 \\
3 \\
4 \\
5\end{array}$ & $\begin{array}{l}\text { N-S } \\
\text { N-S } \\
\text { N-S } \\
\text { T-S } \\
\text { T-S }\end{array}$ & $\begin{array}{l}1.14 \\
1.14 \\
1.14 \\
2.15 \\
2.15\end{array}$ & $\begin{array}{r}4.17 \\
9.87 \\
33.22 \\
7.82 \\
18.60\end{array}$ & $\begin{array}{l}\text { 1. } 91 \\
\text { 2. } 54 \\
\text { 3. } 81 \\
\text { 1. } 91 \\
\text { 2. } 55\end{array}$ & $\begin{array}{l}\text { 1. } 91 \\
\text { 2. } 54 \\
\text { 3. } 81 \\
\text { 1. } 91 \\
\text { 2. } 55\end{array}$ & $\begin{array}{l}1.00 \\
1.00 \\
1.00 \\
1.00 \\
1.00\end{array}$ & $\begin{array}{r}2.86 \\
5.08 \\
11.40 \\
2.86 \\
5.09\end{array}$ & $\begin{array}{l}\text { 1. } 91 \\
\text { 2. } 54 \\
\text { 3. } 81 \\
\text { 1. } 91 \\
\text { 2. } 55\end{array}$ & $\begin{array}{r}3.64 \\
8.61 \\
28.96 \\
3.63 \\
8.64\end{array}$ & $\begin{array}{l}11.46 \\
20.25 \\
45.53 \\
11.44 \\
20.41\end{array}$ \\
\hline $\begin{array}{r}6 \\
7 \\
8 \\
9 \\
10\end{array}$ & $\begin{array}{l}T-S \\
S_{t}-S \\
S_{t}-S \\
S_{t}-S \\
T_{c}-S\end{array}$ & $\begin{array}{r}\text { 2. } 15 \\
7.68 \\
7.68 \\
\text { 7. } 90 \\
14.95\end{array}$ & $\begin{array}{r}62.92 \\
27.76 \\
65.68 \\
229.56 \\
128.34\end{array}$ & $\begin{array}{l}\text { 3. } 82 \\
\text { 1. } 91 \\
\text { 2. } 54 \\
\text { 3. } 80 \\
\text { 2. } 54\end{array}$ & $\begin{array}{l}3.82 \\
1.91 \\
\text { 2. } 54 \\
\text { 3. } 80 \\
2.54\end{array}$ & $\begin{array}{l}\text { 1. } 00 \\
\text { 1. } 00 \\
\text { 1. } 00 \\
\text { 1. } 00 \\
\text { 1. } 00\end{array}$ & $\begin{array}{r}\text { 11. } 43 \\
2.85 \\
5.07 \\
11.36 \\
5.06\end{array}$ & $\begin{array}{l}3.82 \\
1.91 \\
2.54 \\
3.80 \\
2.54\end{array}$ & $\begin{array}{r}29.07 \\
3.62 \\
8.58 \\
28.84 \\
8.58\end{array}$ & $\begin{array}{l}45.78 \\
11.40 \\
20.25 \\
45.28 \\
20.25\end{array}$ \\
\hline $\begin{array}{l}11 \\
12 \\
13 \\
14 \\
15\end{array}$ & $\begin{array}{l}\text { L-OS } \\
\text { L-OS } \\
\text { L-OS } \\
\text { L-PS } \\
\text { L-PS }\end{array}$ & $\begin{array}{l}\text { 10. } 15 \\
10.15 \\
10.15 \\
10.15 \\
10.15\end{array}$ & $\begin{array}{r}21.38 \\
45.30 \\
156.85 \\
9.94 \\
23.26\end{array}$ & $\begin{array}{l}\text { 1. } 91 \\
\text { 2. } 49 \\
\text { 3. } 85 \\
\text { 1. } 91 \\
\text { 2. } 52\end{array}$ & $\begin{array}{l}1.04 \\
1.33 \\
1.89 \\
.96 \\
1.28\end{array}$ & $\begin{array}{l}.54 \\
.53 \\
.49 \\
.50 \\
.51\end{array}$ & $\begin{array}{r}2.88 \\
4.87 \\
11.62 \\
1.44 \\
2.54\end{array}$ & $\begin{array}{l}\text { 1. } 91 \\
2.49 \\
3.85 \\
\text { 1. } 35 \\
\text { 1. } 80\end{array}$ & $\begin{array}{r}2.11 \\
4.64 \\
15.45 \\
.98 \\
2.29\end{array}$ & $\begin{array}{r}\text { 8. } 20 \\
\text { 13. } 86 \\
\text { 31. } 89 \\
\text { 4. } 79 \\
8.71\end{array}$ \\
\hline $\begin{array}{l}16 \\
17 \\
18 \\
19 \\
20\end{array}$ & $\begin{array}{l}\text { L-PS } \\
\text { L-C } \\
\text { L-C } \\
\text { L-C } \\
\text { L-D }\end{array}$ & $\begin{array}{l}10.15 \\
10.15 \\
10.15 \\
10.15 \\
10.15\end{array}$ & $\begin{array}{r}76.52 \\
3.88 \\
8.12 \\
27.49 \\
5.50\end{array}$ & $\begin{array}{l}3.85 \\
1.91 \\
2.54 \\
\text { 3. } 81 \\
1.91\end{array}$ & $\begin{array}{r}1.92 \\
.48 \\
.63 \\
.95 \\
.19\end{array}$ & $\begin{array}{l}.50 \\
.25 \\
.25 \\
.25 \\
.10\end{array}$ & $\begin{array}{l}\text { 5. } 81 \\
.91 \\
\text { 1. } 61 \\
\text { 3. } 63 \\
\text { 2. } 87\end{array}$ & $\begin{array}{l}2.72 \\
1.08 \\
1.43 \\
2.15 \\
1.91\end{array}$ & $\begin{array}{r}7.54 \\
.33 \\
.80 \\
2.71 \\
.54\end{array}$ & $\begin{array}{r}\text { 19. } 9 \\
3.24 \\
5.49 \\
12.79 \\
6.28\end{array}$ \\
\hline $\begin{array}{l}21 \\
22 \\
23 \\
24 \\
25\end{array}$ & $\begin{array}{l}\text { L-D } \\
\text { L-D } \\
\text { A-OS } \\
\text { A-OS } \\
\text { A-OS }\end{array}$ & $\begin{array}{r}10.15 \\
10.15 \\
2.81 \\
2.81 \\
2.81\end{array}$ & $\begin{array}{r}13.07 \\
44.20 \\
5.60 \\
12.66 \\
45.05\end{array}$ & $\begin{array}{l}\text { 2. } 54 \\
3.81 \\
1.91 \\
\text { 2. } 50 \\
\text { 3. } 78\end{array}$ & $\begin{array}{r}.26 \\
.38 \\
.99 \\
1.31 \\
1.96\end{array}$ & $\begin{array}{l}.10 \\
.10 \\
.52 \\
.52 \\
.52\end{array}$ & $\begin{array}{r}5.08 \\
11.42 \\
2.85 \\
4.90 \\
11.21\end{array}$ & $\begin{array}{l}\text { 2. } 54 \\
\text { 3. } 81 \\
1.91 \\
\text { 2. } 50 \\
\text { 3. } 78\end{array}$ & $\begin{array}{r}1.29 \\
\text { 4. } 35 \\
1.99 \\
\text { 4. } 51 \\
\text { 15. } 99\end{array}$ & $\begin{array}{r}12.20 \\
26.13 \\
8.02 \\
15.63 \\
31.70\end{array}$ \\
\hline $\begin{array}{l}26 \\
27 \\
28 \\
29 \\
30\end{array}$ & $\begin{array}{l}\text { A-PS } \\
\text { A-PS } \\
\text { A-PS } \\
\text { A-C } \\
\text { A-C }\end{array}$ & $\begin{array}{l}2.81 \\
2.81 \\
2.81 \\
2.81 \\
2.81\end{array}$ & $\begin{array}{r}2.48 \\
5.98 \\
20.00 \\
.90 \\
2.15\end{array}$ & $\begin{array}{l}1.83 \\
2.50 \\
\text { 3. } 78 \\
\text { 1. } 91 \\
\text { 2. } 54\end{array}$ & $\begin{array}{r}.95 \\
1.27 \\
1.88 \\
.47 \\
.64\end{array}$ & $\begin{array}{l}.52 \\
.51 \\
.50 \\
.25 \\
.25\end{array}$ & $\begin{array}{l}\text { 1. } 37 \\
\text { 2. } 49 \\
\text { 5. } 57 \\
.94 \\
\text { 1. } 62\end{array}$ & $\begin{array}{l}\text { 1. } 32 \\
1.78 \\
\text { 2. } 67 \\
\text { 1. } 09 \\
1.44\end{array}$ & $\begin{array}{r}.88 \\
2.13 \\
7.11 \\
.32 \\
.76\end{array}$ & $\begin{array}{r}\text { 4. } 72 \\
\text { 8. } 52 \\
\text { 19. } 06 \\
\text { 3. } 17 \\
\text { 5. } 76\end{array}$ \\
\hline $\begin{array}{l}31 \\
32 \\
33 \\
34\end{array}$ & $\begin{array}{l}A-C \\
A-D \\
A-D \\
A-D\end{array}$ & $\begin{array}{l}2.81 \\
2.81 \\
2.81 \\
2.81\end{array}$ & $\begin{array}{r}7.62 \\
1.54 \\
3.62 \\
12.27\end{array}$ & $\begin{array}{l}\text { 3. } 81 \\
\text { 1. } 91 \\
\text { 2. } 54 \\
\text { 3. } 81\end{array}$ & $\begin{array}{l}.96 \\
.19 \\
.26 \\
.38\end{array}$ & $\begin{array}{l}.25 \\
10 \\
.10 \\
.10\end{array}$ & $\begin{array}{r}3.64 \\
2.87 \\
5.08 \\
11.39\end{array}$ & $\begin{array}{l}2.15 \\
1.91 \\
2.54 \\
3.81\end{array}$ & $\begin{array}{r}2.71 \\
.55 \\
1.29 \\
4.37\end{array}$ & $\begin{array}{r}12.74 \\
6.87 \\
12.17 \\
27.39\end{array}$ \\
\hline
\end{tabular}

${ }_{1} \mathrm{~N}$, nylon; $\mathrm{T}$, teflon; $\mathrm{S}_{t}$, steel; $\mathrm{T}_{\mathrm{t}}$, tungsten carbide; L, lead; A, aluminum; S, sphere; OS, oblate spheroid; PS, prolate spheroid; C, cylinder; $\mathrm{D}$, disk. 
THE BEHAVIOR OF LARGE PARTICLES FALLING IN QUIESCENT LIQUIDS

TABLE 1.-Particle properties, measured and computed-Continued

Computed

\begin{tabular}{|c|c|c|c|c|c|c|c|c|c|c|c|c|c|}
\hline \multirow{3}{*}{ Particle No. } & \multirow{3}{*}{$\begin{array}{l}\text { Nominal } \\
\text { diameter } \\
d_{n} \\
\text { (cm) }\end{array}$} & \multirow{3}{*}{$\begin{array}{c}\text { Nominal } \\
\text { ares } \\
A_{n} \\
\left(\mathrm{~cm}^{2}\right)\end{array}$} & \multirow{3}{*}{$\begin{array}{c}\text { Surface } \\
\text { diameter } \\
d_{A} \\
(\mathrm{~cm})\end{array}$} & \multirow{3}{*}{$\underset{d_{A} / d_{n}}{\text { Ratio }}$} & \multirow{3}{*}{$\begin{array}{l}\text { Shape } \\
\text { factor } \\
\text { SF }\end{array}$} & \multirow{3}{*}{$\underset{\Psi}{\text { Sphericity }}$} & \multicolumn{7}{|c|}{ Stability number $\mathrm{I} \times 10^{2}$} \\
\hline & & & & & & & \multicolumn{7}{|c|}{ Percent glycerine } \\
\hline & & & & & & & 0.0 & 70.0 & 83.3 & 90.1 & 95.2 & 98.0 & 100.0 \\
\hline 1 & 1. 91 & 2. 86 & 1. 91 & 1. 00 & 1. 00 & 1. 00 & \multicolumn{7}{|c|}{ 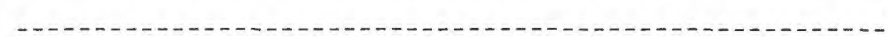 } \\
\hline$\overline{2}$ & 2. 54 & 5. 08 & 2. 54 & 1. 00 & 1. 00 & 1. 00 & \multicolumn{7}{|c|}{ 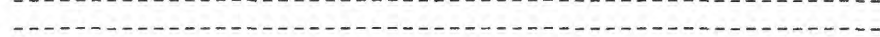 } \\
\hline$\overline{3}$ & 3. 81 & 11. 40 & 3. 81 & 1. 00 & 1. 00 & 1. 00 & \multicolumn{7}{|c|}{ 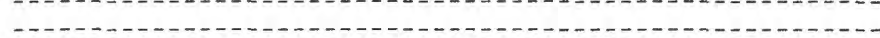 } \\
\hline 4 & 1. 91 & 2. 86 & 1. 91 & 1. 00 & 1. 00 & 1. 00 & \multicolumn{7}{|c|}{ 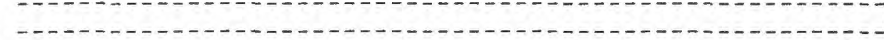 } \\
\hline 5 & 2. 55 & 5. 09 & 2. 54 & 1. 00 & 1. 00 & 1. 00 & \multicolumn{7}{|c|}{ (n.-. } \\
\hline 6 & 3. 82 & 11. 00 & 3. 82 & 1. 00 & 1. 00 & 1. 00 & \multicolumn{7}{|c|}{ - } \\
\hline 7 & 1. 91 & 2.85 & 1. 91 & 1. 00 & 1. 00 & 1. 00 & \multicolumn{7}{|c|}{ 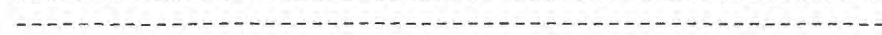 } \\
\hline 8 & 2. 54 & 5. 07 & 2. 54 & 1. 00 & 1. 00 & 1. 00 & \multicolumn{7}{|c|}{ - } \\
\hline 9 & 3. 80 & 11. 36 & 3. 80 & 1. 00 & 1. 00 & 1. 00 & \multicolumn{7}{|c|}{ 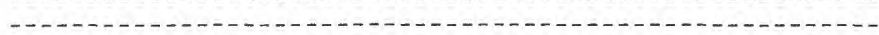 } \\
\hline 10 & 2. 54 & 5. 06 & 2. 54 & 1. 00 & 1. 00 & 1. 00 & \multicolumn{7}{|c|}{ - } \\
\hline 11 & 1. 59 & 1. 99 & 1. 62 & 1. 02 & .54 & .83 & 16. 8 & 13. 9 & 13. 6 & 13. 4 & 13. 3 & 13. 3 & 13. 2 \\
\hline 12 & 2. 04 & 3. 27 & 2. 10 & 1. 03 & .53 & .82 & 16. 8 & 13. 9 & 13. 6 & 13. 4 & 13. 3 & 13. 3 & 13. 2 \\
\hline 13 & 3. 09 & 7. 46 & 3. 17 & 1. 03 & .49 & .80 & 16. 8 & 13. 9 & 13. 6 & 13. 4 & 13. 3 & 13. 3 & 13. 2 \\
\hline 14. & 1. 23 & 1. 19 & 1. 24 & 1. 01 & .71 & .64 & 8. 38 & 6. 90 & 6. 80 & 6. 70 & 6. 64 & 6. 64 & 6.60 \\
\hline 15 & 1. 64 & 2. 12 & 1. 67 & 1. 02 & .71 & .60 & 8. 38 & 6.90 & 6.80 & 6.70 & 6. 64 & 6.64 & 6. 60 \\
\hline 16 & 2. 43 & 4. 63 & 2. 52 & 1. 04 & .71 & .63 & 8. 38 & 6. 90 & 6. 80 & 6. 70 & 6. 64 & 6. 64 & 6. 60 \\
\hline 17 & .86 & .58 & 1. 02 & 1. 18 & .50 & .43 & 4. 38 & 3. 65 & 3. 56 & 3. 50 & 3. $4 \overline{7}$ & 3. $4 \overline{7}$ & 3. 45 \\
\hline 18 & 1. 15 & 1. 04 & 1. 32 & 1. 15 & .50 & .44 & 4. 39 & 3. 65 & 3. 56 & 3. 50 & 3. 47 & 3.47 & 3. 45 \\
\hline 19 & 1. 73 & 2. 36 & 2. 02 & 1. 17 & .50 & .43 & 4. 39 & 3. 65 & 3. 56 & 3. 50 & 3. 47 & 3. 47 & 3.45 \\
\hline 20 & 1. 01 & .80 & 1. 41 & 1. 40 & .10 & .53 & 4. 98 & 4. 21 & 4. 10 & 4. 02 & 3. 99 & 3. 97 & 3. 96 \\
\hline 21 & 1. 35 & 1. 42 & 1. 97 & 1. 46 & .10 & .53 & 4. 98 & 4. 21 & 4. 10 & 4. 02 & 3. 99 & 3. 97 & 3. 96 \\
\hline 22 & 2. 03 & 3. 22 & 2. 88 & 1. 42 & 10 & .53 & 4. 98 & 4. 21 & 4. 10 & 4. 02 & 3. 99 & 3. 97 & 3. 96 \\
\hline 23 & 1. 56 & 1. 90 & 1. 60 & 1. 03 & .50 & .83 & 4. 65 & 3. 88 & 3. 80 & 3. 74 & 3. 71 & 3. 71 & 3. 68 \\
\hline 24 & 2. 05 & 3. 30 & 2. 23 & 1. 09 & .50 & .82 & 4. 65 & 3. 88 & 3. 80 & 3. 74 & 3. 71 & 3. 71 & 3. 68 \\
\hline 25 & 3. 12 & 7. 63 & 3. 16 & 1. 01 & .50 & .82 & 4. 65 & 3. 88 & 3. 80 & 3. 74 & 3. 71 & 3. 71 & 3. 68 \\
\hline 26 & 1. 19 & 1. 12 & 1. 23 & 1. 03 & .72 & .65 & 2. 32 & 1. 95 & 1. 90 & 1. 87 & 1. 86 & 1. 86 & 1. 84 \\
\hline 27 & 1. 60 & 2.00 & 1. 65 & 1. 03 & .71 & .64 & 2. 32 & 1. 95 & 1. 90 & 1. 87 & 1. 86 & 1. 86 & 1. 84 \\
\hline 28 & 2. 39 & 4. 47 & 2. 46 & 1. 03 & .70 & .63 & 2. 32 & 1. 95 & 1. 90 & 1. 87 & 1. 86 & 1. 86 & 1. 84 \\
\hline 29 & .84 & .56 & 1. 00 & 1. 19 & .49 & .43 & 1. 22 & 1. 02 & 1. 00 & .98 & .97 & .97 & .96 \\
\hline 30 & 1. 13 & 1. 00 & 1. 36 & 1. 20 & .50 & .43 & 1. 22 & 1. 02 & 1. 00 & .98 & .97 & .97 & .96 \\
\hline 31 & 1. 73 & 2.34 & 2. 03 & 1. 17 & .50 & .40 & 1. 22 & 1.02 & 1.00 & .98 & .97 & .97 & .96 \\
\hline 32 & 1. 02 & .82 & 1. 48 & 1. 45 & .10 & .53 & 1. 38 & 1. 16 & 1. 13 & 1. 11 & 1. 10 & 1. 10 & 1. 09 \\
\hline 33 & 1. 35 & 1. 43 & 1. 97 & 1. 46 & .10 & .53 & 1. 38 & 1. 16 & 1. 13 & 1. 11 & 1. 10 & 1. 10 & 1. 09 \\
\hline 34 & 2. 02 & 3. 22 & 2. 95 & 1. 46 & .10 & .53 & 1. 38 & 1. 16 & 1. 13 & 1. 11 & 1. 10 & 1. 10 & 1. 09 \\
\hline
\end{tabular}

define the specific mixtures were determined by weight. The glycerine and water were mixed with a large paint mixer for 5-10 minutes in two large interconnected barrels. During the mixing process the fluid was circulated from one barrel to the other to insure a homogeneous fluid. When mixing was completed, the fluid was pumped into the fall column. The viscosities of the liquids (fig. 6) were measured with calibrated CannonFenske viscometers. The densities of the liquid mixtures were taken from standard density tables (fig. 7).

Temperatures were measured at the top, center, and bottom of the test section at the beginning of each day and periodically throughout the day. Rarely did the temperature vary more than $0.5^{\circ} \mathrm{C}$ through the test section or more than $0.2^{\circ} \mathrm{C}$ throughout the day.

\section{EQUIPMENT}

The fall column was a vertical clear plexiglass cylindrical column 3 meters high and $40 \mathrm{~cm}$ in diameter (fig. 8). The wall thickness was $0.625 \mathrm{~cm}$. A 1-meter test section was located near the bottom of the column to allow the particles to fall through the liquid for about 1.5 meters to ensure that they reached terminal fall velocity before they entered the test section. The test section was circled with black plastic tape at 10 $\mathrm{cm}$ intervals. The clear plexiglass column and the fluid made it possible to see the tape on the back of the column and permitted a close approximation of the vertical position of the particle. After the experiments were started, a mirror was added at the bottom of the column to reflect the top light. Then, both the top and the bottom of the particle were illuminated.

A wire basket was suspended below the test section to retrieve the particles. Periodically it was withdrawn from the column and the particles removed. A minimum of 10-15 minutes was allowed for the fluid to 


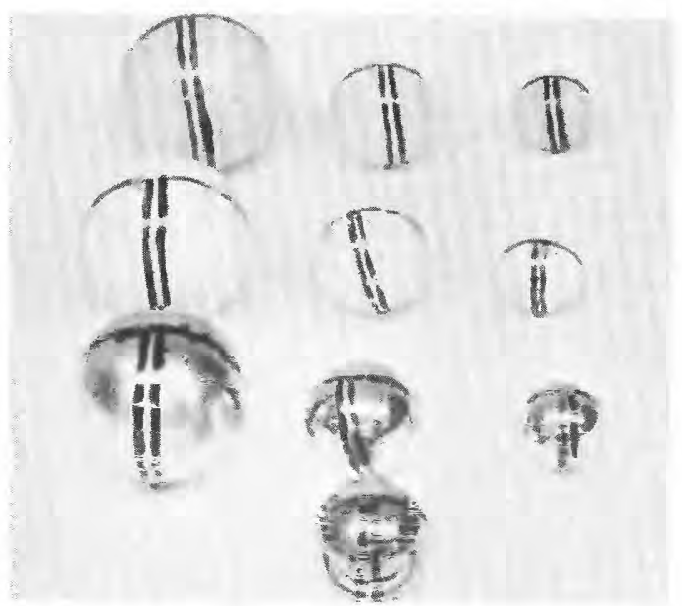

A

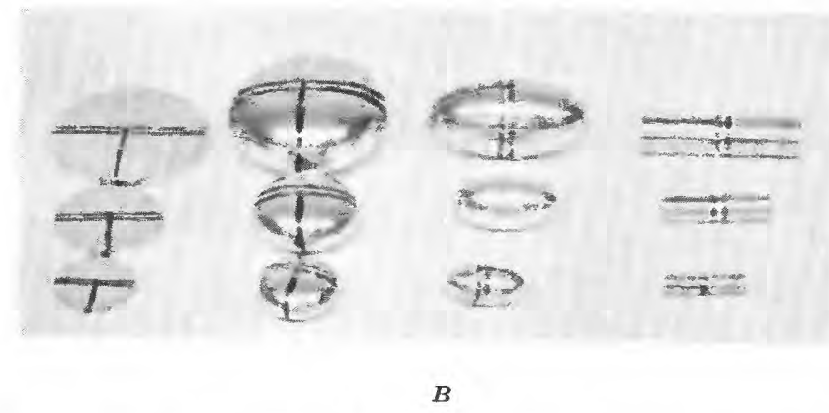

FIGURE 5.-Particles used in experiments. Particles were marked with black stripes to make rotational behavior observable. $A$, Nylon, teflon, steel, and tungsten carbide spheres in order from top to bottom. $B$, Aluminum disks, oblate spheroids, prolate spheroids, and cylinders in order from left to right.

return to equilibrium after the particles had been retrieved.

Photographs of each drop were made with two 16-mm reflex movie cameras equipped with $10-\mathrm{mm}$ wide-angle lenses and set $90^{\circ}$ to one another with respect to the column (fig. 8). The speed of each camera could be varied from 8 to 64 frames per second. All drops were made at 16,32 , or 64 frames per second, depending on the rate of particle fall and detail required to define particle behavior.

A 10-second sweep timer was used to obtain direct readings to 0.1 second and estimated readings to 0.01 second. The timer was mounted at the side of the column and set level with the center of the test section. It was illuminated by two 100-watt incandescent light globes shielded to protect the film from direct exposure by this source. One camera photographed the timer directly, the other photographed an image of the timer reflected to it by a mirror. Thus, a reference time image was recorded on the pictures obtained with both cameras.

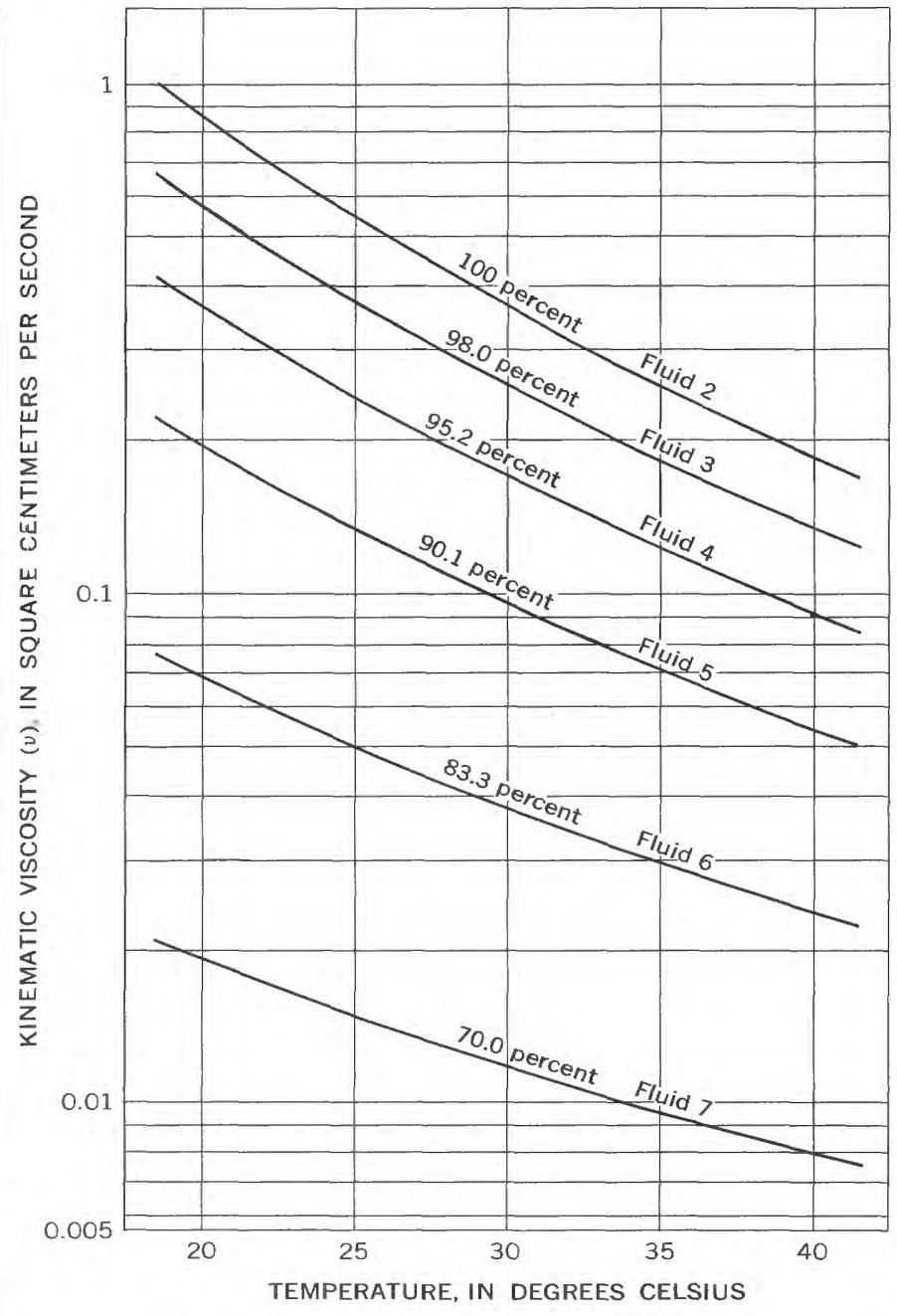

FrgURE 6.-Kinematic viscosity of glycerine-water mixtures in terms of percent glycerine as a function of temperature. Fluid 1 was 100 percent water.

Two 500-watt photo floodlights and a 300-watt incandescent lamp were suspended at the top of the column to direct light down through the column. The lights were turned on only during the run to prevent excess absorption of heat in the top layers of the fluid.

The developed pictures were projected onto a grid to make the necessary particle location measurements. The projector was equipped with a single or multiple framing switch and a reverse switch that enabled the operator to change the pictures one frame at a time, watch a series of pictures as a slow-motion movie, or to reverse the film thus permitting "re-runs" of short sections. These switches were mounted in a remote control box to enable the operator to control the projector from a position near the grid.

The grid was a sheet of 10- by 10-to-the-inch graph paper. The projector was positioned to give a projection 


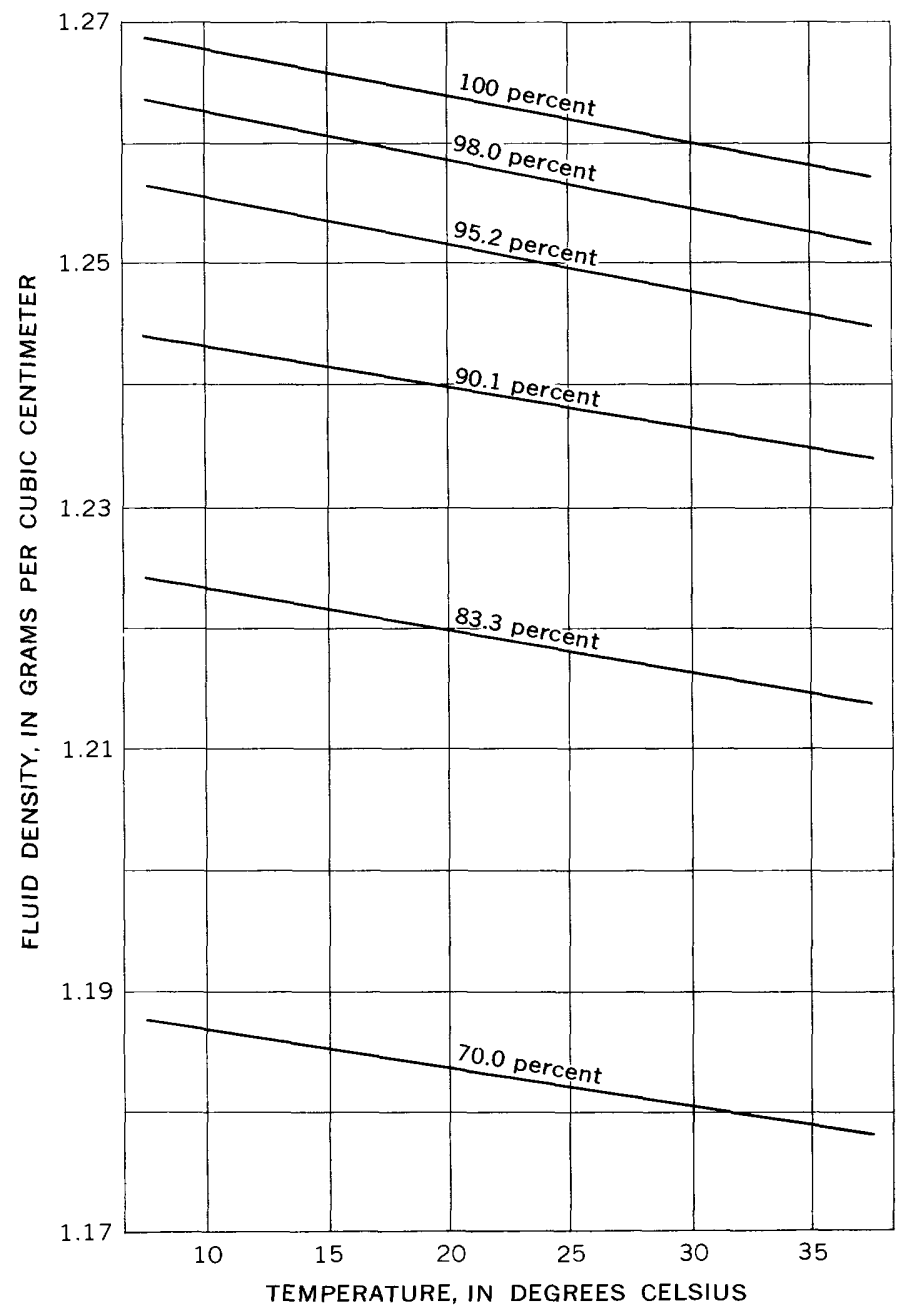

Frgure 7.-Density of glycerine-water mixtures in terms of percent glycerine as a function of temperature.

scale of 1 inch on the grid for $10 \mathrm{~cm}$ of the fall column. This arrangement permitted reasonably accurate estimates of the particle position at any time.

\section{PROCEDURE}

A permanent record was made of each drop of each particle with the two $16-\mathrm{mm}$ movie cameras. The motion pictures thus made permitted a more accurate visualization of particle behavior and fall pattern than could be obtained with still pictures. The cameras were adjusted so that the camera lens were level with the center of the test section. The distance from the camera to the fall column was 7.5 feet for the first series of tests and 6 feet for the last series. The distance was changed to get better lighting characteristics.

The cameras were manually operated throughout the experiment, and the particles were dropped by hand.

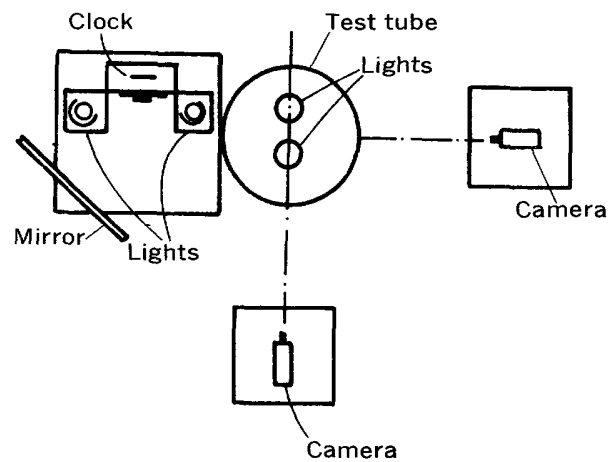

PLAN VIEW

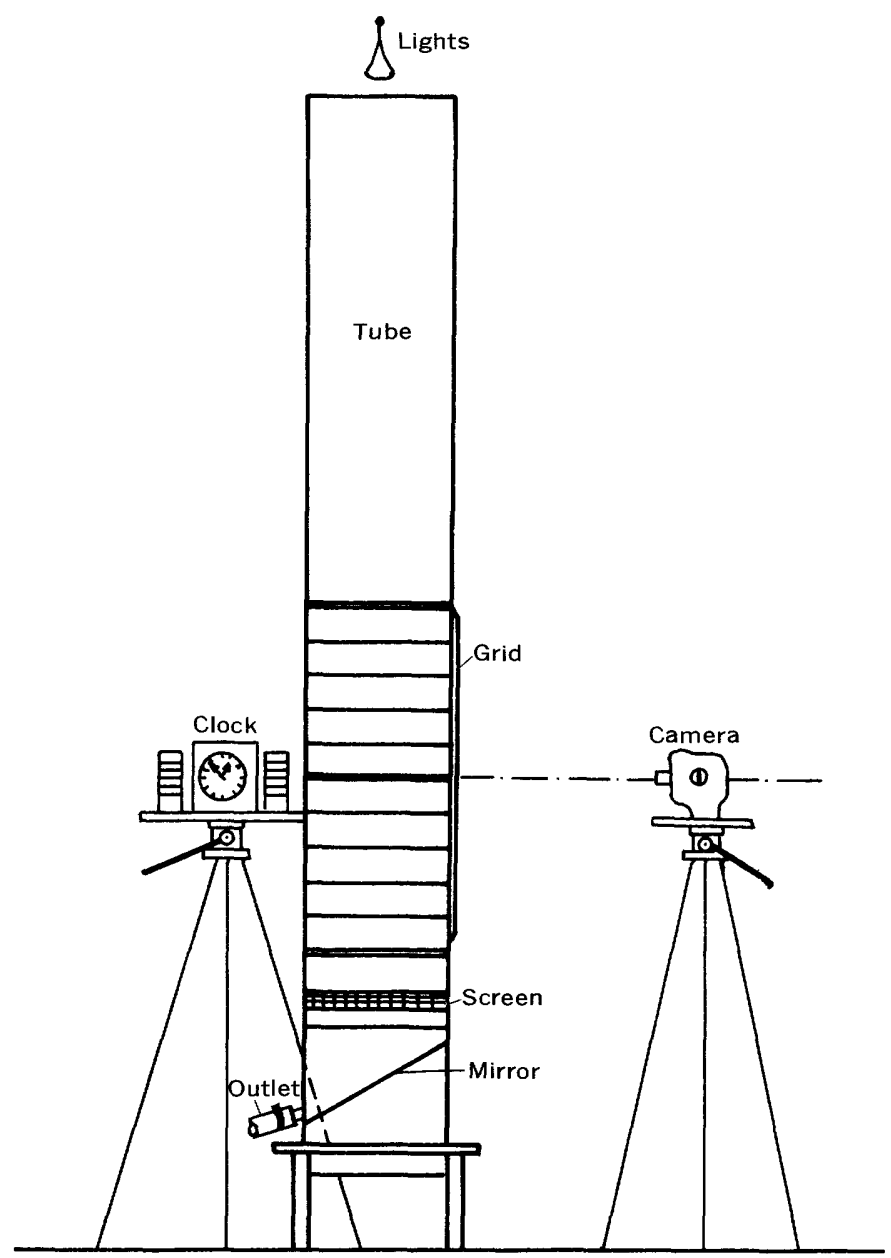

SIDE VIEW

Fraure 8.-Schematic diagram of fall column.

Determination of path and vertical drop lengths required measuring the distances between the positions of the particles in successive pictures as they were projected onto the grid.

Inherent in this procedure is the assumption that the particle fell in a plane through the center line of the 
column perpendicular to the camera. Generally, this was not the case. However, when the angle from the camera to the top or bottom of the measured section and the angle of refraction of the light in the fluid were considered, a maximum error of \pm 6.5 to \pm 8.25 percent in water and \pm 5.95 to \pm 7.45 percent in glycerine can result. No attempt was made to compensate for the error in defining particle behavior.

The distortion of the curved surface of the column was neglected. The error thus caused was affected by the position, parallel to the line of sight, of the particle in the column (fig. 9).

The three-dimensional length of the fall path of the particle was determined by taking the $x$ and $z$, or the horizontal and vertical, coordinates from one camera and the $y$ coordinate, from the other camera. The square root of the sum of the squares of the differences in position of successive pictures, summed for the entire measurable length, determined the length of the fall path. The vertical path was measured by taking the difference in the $z$ coordinates of the particle at the beginning and end of the run. Except for disks, the fall and vertical paths were usually identical.

The path and vertical velocities of the particles were determined by dividing the path and vertical distance by the elapsed time of fall.

Some of the drops for disks required special analysis to determine the fall velocities. For example, during the drop through the test section, a disk would often tumble from one side of the column to the other, strike the wall, bounce along it for a short distance, then move away and begin a tumbling descent through the remainder of a test section. In these cases, only those parts of the drop where the disk was away from the wall were used in the computations. To arrive at a
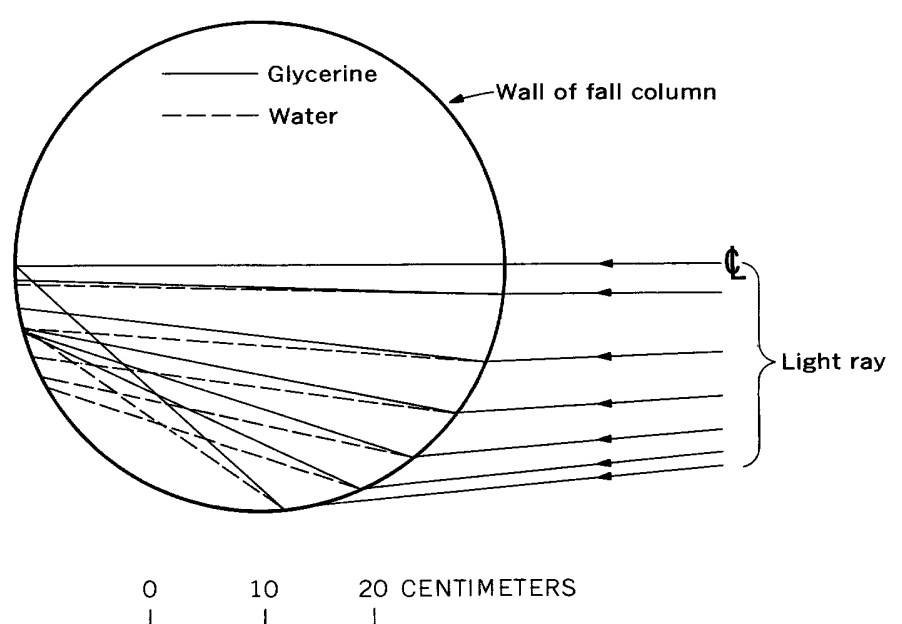

Figure 9.-Distortion of light rays caused by" fluid refraction and the curved surface of the fall column. single value of the velocity for that run, the distances which the particle fell in the center of the column were added and the sum divided by the elapsed time for falling that distance. For example, if a particle fell through the first $18 \mathrm{~cm}$ in 2 seconds and then struck the wall, fell down the wall for $10 \mathrm{~cm}$, and then fell freely for $52 \mathrm{~cm}$ in 5 seconds before striking the opposite wall, the length of the fall path was treated as being $70 \mathrm{~cm}$, elapsed time as 7 seconds, and the velocity as $10 \mathrm{~cm} / \mathrm{sec}$. If the same disk was dropped in the same fluid more than once, then the aggregate free-fall distance of all drops was divided by the accumulated free-fall time to determine the single velocity used in computations of $C_{D}$ and $\mathbf{R}$ for that disk in that fluid.

The procedure outlined above gave the greatest weight in the averaging process to the longest free-fall distance.

\section{EXPERIMENTAL RESULTS}

In the presentation of results, a few symbols have been changed from those common to current literature. Fall velocities and resistance to fall are expressed in terms of the coefficient of drag and the Reynolds number diagrams. The basic drop data and some parameters computed therefrom are given in tables 2-6 for spheres, disks, oblate spheroids, cylinders, and prolate spheroids. The results for each differently shaped particle are plotted separately to avoid obscuring any significant relationships in a maze of points. The curves thus developed are later plotted together for comparison. The curves of the relation of $C_{D}$ to $\mathbf{R}$ for fixed spheres and for disks, and a curve computed from Stokes' equation, are plotted on all diagrams for reference. The particular curves for fixed disks and spheres were taken from Rouse (1946).

\section{DESCRIPTION OF FINDINGS}

Terms relating to orientation, velocity, and path of travel of a particle need to be clearly defined. When a particle falls with its maximum projected area perpendicular to the direction of fall, in a straight vertical path at a constant velocity, the particle is said to be steady, and the condition of the fall is stable. When the particle orientation, direction of path, and velocity change during fall, the particle is said to be unsteady, and the condition of fall may be either stable or unstable. Reference to fall patterns of particles and their effect on the appropriate descriptive parameters will be made in these terms.

\section{SPHERES}

Generally, the spheres fell in a straight, vertical path. Exceptions were small erratic nonrepeating horizontal movements exhibited by two or three of the nylon and teflon spheres as they dropped in water. The 
TABLE 2.-Drop data for spheres ${ }^{1}$

\begin{tabular}{|c|c|c|c|c|}
\hline \multirow{2}{*}{ Run No. ${ }^{2}$} & \multirow{2}{*}{$\begin{array}{c}\text { Travel } \\
\text { distance } \\
(\mathrm{cm})\end{array}$} & \multirow{2}{*}{$\begin{array}{c}\text { Mean } \\
\text { velocity } \\
\text { (cm/sec) }\end{array}$} & \multicolumn{2}{|c|}{$\begin{array}{c}C_{D} \text { and } \mathbf{R} \text { values for } \\
d_{m} \text { and } d_{n}\end{array}$} \\
\hline & & & $C_{D}$ & $\overline{\mathbf{R} \times 10^{-2}}$ \\
\hline $\begin{array}{l}1-1-10 \\
2-1-9=- \\
3-1-8= \\
4-1-7=- \\
5-1-7=-\end{array}$ & $\begin{array}{l}100.0 \\
103.4 \\
102.7 \\
102.0 \\
100.6\end{array}$ & $\begin{array}{l}303.0 \\
258.6 \\
209.6 \\
185.4 \\
192.8\end{array}$ & $\begin{array}{r}0.51 \\
.51 \\
.49 \\
.51 \\
.42\end{array}$ & $\begin{array}{r}927 \\
1,180 \\
641 \\
426 \\
461\end{array}$ \\
\hline $\begin{array}{r}6-1-6-- \\
7-1-6=- \\
8-1-5- \\
15-1-1=- \\
16-1-4=\end{array}$ & $\begin{array}{l}104.6 \\
101.6 \\
102.6 \\
100.1 \\
102.5\end{array}$ & $\begin{array}{l}94.7 \\
98.4 \\
87.5 \\
29.9 \\
80.0\end{array}$ & $\begin{array}{l}.64 \\
.60 \\
.51 \\
.42 \\
.46\end{array}$ & $\begin{array}{r}435 \\
453 \\
268 \\
69 \\
184\end{array}$ \\
\hline $\begin{array}{l}17-1-3 \\
18-1-2 \\
57-2-5 \\
58-2-6 \\
59-2-7\end{array}$ & $\begin{array}{l}102.4 \\
101.5 \\
100.0 \\
100.0 \\
100.0\end{array}$ & $\begin{array}{l}39.0 \\
34.4 \\
24.9 \\
44.5 \\
83.9\end{array}$ & $\begin{array}{r}.39 \\
.43 \\
\text { 3. } 81 \\
1.79 \\
1.80\end{array}$ & $\begin{array}{l}179 \\
105 \\
.18 \\
.4 \\
.4\end{array}$ \\
\hline $\begin{array}{l}60-2-8 \\
61-2-9 \\
62-2-9 \\
63-2-10 \\
89-3-4\end{array}$ & $\begin{array}{r}99.0 \\
100.0 \\
102.0 \\
98.0 \\
100.0\end{array}$ & $\begin{array}{r}114.0 \\
180.0 \\
151.0 \\
206.0 \\
22.0\end{array}$ & $\begin{array}{r}1.29 \\
.82 \\
.96 \\
1.07 \\
4.05\end{array}$ & $\begin{array}{r}.80 \\
1.85 \\
1.55 \\
1.46 \\
.15\end{array}$ \\
\hline $\begin{array}{l}90-3-5- \\
91-3-6- \\
92-3-7- \\
93-3-8- \\
94-3-9-\end{array}$ & $\begin{array}{r}100.0 \\
100.0 \\
100.0 \\
101.0 \\
98.1\end{array}$ & $\begin{array}{r}31.4 \\
49.6 \\
91.0 \\
122.0 \\
184.5\end{array}$ & $\begin{array}{l}2.42 \\
1.47 \\
1.54 \\
1.14 \\
.78\end{array}$ & $\begin{array}{r}.29 \\
.64 \\
.62 \\
1.11 \\
2.51\end{array}$ \\
\hline $\begin{array}{r}95-3-9 \\
96-3-10 \\
122-4-4 \\
123-4-5 \\
124-4-6 \\
125-4-7\end{array}$ & $\begin{array}{r}98.1 \\
98.0 \\
100.0 \\
100.0 \\
100.0 \\
99.1\end{array}$ & $\begin{array}{r}190.0 \\
202.0 \\
25.0 \\
35.0 \\
56.0 \\
101.0\end{array}$ & $\begin{array}{r}.74 \\
.88 \\
2.90 \\
1.98 \\
1.16 \\
1.26\end{array}$ & $\begin{array}{r}2.58 \\
1.84 \\
.21 \\
.39 \\
.93 \\
.84\end{array}$ \\
\hline $\begin{array}{l}126-4-8 \\
128-4-9 \\
129-4-100 \\
153-4-9-9 \\
183-5-4\end{array}$ & $\begin{array}{r}98.1 \\
69.7 \\
97.8 \\
91.3 \\
100.0\end{array}$ & $\begin{aligned} 134.0 \\
201.0 \\
231.0 \\
197.0 \\
37.0\end{aligned}$ & $\begin{array}{r}.94 \\
.66 \\
.87 \\
.69 \\
1.34\end{array}$ & $\begin{array}{r}1.48 \\
3.33 \\
2.55 \\
3.25 \\
.59\end{array}$ \\
\hline $\begin{array}{l}184-5-5-\ldots \\
185-5-6- \\
190-5-9-1 \\
194-5-7- \\
195-5-10 \\
19-\end{array}$ & $\begin{aligned} & 99 . 0 \\
& 100.3 \\
& 100.8 \\
& 100.1 \\
& 77.0\end{aligned}$ & $\begin{array}{r}48.8 \\
70.2 \\
252.0 \\
129.8 \\
256.5\end{array}$ & $\begin{array}{l}1.03 \\
.76 \\
.42 \\
.76 \\
.56\end{array}$ & $\begin{array}{l}\text { 1. } 03 \\
2.22 \\
\text { 7. } 75 \\
2.05 \\
\text { 5. } 39\end{array}$ \\
\hline 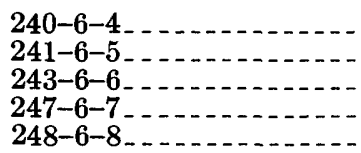 & $\begin{aligned} 100.5 \\
61.2 \\
100.9 \\
101.5 \\
97.4\end{aligned}$ & $\begin{array}{r}45.7 \\
55.6 \\
80.8 \\
145.2 \\
198.2\end{array}$ & $\begin{array}{l}.91 \\
.83 \\
.59 \\
.62 \\
.44\end{array}$ & $\begin{array}{l}\text { 1. } 40 \\
2.27 \\
\text { 4. } 95 \\
\text { 4. } 45 \\
\text { 8. } 05\end{array}$ \\
\hline 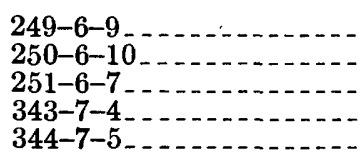 & $\begin{aligned} 98.2 \\
102.7 \\
101.3 \\
101.8 \\
101.1\end{aligned}$ & $\begin{aligned} 233.0 \\
267.0 \\
158.3 \\
67.1 \\
77.4\end{aligned}$ & $\begin{array}{l}.51 \\
.53 \\
.53 \\
.45 \\
.40\end{array}$ & $\begin{aligned} 14.1 \\
10.8 \\
4.85 \\
7.64 \\
11.7\end{aligned}$ \\
\hline $\begin{array}{l}345-7-6 \\
346-7-7-7 \\
347-7-8 \\
348-7-9 \\
349-7-10\end{array}$ & $\begin{array}{r}95.6 \\
97.1 \\
100.2 \\
96.7 \\
100.3\end{array}$ & $\begin{array}{l}101.0 \\
162.5 \\
208.0 \\
263.0 \\
305.0\end{array}$ & $\begin{array}{l}.41 \\
.50 \\
.40 \\
.41 \\
.40\end{array}$ & $\begin{array}{l}23 \\
18.5 \\
31.4 \\
58.5 \\
46\end{array}$ \\
\hline
\end{tabular}

1 The vertical and path data for travel distance, velocity, $C_{D}$ and $\mathbf{R}$ are identical for spheres. particle number. horizontal movements increased the fall-path length a maximum of 3 percent. Average increase in length was 1 percent. Occasionally, a steel sphere exhibited a horizontal translation as it fell through the test section. This translation also increased path length to a maximum of 3 percent. Specific characteristics of this unstable condition could not be repeated with other drops.

Only one sphere exhibited any perceptible rotation. The $3.81-\mathrm{cm}$ teflon sphere falling in water rotated approximately $45^{\circ}$ during the last $50 \mathrm{~cm}$ of fall.

The $C_{D}-\mathbf{R}$ curve for the falling spheres was virtually the same as for spheres rigidly mounted in a moving fluid (fig. 10). The scatter in the data can be ascribed to experimental error.

\section{DISKS}

Several broad systematic patterns of fall existed for a freely falling disk.

steady-fat fall

When the Reynolds number for a falling disk was less than 100 , the disk fell at a uniform velocity with the maximum projected area perpendicular to the direction of fall and had no tendency to oscillate. This indicated a very stable condition because oscillations caused by some outside influence damped out with time and distance. The stable fall pattern of a falling disk is typified in figure 11. Drawings from successive pictures of the movies are used to represent the steady-flat fall pattern (fig. 11).

Regular oscillation

At Reynolds numbers slightly greater than 100 , the disk oscillated about a diameter perpendicular to the direction of fall. Very little horizontal translation was associated with the oscillation (fig. 1). As $\mathbf{R}$ increased, the amplitude of the oscillation and the horizontal translation increased. The path of travel was almost parallel to the face of the disk, and the drag was mainly shear drag (figs. 1, 12).

In theory, the amplitude of the arc through which the disk oscillates is a function of the balance between the weight of the disk and the lift and drag forces acting on it. The greater the lift force with respect to the disk weight and the drag force, the greater will be the amplitude of the arc through which the disk oscillates. Wilmarth, Hawk, and Harvey (1964) found that the amplitude of the arc was inversely proportional to the stability number I of the disk. Because I is the product of (a) the density ratio of the disk and the fluid and (b) the thickness-diameter ratio of the disk, decreasing I merely decreases the ratio of the weight to area of the disk. Therefore, assuming a constant velocity, decreasing I will increase the lift-weight ratio of the 
TABLE 3.-Drop data for disks

\begin{tabular}{|c|c|c|c|c|c|c|c|c|c|c|c|c|c|}
\hline \multirow{2}{*}{ Run No. 1} & \multicolumn{2}{|c|}{ Travel distance } & \multicolumn{2}{|c|}{ Velocity } & \multicolumn{4}{|c|}{$C_{\mathrm{D}}$ and $\mathbf{R}$ values for $d_{\mathrm{m}}$} & \multicolumn{4}{|c|}{$C_{\mathrm{D}}$ and $\mathbf{R}$ values for $d_{\mathrm{n}}$} & \multirow{2}{*}{ lity ${ }^{2}$} \\
\hline & $\begin{array}{l}\text { Path } \\
\text { (cm) }\end{array}$ & $\begin{array}{l}\text { Vertical } \\
(\mathrm{cm})\end{array}$ & $\begin{array}{l}\text { ath } \\
\text { /sec) }\end{array}$ & $\begin{array}{l}\text { Vertical } \\
\text { (cm/sec) }\end{array}$ & $C_{\mathrm{D}}{ }^{\mathrm{P}}$ & Path $_{\mathbf{R} \times 10^{-2}}$ & $C_{\mathrm{D}}$ & $\stackrel{\text { ical }}{\mathbf{i}} \times 10^{-2}$ & $C_{\mathrm{D}}{ }^{\mathrm{Pa}}$ & ${ }^{a t h}{ }_{\mathbf{R}}$ & & -2 & \\
\hline $\begin{array}{l}19-1-34- \\
20-1-33- \\
21-1-32= \\
23-1-33- \\
24-1-33 \ldots\end{array}$ & $\begin{array}{r}121.8 \\
61.8 \\
95.0 \\
30.4 \\
129.0\end{array}$ & $\begin{array}{l}70.5 \\
31.0 \\
46.5 \\
21.0 \\
91.5\end{array}$ & $\begin{array}{l}86.5 \\
74.3 \\
58.0 \\
73.5 \\
58.5\end{array}$ & $\begin{array}{l}50.2 \\
37.1 \\
28.4 \\
50.9 \\
41.6\end{array}$ & $\begin{array}{r}0.28 \\
.16 \\
.20 \\
.17 \\
.26\end{array}$ & $\begin{array}{l}324 \\
226 \\
133 \\
224 \\
179\end{array}$ & $\begin{array}{l}0.54 \\
.66 \\
.85 \\
.35 \\
.48\end{array}$ & $\begin{array}{r}231 \\
114 \\
65 \\
155 \\
134\end{array}$ & $\begin{array}{l}0.98 \\
.59 \\
.72 \\
.60 \\
.94\end{array}$ & $\begin{array}{l}172 \\
121 \\
70.5 \\
120 \\
95.4\end{array}$ & $\begin{array}{l}1 . \\
2 . \\
3 . \\
1 . \\
1 .\end{array}$ & $\begin{array}{l}123 \\
60.4 \\
34.6 \\
83.0 \\
67.9\end{array}$ & $\begin{array}{l}G T \\
G T \\
\text { GT } \\
\text { GT } \\
\text { GT }\end{array}$ \\
\hline $\begin{array}{l}25-1-32 \\
42-1-21- \\
43-1-22 \\
73-2-20 \\
74-2-21=\end{array}$ & $\begin{array}{r}121.2 \\
51.7 \\
102.9 \\
100.0 \\
100.0\end{array}$ & $\begin{array}{r}69.5 \\
33.5 \\
67.5 \\
100.0\end{array}$ & $\begin{array}{r}70.5 \\
76.2 \\
102.5 \\
26.2 \\
36.2\end{array}$ & $\begin{array}{l}40.5 \\
49.8 \\
67.5 \\
26.2\end{array}$ & $\begin{array}{r}.14 \\
.79 \\
.65 \\
3.82 \\
2.68\end{array}$ & $\begin{array}{ll} & 163 \\
234 \\
472 \\
\\
\\
\quad .14 \\
& .26\end{array}$ & $\begin{array}{l}.42 \\
1.84 \\
1.52\end{array}$ & $\begin{array}{c}93.4 \\
1.53 \\
310\end{array}$ & $\begin{array}{c}.48 \\
2.80 \\
2.33 \\
13.6 \\
9.56\end{array}$ & $\begin{array}{l}86.6 \\
124 \\
250 \\
\quad .07 \\
.14\end{array}$ & 6 & $\begin{array}{r}49.7 \\
81.0 \\
164\end{array}$ & $\begin{array}{l}T \\
T \\
T \\
S\end{array}$ \\
\hline $\begin{array}{r}75-2-22 \\
87-2-34 \\
106-3-20 \\
107-3-21 \\
108-3-22 \\
\end{array}$ & $\begin{array}{r}100.0 \\
100.0 \\
100.0 \\
80.0 \\
100.0\end{array}$ & & $\begin{array}{l}53.9 \\
17.4 \\
29.4 \\
42.0 \\
61.0\end{array}$ & & $\begin{array}{l}.82 \\
.05 \\
.04 \\
.00 \\
.42\end{array}$ & $\begin{array}{l}.57 \\
.19 \\
.20 \\
.38 \\
.83\end{array}$ & & & $\begin{array}{c}6.45 \\
10.8 \\
10.9 \\
7.15 \\
5.05\end{array}$ & $\begin{array}{l}.30 \\
.10 \\
.11 \\
.20 \\
.44\end{array}$ & & & S \\
\hline $\begin{array}{l}9-3-33 \ldots \\
0-3-34- \\
1-3-34 \ldots \\
3-4-33 \ldots \\
4-4-34 \ldots\end{array}$ & & $\ldots \ldots$ & $\begin{array}{l}12.2 \\
19.6 \\
20.2 \\
13.6 \\
20.4\end{array}$ & & & $\begin{array}{l}.11 \\
.27 \\
.28 \\
.15 \\
.34\end{array}$ & & & $\begin{array}{c}14.7 \\
8.60 \\
8.05 \\
11.8 \\
7.97\end{array}$ & $\begin{array}{l}.06 \\
.14 \\
.15 \\
.08 \\
.18\end{array}$ & & & \\
\hline $\begin{array}{l}5-4-20 \\
6-4-21 \\
7-4-22- \\
8-4-22= \\
6-5-32 \\
6-\end{array}$ & $\begin{array}{r}100.0 \\
99.0 \\
99.0 \\
100.0\end{array}$ & $\ldots$ & & & & $\begin{array}{r}.28 \\
.51 \\
1.12 \\
1.09 \\
.22\end{array}$ & & & $\begin{array}{l}8.30 \\
5.96 \\
4.11 \\
4.36 \\
8.23\end{array}$ & $\begin{array}{l}.15 \\
.27 \\
.60 \\
.58 \\
.12\end{array}$ & $\ldots$ & & 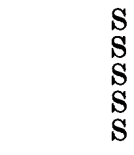 \\
\hline $\begin{array}{l}7-5-33-- \\
8-5-34-- \\
9-5-20-- \\
0-5-21- \\
1-5-22-\ldots\end{array}$ & & -.... & & 74.5 & $\begin{array}{r}1.80 \\
1.28 \\
1.30 \\
1.11 \\
.60\end{array}$ & $\begin{array}{r}.39 \\
.79 \\
.70 \\
1.20 \\
3.00\end{array}$ & .97 & & $\begin{array}{l}6.40 \\
4.53 \\
4.63 \\
3.94 \\
2.10\end{array}$ & $\begin{array}{r}.21 \\
.42 \\
.38 \\
.64 \\
1.60\end{array}$ & 3.44 & 1.25 & GT \\
\hline $\begin{array}{l}62-5-22- \\
69-5-22- \\
70-5-22- \\
86-5-22- \\
87-5-22\end{array}$ & $\begin{array}{l}91 \\
75 \\
83\end{array}$ & $\begin{array}{r}72.5 \\
60.0 \\
70.0 \\
100.0 \\
96.5\end{array}$ & & & $\begin{array}{l}.64 \\
.61 \\
.54 \\
.70 \\
.57\end{array}$ & $\begin{array}{l}2.90 \\
2.96 \\
3.17 \\
2.76 \\
3.06\end{array}$ & $\begin{array}{r}.99 \\
.96 \\
.76 \\
1.01 \\
.90\end{array}$ & $\begin{array}{l}2.28 \\
2.36 \\
2.68 \\
2.30 \\
2.44\end{array}$ & & 1. & & & $\begin{array}{l}\text { GT } \\
\text { GT } \\
\text { GT } \\
\text { GT } \\
\text { GT }\end{array}$ \\
\hline $\begin{array}{l}88-5-22- \\
89-5-22- \\
92-5-22- \\
93-5-22- \\
96-1-32- \\
96\end{array}$ & 93.3 & & & & $\begin{array}{l}.52 \\
.68 \\
.52 \\
.55 \\
.20\end{array}$ & $\begin{array}{c}3.2 \\
2.8 \\
3.2 \\
3.1 \\
108\end{array}$ & $\begin{array}{r}1.17 \\
1.17 \\
1.00 \\
.92 \\
.56\end{array}$ & $\begin{array}{c}2.13 \\
2.14 \\
2.31 \\
2.40 \\
65.6\end{array}$ & $\begin{array}{r}1.94 \\
.72\end{array}$ & & & & $\begin{array}{l}\text { GT } \\
\text { GT } \\
\text { GT } \\
\text { GT } \\
\text { GT }\end{array}$ \\
\hline $\begin{array}{l}97-1-32- \\
98-1-33- \\
99-1-33- \\
00-1-34- \\
01-1-34-\end{array}$ & $\begin{array}{r}58.0 \\
114.5 \\
58.9 \\
147.6 \\
55.5\end{array}$ & & & & $\begin{array}{l}.21 \\
.16 \\
.10 \\
.22 \\
.14\end{array}$ & $\begin{array}{l}234 \\
294 \\
373\end{array}$ & $\begin{array}{r}1.00 \\
.52 \\
.23 \\
.86 \\
.47\end{array}$ & $\begin{array}{r}49 \\
104 \\
155 \\
149 \\
203\end{array}$ & $\begin{array}{l}.73 \\
.57 \\
.36 \\
.78 \\
.48\end{array}$ & & 1 & & $\begin{array}{l}\text { GT } \\
\text { GT } \\
\text { GT } \\
\text { GT } \\
\text { GT }\end{array}$ \\
\hline $7-1-22$ & $\begin{array}{l}76.8 \\
74.0 \\
64.0 \\
72.9 \\
98.6\end{array}$ & & $\begin{array}{l}51 \\
78\end{array}$ & & $\begin{array}{r}1.29 \\
.54 \\
1.02 \\
.62 \\
.82\end{array}$ & $\begin{array}{l}97.6 \\
148 \\
168 \\
409 \\
343\end{array}$ & $\begin{array}{l}4.09 \\
1.69 \\
2.02 \\
.88 \\
1.80\end{array}$ & $\begin{array}{l}54.1 \\
84.2 \\
119 \\
332 \\
232\end{array}$ & $\begin{array}{l}4.66 \\
1.95 \\
3.64 \\
2.23 \\
2.90\end{array}$ & $\begin{array}{l}51.2 \\
78.6 \\
88.9 \\
222 \\
183\end{array}$ & $\begin{array}{r}14.65 \\
6.04 \\
7.25 \\
3.11 \\
6.36\end{array}$ & $\begin{array}{l}28.6 \\
44.7 \\
63.0 \\
177 \\
124\end{array}$ & $\begin{array}{r}\mathrm{T} \\
\mathrm{T} \\
\mathrm{T} \\
\mathrm{GT} \\
\mathrm{GT}\end{array}$ \\
\hline $8-6-21 \ldots$ & $\begin{array}{r}99.5 \\
115.8 \\
112.4\end{array}$ & $\begin{array}{r}100.0 \\
76.5\end{array}$ & & $\begin{array}{l}46.7 \\
53.5\end{array}$ & $\begin{array}{r}1.56 \\
1.32 \\
1.15 \\
.94 \\
.59\end{array}$ & $\begin{array}{r}.52 \\
.90 \\
1.79 \\
1.64 \\
3.20\end{array}$ & $\begin{array}{l}1.24 \\
1.27\end{array}$ & 2.18 & $\begin{array}{l}5.46 \\
4.69 \\
4.06 \\
3.40 \\
2.10\end{array}$ & $\begin{array}{r}.2 \\
.4 \\
.9 \\
.8 \\
1.7\end{array}$ & $\begin{array}{l}4.46 \\
4.55\end{array}$ & $\begin{array}{l}.75 \\
1.16\end{array}$ & $\stackrel{1}{0}$ \\
\hline $\begin{array}{l}29-6-34-\ldots \\
30-6-20- \\
31-6-21 \\
32-6-22- \\
33-6-22-\end{array}$ & $\begin{array}{r}80.0 \\
111.9 \\
89.0 \\
101.2 \\
96.4\end{array}$ & $\begin{array}{r}100.5 \\
66.5 \\
68.0 \\
66.5\end{array}$ & $\begin{array}{l}50 \\
79\end{array}$ & $\begin{array}{l}44.6 \\
59.1 \\
53.4 \\
65.4\end{array}$ & $\begin{array}{r}1.09 \\
1.05 \\
.58 \\
.87 \\
.61\end{array}$ & $\begin{array}{l}1.83 \\
1.51 \\
3.22 \\
4.84 \\
5.76\end{array}$ & $\begin{array}{l}1.04 \\
1.93 \\
1.28\end{array}$ & $\begin{array}{l}2.40 \\
3.24 \\
3.98\end{array}$ & $\begin{array}{l}3.76 \\
3.08 \\
3.08 \\
2.18\end{array}$ & $\begin{array}{r}.97 \\
.82 \\
1.71 \\
2.58 \\
3.07\end{array}$ & & $\begin{array}{l}1.28 \\
1.73 \\
2.12\end{array}$ & $\begin{array}{r}\stackrel{o}{\mathrm{~T}} \\
\mathrm{GT} \\
\mathrm{GT}\end{array}$ \\
\hline
\end{tabular}


THE BEHAVIOR OF LARGE PARTICLES FALLING IN QUIESCENT LIQUIDS

TABLE 3.-Drop data for disks--Continued

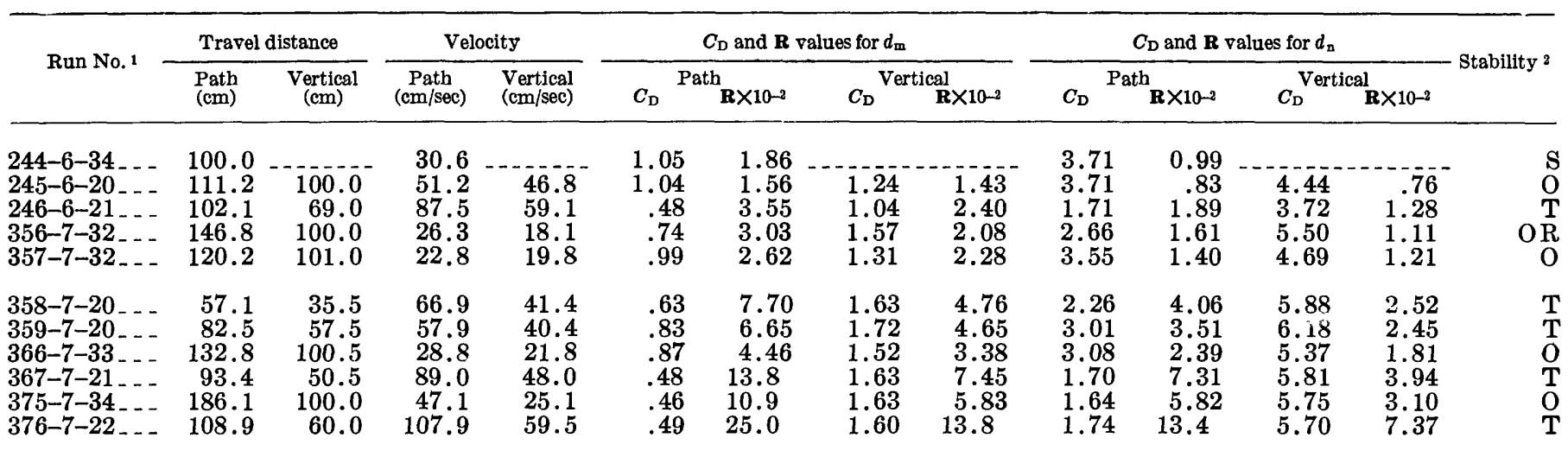

1 The run number is a combination of drop number, fluid number (fig. 6 ), and particle number. ${ }^{2} \mathrm{G}$, glide fall; $\mathrm{T}$, tumbling fall; $\mathrm{S}$, stable orientation and path; $O$, regular oscillation; $R$, rotation about vertical axis.

TABLE 4.-Drop data for oblate spheroids ${ }^{1}$

\begin{tabular}{|c|c|c|c|c|c|c|c|}
\hline \multirow[t]{2}{*}{ Run No. ${ }^{2}$} & \multirow{2}{*}{$\begin{array}{c}\text { Travel } \\
\text { distance } \\
\text { (cm) }\end{array}$} & \multirow{2}{*}{$\begin{array}{l}\text { Velocity } \\
(\mathrm{cm} / \mathrm{sec})\end{array}$} & \multicolumn{2}{|c|}{$\begin{array}{l}C_{D} \text { and } \mathbf{R} \text { values } \\
\quad \text { for } d_{m}\end{array}$} & \multicolumn{2}{|c|}{$\begin{array}{l}C_{D} \text { and } \mathbf{R} \text { values } \\
\text { for } d_{n}\end{array}$} & \multirow{2}{*}{$\begin{array}{c}\text { Sta- } \\
\text { bility }\end{array}$} \\
\hline & & & $C_{D}$ & $R \times 10^{-2}$ & $C_{D}$ & $R \times 10^{-2}$ & \\
\hline 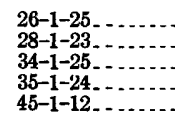 & $\begin{array}{r}29.0 \\
108.4 \\
102.1 \\
103.4 \\
101.2\end{array}$ & $\begin{array}{r}88.1 \\
65.6 \\
78.6 \\
89.6 \\
168.9\end{array}$ & $\begin{array}{l}0.66 \\
.58 \\
.83 \\
.41 \\
.58\end{array}$ & $\begin{array}{l}400 \\
750 \\
358 \\
270 \\
506\end{array}$ & $\begin{array}{r}0.98 \\
.87 \\
1.22 \\
.61 \\
.86\end{array}$ & $\begin{array}{l}331 \\
124 \\
296 \\
221 \\
415\end{array}$ & $\begin{array}{l}O T \\
O T \\
O T \\
T \\
\mathbf{S}\end{array}$ \\
\hline 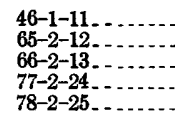 & $\begin{array}{l}102.4 \\
100.0 \\
100.0 \\
100.0 \\
100.0\end{array}$ & $\begin{array}{r}148.5 \\
91.5 \\
135.5 \\
26.7 \\
41.6\end{array}$ & $\begin{array}{l}.60 \\
1.52 \\
.99 \\
3.12 \\
1.98\end{array}$ & $\begin{array}{r}342 \\
.64 \\
1.45 \\
.19 \\
.44\end{array}$ & $\begin{array}{l}.87 \\
2.26 \\
1.56 \\
4.61 \\
2.91\end{array}$ & $\begin{array}{r}285 \\
.52 \\
1.17 \\
.15 \\
.36\end{array}$ & $\begin{array}{l}\mathbf{S} \\
\mathbf{S} \\
\mathbf{S} \\
\mathbb{S} \\
\mathbf{S}\end{array}$ \\
\hline $\begin{array}{r}97-3-11 \\
98-3-12 \\
99-3-13 \\
109-3-23 \\
110-3-24\end{array}$ & $\begin{array}{r}100.0 \\
100.0 \\
98.0 \\
100.0 \\
100.0\end{array}$ & $\begin{array}{r}74.0 \\
95.8 \\
137.7 \\
22.4 \\
31.0\end{array}$ & $\begin{array}{l}1.86 \\
1.39 \\
.97 \\
3.39 \\
2.32\end{array}$ & $\begin{array}{r}.50 \\
.85 \\
1.89 \\
.15 \\
.28\end{array}$ & $\begin{array}{l}2.67 \\
2.06 \\
1.51 \\
5.06 \\
3.44\end{array}$ & $\begin{array}{r}.43 \\
.70 \\
1.52 \\
.13 \\
.23\end{array}$ & $\begin{array}{l}\mathbf{S} \\
\mathrm{S} \\
\mathrm{S} \\
\mathrm{S} \\
\mathrm{S}\end{array}$ \\
\hline $\begin{array}{l}111-3-25 \\
130-4-23 \\
131-4-24 \\
132-4-25 \\
133-4-11\end{array}$ & $\begin{array}{l}100.0 \\
100.0 \\
100.0 \\
99.0 \\
100.0\end{array}$ & $\begin{array}{l}48.8 \\
25.3 \\
34.5 \\
51.0 \\
90.0\end{array}$ & $\begin{array}{l}1.47 \\
2.75 \\
1.88 \\
1.35 \\
1.27\end{array}$ & $\begin{array}{l}.66 \\
.21 \\
.38 \\
.83 \\
.75\end{array}$ & $\begin{array}{l}2.16 \\
4.13 \\
2.80 \\
1.98 \\
1.84\end{array}$ & $\begin{array}{l}.55 \\
.17 \\
.31 \\
.69 \\
.62\end{array}$ & $\begin{array}{l}\mathbf{S} \\
\mathbf{S} \\
\mathbf{S} \\
\mathbf{S} \\
\mathbf{S}\end{array}$ \\
\hline $\begin{array}{l}134-4-12 \\
135-4-13 \\
163-5-23 \\
164-5-24 \\
165-5-25\end{array}$ & $\begin{array}{r}100.0 \\
101.1 \\
99.0 \\
99.0 \\
99.0\end{array}$ & $\begin{array}{r}110.0 \\
146.5 \\
36.2 \\
45.4 \\
61.9\end{array}$ & $\begin{array}{r}1.06 \\
.87 \\
1.32 \\
1.10 \\
.94\end{array}$ & $\begin{array}{r}1.19 \\
2.45 \\
.57 \\
.94 \\
1.94\end{array}$ & $\begin{array}{l}1.57 \\
1.35 \\
1.99 \\
1.65 \\
1.37\end{array}$ & $\begin{array}{r}.98 \\
1.96 \\
.47 \\
.77 \\
1.59\end{array}$ & $\begin{array}{l}\mathbf{S} \\
\mathbb{S} \\
\mathbb{S} \\
\mathbb{S} \\
\mathbf{S}\end{array}$ \\
\hline $\begin{array}{l}166-5-11 \\
167-5-12 \\
168-5-13 \\
234-6-23 \\
235-6-24\end{array}$ & $\begin{array}{r}102.1 \\
99.0 \\
100.0 \\
100.0 \\
101.5\end{array}$ & $\begin{array}{r}113.0 \\
1128.9 \\
166.5 \\
42.7 \\
53.4\end{array}$ & $\begin{array}{l}.81 \\
.78 \\
.58 \\
.98 \\
.83\end{array}$ & $\begin{array}{l}1.79 \\
2.65 \\
5.30 \\
1.31 \\
2.13\end{array}$ & $\begin{array}{l}1.18 \\
1.16 \\
1.06 \\
1.47 \\
1.23\end{array}$ & $\begin{array}{l}1.48 \\
2.18 \\
4.25 \\
1.07 \\
1.75\end{array}$ & $\begin{array}{l}\mathbf{S} \\
\mathbf{S} \\
\mathbf{S} \\
\mathbf{S} \\
\mathbf{S}\end{array}$ \\
\hline $\begin{array}{l}236-6-25 \\
237-6-11 \\
238-6-12 \\
239-6-13 \\
354-7-23\end{array}$ & $\begin{array}{r}99.6 \\
99.0 \\
97.6 \\
101.6 \\
100.0\end{array}$ & $\begin{array}{r}70.8 \\
123.8 \\
139.2 \\
177.5 \\
54.1\end{array}$ & $\begin{array}{l}.73 \\
.69 \\
.68 \\
.63 \\
.64\end{array}$ & $\begin{array}{c}4.25 \\
3.79 \\
5.56 \\
10.6 \\
6.22\end{array}$ & $\begin{array}{r}1.07 \\
.99 \\
1.01 \\
.98 \\
.99\end{array}$ & $\begin{array}{l}3.54 \\
3.14 \\
4.55 \\
8.56 \\
5.08\end{array}$ & $\begin{array}{l}\mathbf{S} \\
\mathbf{S} \\
\mathbf{S} \\
\mathbf{S} \\
\mathbf{S}\end{array}$ \\
\hline $\begin{array}{l}355-7-11 \\
364-7-24 \\
368-7-12 \\
374-7-13 \\
377-7-25\end{array}$ & $\begin{array}{r}81.5 \\
100.5 \\
99.6 \\
96.5 \\
97.5\end{array}$ & $\begin{array}{r}139.0 \\
64.7 \\
151.8 \\
177.8 \\
81.2\end{array}$ & $\begin{array}{l}.56 \\
.63 \\
.59 \\
.63 \\
.59\end{array}$ & $\begin{array}{l}16 \\
9.85 \\
23 \\
41.5 \\
18.8\end{array}$ & $\begin{array}{l}.80 \\
.93 \\
.88 \\
.97 \\
.86\end{array}$ & $\begin{array}{l}13.3 \\
8.08 \\
18.9 \\
33.4 \\
15.5\end{array}$ & $\begin{array}{l}\mathbf{S} \\
\mathbf{S} \\
\mathbf{S} \\
\mathbf{S} \\
\mathbf{S}\end{array}$ \\
\hline
\end{tabular}

1 The vertical and path data for travel distance, velocity, $C \mathrm{D}$, and $\mathbf{R}$ are identical

2 The run number is a combination of drop number, fiuid number (fig. 6), and particle number.

$3 \mathrm{O}$, regular oscillation; $\mathrm{T}$, tumbling fall; $\mathrm{S}$, stable orientation and path.

disk because the lift is directly proportional to the area. Hence, the amplitude of oscillation should increase with I, as observed.

Glide-tumble

The third general fall pattern which the disks exhibited as $\mathbf{R}$ continued to increase was a combination of oscillation, gliding, and tumbling (figs. 13, 14). In the glide-tumble pattern, the amplitude of the disk oscillation increased until the plane of the disk face was almost vertical at the end of the arc. At this point, the disk fell vertically, on edge. The torque caused by circulation then changed the angle of inclination from vertical to horizontal and to vertical again. Associated with the change in angle of inclination was a change in path direction from vertically downward to horizontal to vertically upward. When the drag and gravity forces stopped the upward motion of the disk, the cycle was repeated. Whether or not the particle continued in the same horizontal direction on the next arc or returned on its path depended on the position of the disk at the end of the arc. If, for example, the disk approached the end of the arc from the right and stopped with the angle of inclination slightly to the right of the vertical, it would move back to the right on the next are (see upper half, fig. 13). If the disk stopped with the angle of inclination to the left of the vertical, it would move on to the left in the succeeding arc (see lower half, fig. 13). The oscillation frequency of the disk was much less during the glide-tumble fall pattern than during the regular oscillation fall pattern.

Tumble

With further increases in $\mathbf{R}$, the disks exhibited a fourth fall pattern, the tumble pattern. In the tumble fall pattern, the disk rotated through $360^{\circ}$ at a nearly constant angular velocity, and the path of travel was nearly a straight line inclined at an angle with the horizontal (fig. 15). The tumble fall pattern is a stable one where the frequency of angular rotation approaches the frequency of oscillation in the regular oscillation pattern. 
TABLE 5.-Drop data for cylinders

\begin{tabular}{|c|c|c|c|c|c|c|c|c|c|c|c|c|c|}
\hline \multirow{3}{*}{ Run No. ${ }^{1}$} & \multicolumn{2}{|c|}{ Travel distance } & \multicolumn{2}{|c|}{ Velocity } & \multicolumn{4}{|c|}{$C_{D}$ and $\mathbf{R}$ values for $d_{m}$} & \multicolumn{4}{|c|}{$C_{D}$ and $\mathbf{R}$ values for $d_{n}$} & \multirow{3}{*}{ Stability } \\
\hline & \multirow{2}{*}{$\begin{array}{l}\text { Path } \\
\text { (cm) }\end{array}$} & \multirow{2}{*}{$\begin{array}{c}\text { Vertical } \\
\text { (cm) }\end{array}$} & \multirow{2}{*}{$\begin{array}{c}\text { Path } \\
\text { (cm/sec) }\end{array}$} & \multirow{2}{*}{$\begin{array}{l}\text { Vertical } \\
(\mathrm{cm} / \mathrm{sec})\end{array}$} & \multicolumn{2}{|c|}{ Path } & \multicolumn{2}{|c|}{ Vertical } & \multicolumn{2}{|c|}{ Path } & \multicolumn{2}{|c|}{ Vertical } & \\
\hline & & & & & $C_{D}$ & $\mathbf{R} \times 10^{-2}$ & $C_{D}$ & $\mathbf{R} \times 10^{-2}$ & $C_{D}$ & $\mathbf{R} \times 10^{-2}$ & $C_{D}$ & $\mathbf{R} \times 10^{-2}$ & \\
\hline $\begin{array}{l}105-3-19 \\
117-3-31= \\
149-4-19= \\
150-4-18 \\
151-4-31\end{array}$ & $\begin{array}{r}100.0 \\
100.0 \\
99.0 \\
100.0 \\
100.0\end{array}$ & - & $\begin{array}{l}65.4 \\
21.3 \\
77.4 \\
52.1 \\
23.6\end{array}$ & 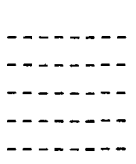 & $\begin{array}{l}2.44 \\
4.00 \\
1.73 \\
2.56 \\
3.27\end{array}$ & $\begin{array}{l}.50 \\
.16 \\
.72 \\
.32 \\
.22\end{array}$ & & & $\begin{array}{l}3.74 \\
6.16 \\
2.63 \\
3.96 \\
5.09\end{array}$ & $\begin{array}{l}.40 \\
.13 \\
.58 \\
.26 \\
.18\end{array}$ & $\begin{array}{l}- \\
- \\
- \\
- \\
-\end{array}$ & & $\begin{array}{l}\mathbf{S} \\
\mathbf{S} \\
\mathbf{S} \\
\mathbf{S} \\
\mathbf{S}\end{array}$ \\
\hline $\begin{array}{l}175-5-18 \\
176-5-19= \\
208-1-18 \\
209-1-19= \\
210-1-31\end{array}$ & $\begin{array}{r}100.0 \\
100.0 \\
33.1 \\
106.4 \\
111.4\end{array}$ & $\begin{array}{r}31.0 \\
100.0 \\
98.5\end{array}$ & $\begin{array}{r}66.7 \\
102.0 \\
132.4 \\
152.2 \\
66.5\end{array}$ & $\begin{array}{r}124.0 \\
143.0 \\
58.8\end{array}$ & $\begin{array}{r}1.58 \\
1.01 \\
.51 \\
.58 \\
.60\end{array}$ & $\begin{array}{l}1.79 \\
187^{.82} \\
322 \\
141\end{array}$ & $\begin{array}{l}.58 \\
.65 \\
.76\end{array}$ & $\begin{array}{l}175 \\
303 \\
125\end{array}$ & $\begin{array}{r}2.44 \\
1.58 \\
.79 \\
.89 \\
.92\end{array}$ & $\begin{array}{l}.64 \\
1.46 \\
150 \\
260 \\
113\end{array}$ & $\begin{array}{r}.90 \\
1.01 \\
1.18\end{array}$ & $\begin{array}{l}140 \\
244 \\
100\end{array}$ & $\begin{array}{l}\mathbf{S} \\
\mathbf{S} \\
\mathrm{OR} \\
\mathrm{OR} \\
\mathrm{OR}\end{array}$ \\
\hline $\begin{array}{l}212-6-29- \\
213-6-30- \\
214-6-31=- \\
215-6-17-\cdots \\
216-6-18-\cdots\end{array}$ & $\begin{array}{r}100.2 \\
100.0 \\
100.0 \\
101.1 \\
99.0\end{array}$ & 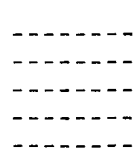 & $\begin{array}{l}18.6 \\
24.9 \\
39.7 \\
60.6 \\
82.6\end{array}$ & 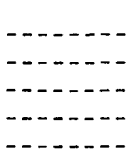 & $\begin{array}{l}2.51 \\
1.96 \\
1.22 \\
1.44 \\
1.05\end{array}$ & $\begin{array}{r}.32 \\
.57 \\
1.37 \\
1.05 \\
1.89\end{array}$ & $\begin{array}{l}--- \\
-- \\
--\end{array}$ & & $\begin{array}{l}4.22 \\
3.17 \\
1.89 \\
2.26 \\
1.62\end{array}$ & $\begin{array}{r}.25 \\
.45 \\
1.10 \\
.83 \\
1.52\end{array}$ & $\begin{array}{l}- \\
- \\
- \\
-\end{array}$ & & $\begin{array}{l}\mathbf{S} \\
\mathbf{S} \\
\mathbf{S} \\
\mathbf{S} \\
\mathbf{S}\end{array}$ \\
\hline
\end{tabular}

1 The run number is a combination of drop number, fluid number (fig. 6), and particle number. ${ }^{2} \mathrm{O}$, regular oscillation; $\mathrm{R}$, rotation about vertical axis, $\mathrm{S}$, stable orientation and path. 
FORCE NUMBER $(\lambda)$

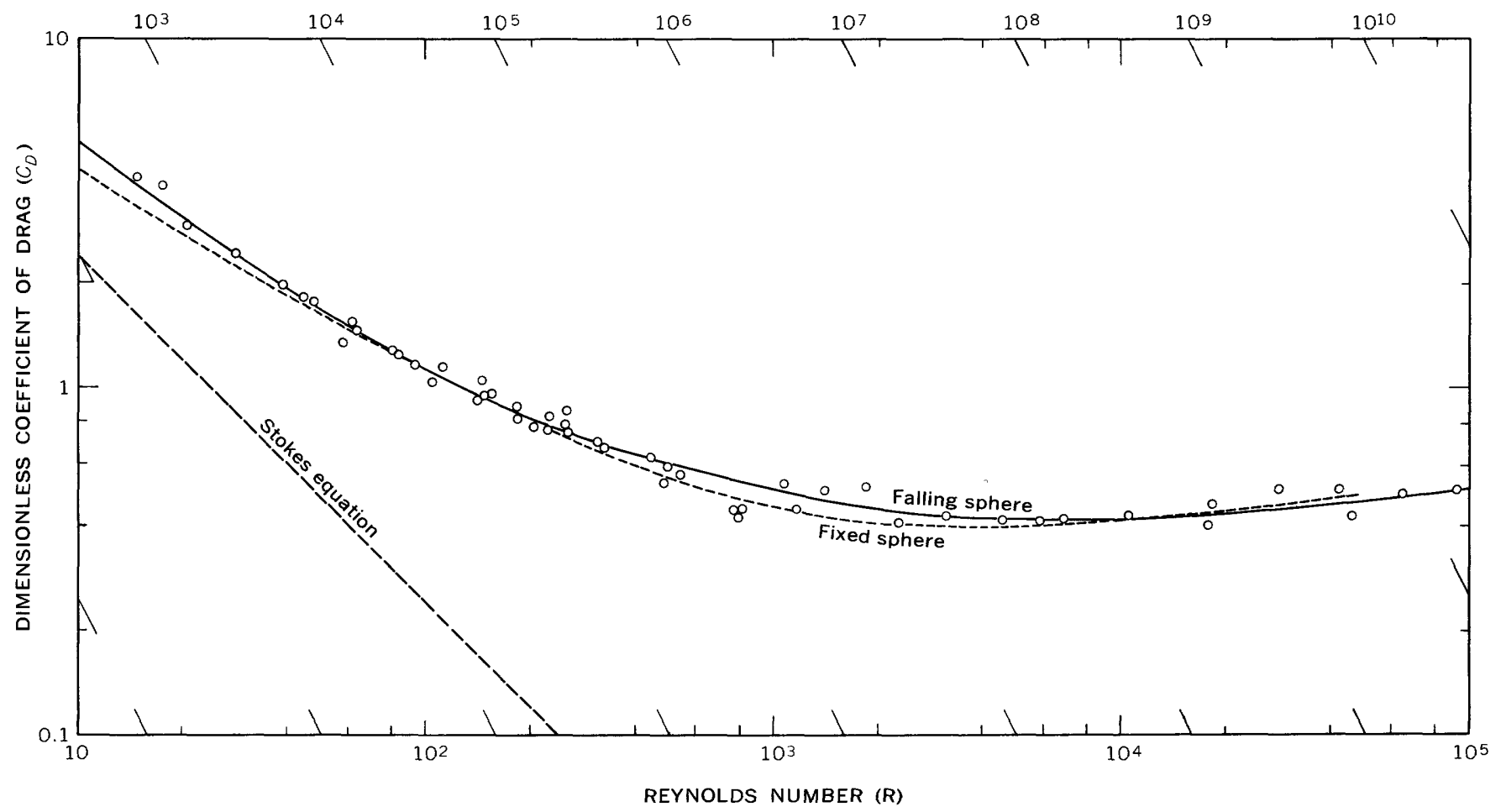

Figore 10.-Coefficient of drag as a function at Reynolds number and force number for falling and fixed spheres.

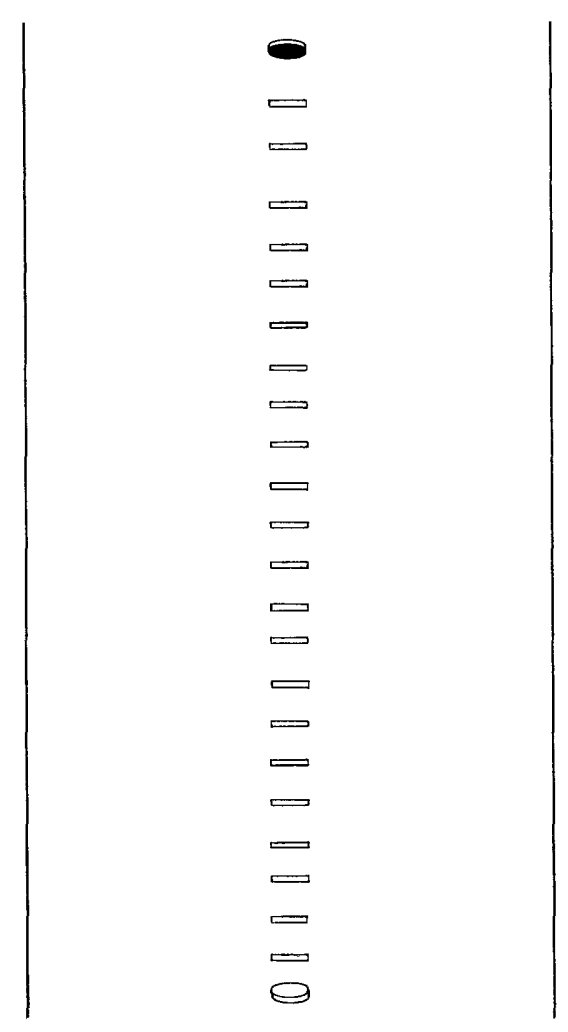

FIGURE 11.- Steady fall pattern of a steady disk. The example is from drop 107 consisting of a lead disk with $d_{m}=2.54 \mathrm{~cm}$ in a fluid of 98 percent glycerine and showing a time interval of 0.075 sec. Path parameters are $\omega=42 \mathrm{~cm} / \mathrm{sec}, \mathbf{R}=38$, $C_{D}=2.00$. Shaded surface is bottom of disk.

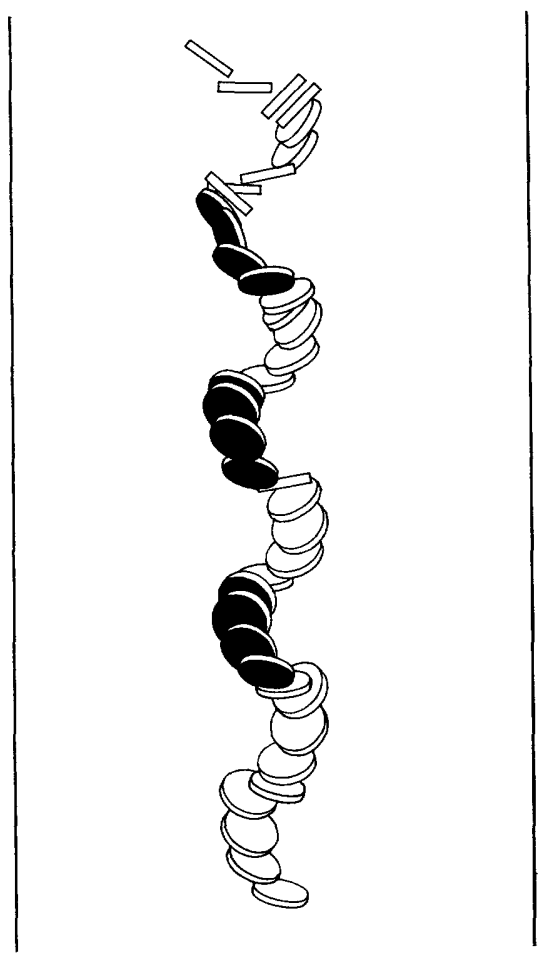

Figure 12.- Regular oscillation fall pattern of a disk. The example is from drop 375 consisting of an aluminum disk with $d_{m}=3.81 \mathrm{~cm}$ in a fluid of 70 percent glycerine and showing a time inverval of 0.055 sec. Path parameters are $\omega=47.1 \mathrm{~cm} / \mathrm{sec}, \mathbf{R}=1,092, C_{D}=0.46$. Vertical parameters are $\omega=25.1 \mathrm{~cm} / \mathrm{sec}, \mathbf{R}=583, C_{D}=1.63$. Shaded surface is bottom of disk. 


\begin{tabular}{|c|c|c|c|c|c|c|c|}
\hline \multirow[t]{2}{*}{ Run No. ${ }^{2}$} & \multirow{2}{*}{$\underset{\text { distance }}{\text { (cm) }}$} & \multirow{2}{*}{$\begin{array}{l}\text { Velocity } \\
\text { (cm/sec) }\end{array}$} & \multicolumn{2}{|c|}{$\begin{array}{l}C_{D} \text { and } \mathbf{R} \text { values } \\
\text { for } \mathrm{d}_{m}\end{array}$} & \multicolumn{2}{|c|}{$\begin{array}{l}C_{D} \text { and } \mathbf{R} \text { values } \\
\text { for } \mathrm{d}_{n}\end{array}$} & \multirow{2}{*}{$\begin{array}{c}\text { Sta- } \\
\text { bility }\end{array}$} \\
\hline & & & $C_{D}$ & $\mathbf{R} \times 10^{-2}$ & $C_{D}$ & $\mathbf{R} \times 10^{-2}$ & \\
\hline $\begin{array}{l}29-1-28 \\
30-1-26 \\
31-1-27 \\
36-1-28 \\
37-1-26\end{array}$ & $\begin{array}{l}104.1 \\
103.1 \\
100.4 \\
103.7 \\
104.3\end{array}$ & $\begin{array}{l}85.5 \\
65.7 \\
75.2 \\
89.5 \\
65.2\end{array}$ & $\begin{array}{l}0.63 \\
.53 \\
.54 \\
.57 \\
.54\end{array}$ & $\begin{array}{l}275 \\
104 \\
159 \\
288 \\
104\end{array}$ & $\begin{array}{l}0.78 \\
.66 \\
.67 \\
.71 \\
.68\end{array}$ & $\begin{array}{l}245 \\
940 \\
145 \\
258 \\
93.3\end{array}$ & $\begin{array}{l}\text { Uo } \\
\text { UO } \\
\text { SO } \\
\text { Uo } \\
\text { Uo }\end{array}$ \\
\hline $\begin{array}{l}48-1-15 \\
49-1-16 \\
53-1-15 \\
67-2-14 \\
68-2-15\end{array}$ & $\begin{array}{r}104.4 \\
52.2 \\
105.2 \\
100.0 \\
100.0\end{array}$ & $\begin{array}{r}174.0 \\
196.0 \\
178.0 \\
57.2 \\
81.3\end{array}$ & $\begin{array}{l}.54 \\
.61 \\
.52 \\
2.88 \\
1.89\end{array}$ & $\begin{array}{l}378 \\
644 \\
386 \\
\quad .21 \\
.41\end{array}$ & $\begin{array}{r}.65 \\
.76 \\
.67 \\
3.49 \\
2.26\end{array}$ & $\begin{array}{l}344 \\
572 \\
352 \\
\quad .20 \\
.37\end{array}$ & $\begin{array}{l}\mathbf{R} \\
\mathbf{R} \\
\mathbf{R} \\
\mathbf{S} \\
\mathbf{S}\end{array}$ \\
\hline $\begin{array}{r}69-2-16 \\
81-2-28 \\
100-3-14 \\
101-3-15 \\
102-3-16\end{array}$ & $\begin{array}{l}100.0 \\
100.0 \\
100.0 \\
100.0 \\
100.0\end{array}$ & $\begin{array}{r}114.2 \\
33.6 \\
62.1 \\
85.5 \\
128.0\end{array}$ & $\begin{array}{l}1.38 \\
2.71 \\
2.46 \\
1.71 \\
1.10\end{array}$ & $\begin{array}{r}.87 \\
.25 \\
.30 \\
.55 \\
1.24\end{array}$ & $\begin{array}{l}1.72 \\
3.38 \\
2.99 \\
2.08 \\
1.38\end{array}$ & $\begin{array}{r}.78 \\
.22 \\
.27 \\
.50 \\
1.11\end{array}$ & $\begin{array}{l}\mathbf{S} \\
\mathbf{S} \\
\mathbf{S} \\
\mathbf{S} \\
\mathbf{S}\end{array}$ \\
\hline $\begin{array}{l}113-3-27 \ldots \ldots \\
114-3-28 \ldots \\
136-4-16 \ldots \\
137-4-15 \ldots \\
138-4-14 \ldots \\
18 .\end{array}$ & $\begin{array}{l}100.0 \\
100.0 \\
100.0 \\
100.0 \\
100.0\end{array}$ & $\begin{array}{r}24.3 \\
42.5 \\
141.0 \\
96.5 \\
66.7\end{array}$ & $\begin{array}{l}3.50 \\
1.72 \\
.91 \\
1.35 \\
2.13\end{array}$ & $\begin{array}{r}.54 \\
.40 \\
1.66 \\
.76 \\
.55\end{array}$ & $\begin{array}{l}4.39 \\
2.14 \\
1.14 \\
1.62 \\
2.59\end{array}$ & $\begin{array}{r}.14 \\
.36 \\
1.49 \\
.68 \\
.36\end{array}$ & $\begin{array}{l}\mathbf{S} \\
\mathbf{S} \\
\mathbf{S} \\
\mathbf{S} \\
\mathbf{S}\end{array}$ \\
\hline $\begin{array}{l}140-4-27 \ldots \ldots \\
141-4-28 \ldots \\
177-5-26-\ldots \\
178-5-27 \\
179-5-28 . \\
17 .\end{array}$ & $\begin{array}{l}100.0 \\
100.0 \\
100.0 \\
100.0 \\
100.0\end{array}$ & $\begin{array}{l}26.6 \\
42.0 \\
27.6 \\
37.2 \\
55.6\end{array}$ & $\begin{array}{l}2.82 \\
1.79 \\
2.10 \\
1.55 \\
1.01\end{array}$ & $\begin{array}{r}.21 \\
.49 \\
.30 \\
. .55 \\
1.23\end{array}$ & $\begin{array}{l}3.50 \\
2.20 \\
2.62 \\
1.92 \\
1.26\end{array}$ & $\begin{array}{r}.19 \\
.44 \\
.27 \\
.49 \\
1.11\end{array}$ & $\begin{array}{l}\mathbf{S} \\
\mathbf{S} \\
\mathbf{S} \\
\mathbf{S} \\
\mathbf{S}\end{array}$ \\
\hline $\begin{array}{l}180-5-14 \ldots \ldots \ldots \\
181-5-15 \\
182-5-16 \ldots \ldots \\
218-6-26 \ldots \\
219-6-27 \ldots \ldots\end{array}$ & $\begin{array}{r}100.0 \\
99.0 \\
97.2 \\
100.0 \\
101.0\end{array}$ & $\begin{array}{r}94.4 \\
122.0 \\
165.8 \\
35.7 \\
47.8\end{array}$ & $\begin{array}{r}1.09 \\
.86 \\
.67 \\
1.31 \\
.96\end{array}$ & $\begin{array}{l}1.06 \\
1.82 \\
3.73 \\
.75 \\
1.36\end{array}$ & $\begin{array}{l}1.32 \\
1.03 \\
.84 \\
1.60 \\
1.19\end{array}$ & $\begin{array}{l}.96 \\
1.65 \\
3.34 \\
.68 \\
1.22\end{array}$ & $\begin{array}{l}\mathbf{S} \\
\mathbf{S} \\
\mathbf{S} \\
\mathbf{S} \\
\mathbf{S}\end{array}$ \\
\hline $\begin{array}{l}220-6-28 \ldots \ldots \\
221-6-14 \ldots \ldots \\
222-6-15 \ldots \\
223-6-16 \ldots \\
352-7-26 \ldots \\
\end{array}$ & $\begin{array}{r}100.0 \\
100.0 \\
102.2 \\
99.6 \\
100.5\end{array}$ & $\begin{array}{r}65.0 \\
108.5 \\
132.8 \\
175.3 \\
50.2\end{array}$ & $\begin{array}{l}.79 \\
.83 \\
.73 \\
.61 \\
.69\end{array}$ & $\begin{array}{l}2.77 \\
2.34 \\
3.82 \\
7.63 \\
4.00\end{array}$ & $\begin{array}{r}.96 \\
1.00 \\
.88 \\
.76 \\
.48\end{array}$ & $\begin{array}{l}2.49 \\
2.14 \\
3.48 \\
5.82 \\
3.40\end{array}$ & $\begin{array}{l}\mathbf{S} \\
\mathbf{S} \\
\mathbf{S} \\
\mathbf{S} \\
\mathbf{S}\end{array}$ \\
\hline $\begin{array}{l}353-7-14 \\
362-7-27-\ldots \\
363-7-15 \\
371-7-28 \\
372-7-16 \ldots\end{array}$ & $\begin{array}{r}92.5 \\
100.0 \\
72.0 \\
101.5 \\
90.0\end{array}$ & $\begin{array}{r}138.0 \\
61.5 \\
164.5 \\
81.9 \\
210.0\end{array}$ & $\begin{array}{l}.53 \\
.63 \\
.50 \\
51 \\
.43\end{array}$ & $\begin{array}{l}11.2 \\
6.67 \\
18.0 \\
13.3 \\
34.8\end{array}$ & $\begin{array}{l}.64 \\
.80 \\
.59 \\
.64 \\
.54\end{array}$ & $\begin{array}{r}10.2 \\
6.0 \\
16.4 \\
13.0 \\
31.2\end{array}$ & $\begin{array}{l}\mathbf{S} \\
\mathbf{S} \\
\mathbf{S} \\
\mathbf{S} \\
\mathbf{S}\end{array}$ \\
\hline
\end{tabular}

1 The vertical and path data for travel distance, velocity, $C_{D}$ and $\mathbf{R}$ are identical for prolate spheroids.

2 The run number is a combination of drop number, fluid number (fig. 6), and particle number.

${ }^{3} \mathrm{~S}$, stable orientation and path; O, regular oscillation; U, unstable path; $R$, rotation about vertical axis.

In summary, the four general fall patterns for disks are:

1. Steady-flat

2. Regular oscillation

3. Glide-tumble, and

4. Tumble.

Except for the boundary between steady-flat fall and regular oscillation, no definitive boundaries between each pattern exists. Instead, there was a progressive transition from one pattern to another.

All the disks did not exhibit all the patterns described as a result of the step-changes in the viscosity of the fluids and the subsequent step-changes in the Reynolds number. The lead disks exhibited the glide-tumble fall pattern at much smaller Reynolds numbers than did the aluminum disks, indicating that the stability number I was a significant parameter in defining the fall patterns of disks. Since the thickness-diameter ratio of all the disks was the same, the apparent affect of I must be due solely to the density ratio of the disk and the fluid.

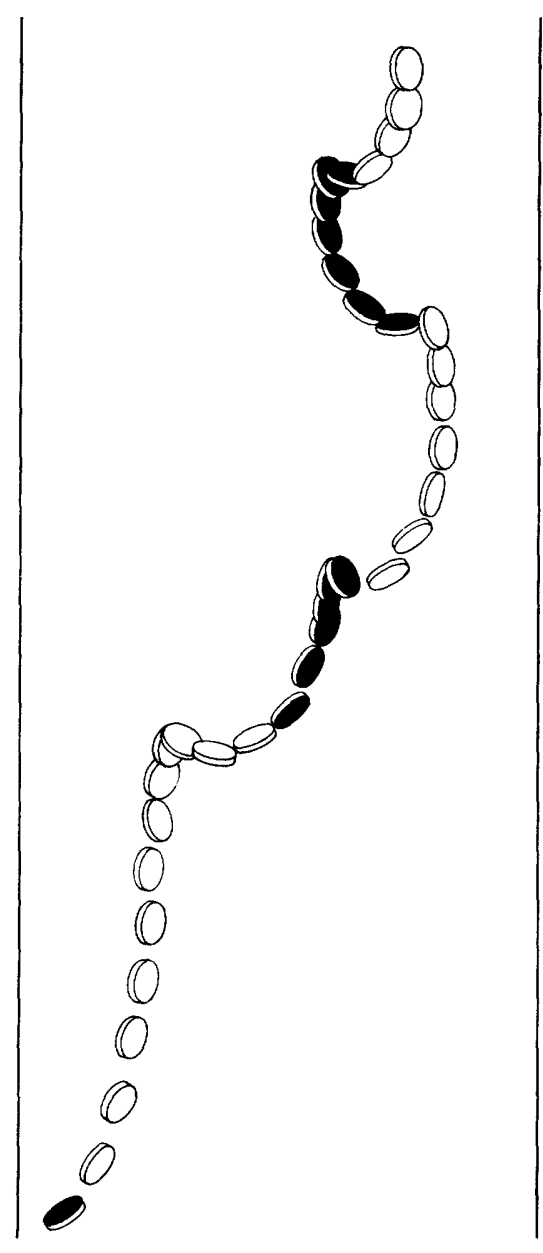

Frgure 13.-Fall of a disk just after entering the glide-tumble pattern. The example is from drop 24 consisting of an aluminum disk with $d_{m}=2.54 \mathrm{~cm}$ in a fluid of water and showing a time interval of 0.051 sec. Path parameters are $\omega=58.5$ $\mathrm{cm} / \mathrm{sec}, \mathbf{R}=17,900, C_{D}=0.26$. Vertical parameters are $\omega=41.6$ $\mathrm{cm} / \mathrm{sec}, \mathbf{R}=13,400, C_{D}=0.48$. Shaded surface is bottom of disk.

Changes in I as a result of changes in the thicknessdiameter ratio of the disk would produce similar changes in fall patterns if the density ratio of the disk and fluid were kept constant. Further evidence of the importance of the density ratio will be discussed in connection with the $C_{\mathbf{D}}-\mathbf{R}$ diagrams in a following section.

Regimes of rall

As the Reynolds number for a falling disk was further increased, the fall of the disk changed from a stable pattern of steady-flat fall, through a period of transition until the disk reached a second stable condition of constant angular rotation or tumble. Thus, the patterns of fall for a disk can be divided into three regimes: a steady regime, where a stable pattern of steady-flat fall exists; the transition regime which includes the oscillation and glide-tumble fall patterns; and the tumble regime where a second stable condition exists as a uniform tumble and constant angular rotation. 


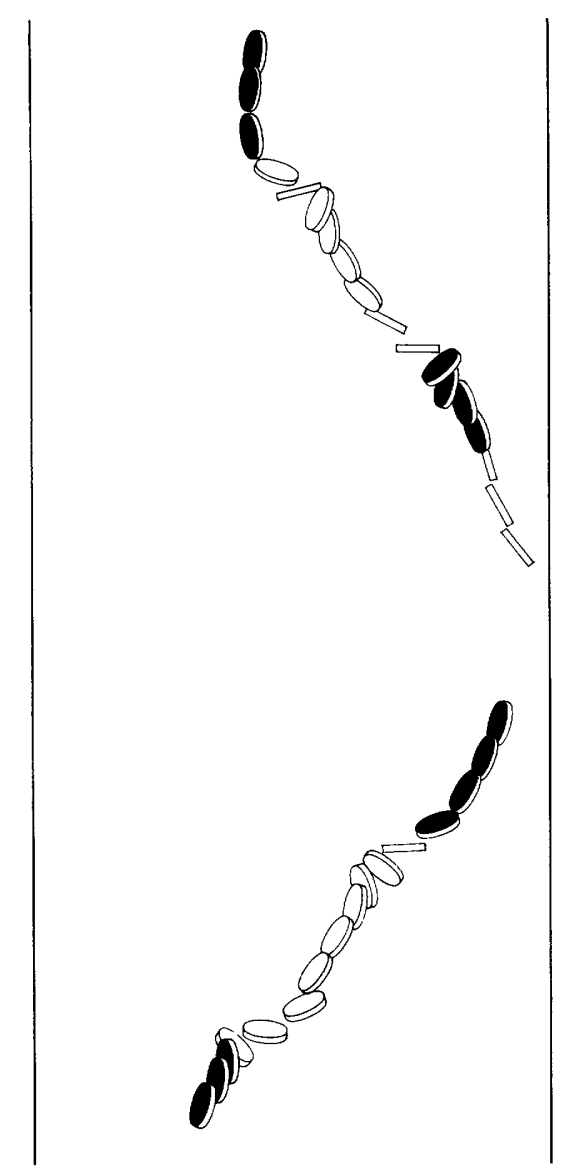

Figure 14.-Fall of a disk just before leaving the glide-tumble fall pattern. The example is from drop 161 consisting of a lead disk with $d_{m}=3.81 \mathrm{~cm}$ in a fluid of 90.1 percent glycerine and showing a time interval of 0.029 sec. Path parameters are $\omega=95.1 \mathrm{~cm} / \mathrm{sec}, \mathbf{R}=300, C_{D}=0.60$. Vertical parameters are $\omega=74.5 \mathrm{~cm} / \mathrm{sec}, \mathbf{R}=235, C_{D}=0.97$. Shaded surface is bottom of disk.

The regime classification is dependent, not only upon the coefficient of drag $C_{D}$ and the Reynolds number $\mathbf{R}$, but also upon the stability number I and the frequency number $\theta$. Thus, the regimes of fall can be related to the $C_{D}-\mathbf{R}$ diagram (fig. 16).

C $^{-R}$ curves and fall regimes

The steady regime exists when $10<\mathbf{R}<100$. The limits of the steady regime are fixed by the Reynolds number; they are not dependent upon particle density.

The lower limit of the transition regime is coincident with the upper limit of the steady regime. Limits between the transition and tumble regimes are not so clearly defined. It is often difficult to tell whether a disk is in the transition or tumble regime. In this particular study, the transition regime includes the part of the $C_{D}-\mathbf{R}$ curve when $100<\mathbf{R}<2,000$, and the lower branch of the $C_{D}-\mathbf{R}$ curve in figure 16 when $\mathbf{R}$ $>2,000$. The tumble regime consists of the upper branch

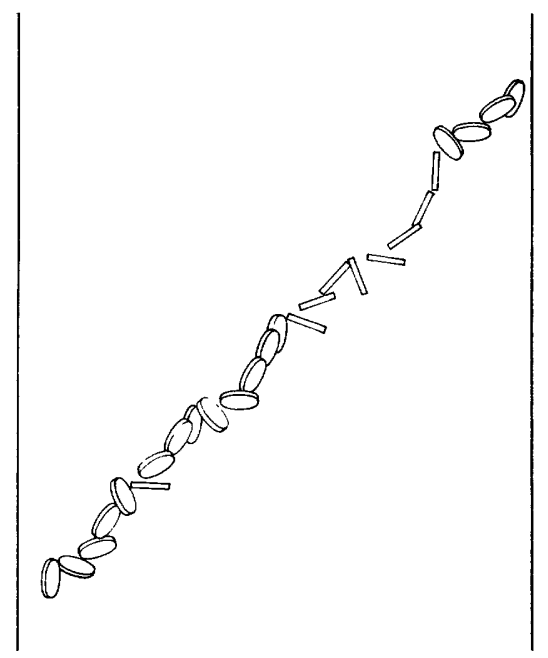

Figure 15.-Tumble fall pattern of a disk. The example is from drop 204 consisting of a lead disk with $d_{m}=2.54 \mathrm{~cm}$ in a fluid of water and showing a time interval of 0.03 sec. Path parameters are $\omega=66.8 \mathrm{~cm} / \mathrm{sec}, \mathbf{R}=16,800, C_{D}=1.02$. Vertical parameters are $\omega=47.3 \mathrm{~cm} / \mathrm{sec}, \mathrm{R}=11,900, C_{D}=2.02$.

of the $C_{D}-\mathbf{R}$ curve of figure 16 where the angular velocity is nearly constant.

Unsteady conditions

The preceding discussion on the fall pattern and regimes of disks makes it clear that the velocity of a disk is not constant once oscillation begins. The disk, thereafter, continually accelerates or decelerates in a vertical direction, angularly, or both.

The method of data collection permitted both vertical and path velocities to be determined for short periods of time, that is, periods down to less than 0.015 second. Graphs of the time-variation of velocity were obtained plotting the incremental velocities against time for several of the drops (figs. 17-19).

The three horizontal lines on the graphs represent the average velocity of fall through the entire test section. The long-dashed line represents the vertical fall velocity of the disk, the short-dashed line represents the path velocity, and the large solid dots represent the three-point moving average of the path velocities. The three-point moving average was determined by plotting the average of three consecutive path velocities at the midpoint of the three. When the data were taken from the film, movements of less than one-half centimeter were difficult to measure. Because of the high speed of the camera and slow speed of some of the particles, movement of that magnitude was not uncommon. It should also be noted that a gradual change over two or three consecutive intervals was recorded in one interval because the minimum length recorded was one-half centimeter. When the lengths were converted to velocities, a sudden change seemed to have occurred at 


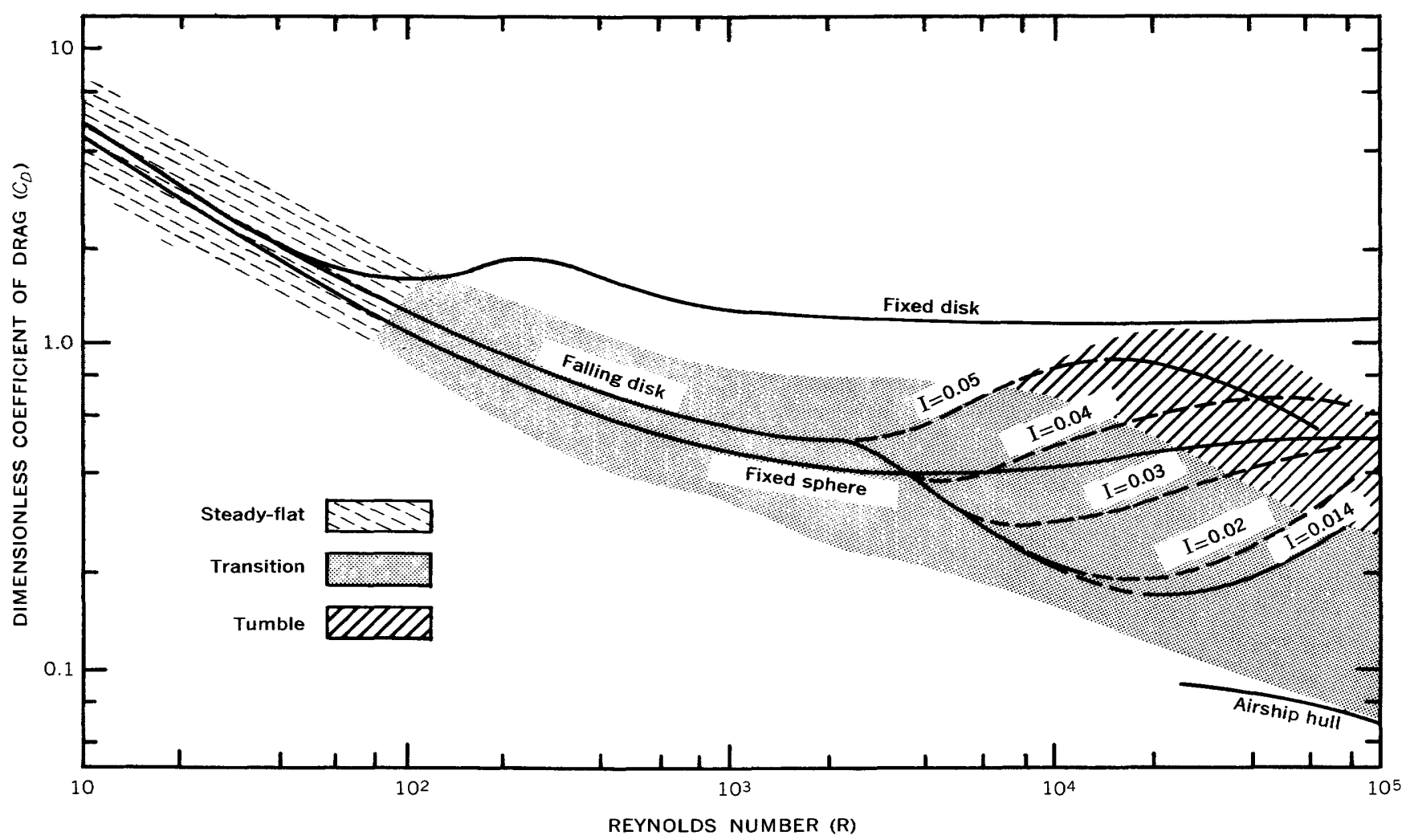

Figure 16.-Regimes of fall for a free-falling disk.

such intervals. Therefore, the three-point moving averages should better represent path velocity than the singly determined values shown by the short-dashed line.

When a disk falling in a glide-tumble pattern (fig. 18) is accelerating vertically (positive slope on the velocitytime curve), the vertical and path velocities are identical. When the path of travel is not vertical, the velocities are no longer identical and the vertical velocity decreases earlier in time than does the path velocity. After a disk begins a regular tumble (fig. 19), it moves laterally across the column throughout the entire fall. Therefore, the path velocity is always greater than the vertical velocity.

The cyclic nature of the velocity-time relationship is typical for all disks in all fall patterns except the steady-flat fall pattern. Several times, particularly in the glide-tumble pattern, negative vertical velocities were recorded. By definition, the path velocity is always positive except at the apecies of the arcs where it goes to zero.

Average velocities

Current methods of expressing resistance to motion do not account for accelerating motion because average velocities are used. The apparent cyclic nature of the fall of disks, indicating that the disk does not continually accelerate or decelerate, tends to justify this approximation.

In all tests in the transition and tumble regimes, the average path velocity was greater than the average vertical velocity (see heavy horizontal lines, figs. 17-18). In one test the average path velocity was 81 percent greater than the average vertical velocity.

The path velocity of a falling disk will generally be greater than the velocity of a fluid, of the same density and viscosity as the one in which the given disk is falling, flowing past a rigidly mounted disk, of the same cross-sectional area as the falling disk, which would exert a force on the fixed disk equal to the weight of the falling disk. Such a velocity can be computed from the $C_{D}-\mathbf{R}$ diagram for fixed disks and from the force number of the falling disk (see heavy broken lines, fig. 17-19).

Frequency of oscllation

Two variables which affect the frequency of oscillation or rotation are disk size and density. If the densityfrequency number $\Phi$ previously derived by dimensionless analysis is written as:

$$
f^{2}=\Phi \frac{\pi}{4} \frac{\rho_{p}-\rho_{f}}{\rho_{f}} \frac{c}{a} \frac{g}{a},
$$

it is evident that for a constant thickness-diameter ratio of the disk, the square of the frequency is inversely 


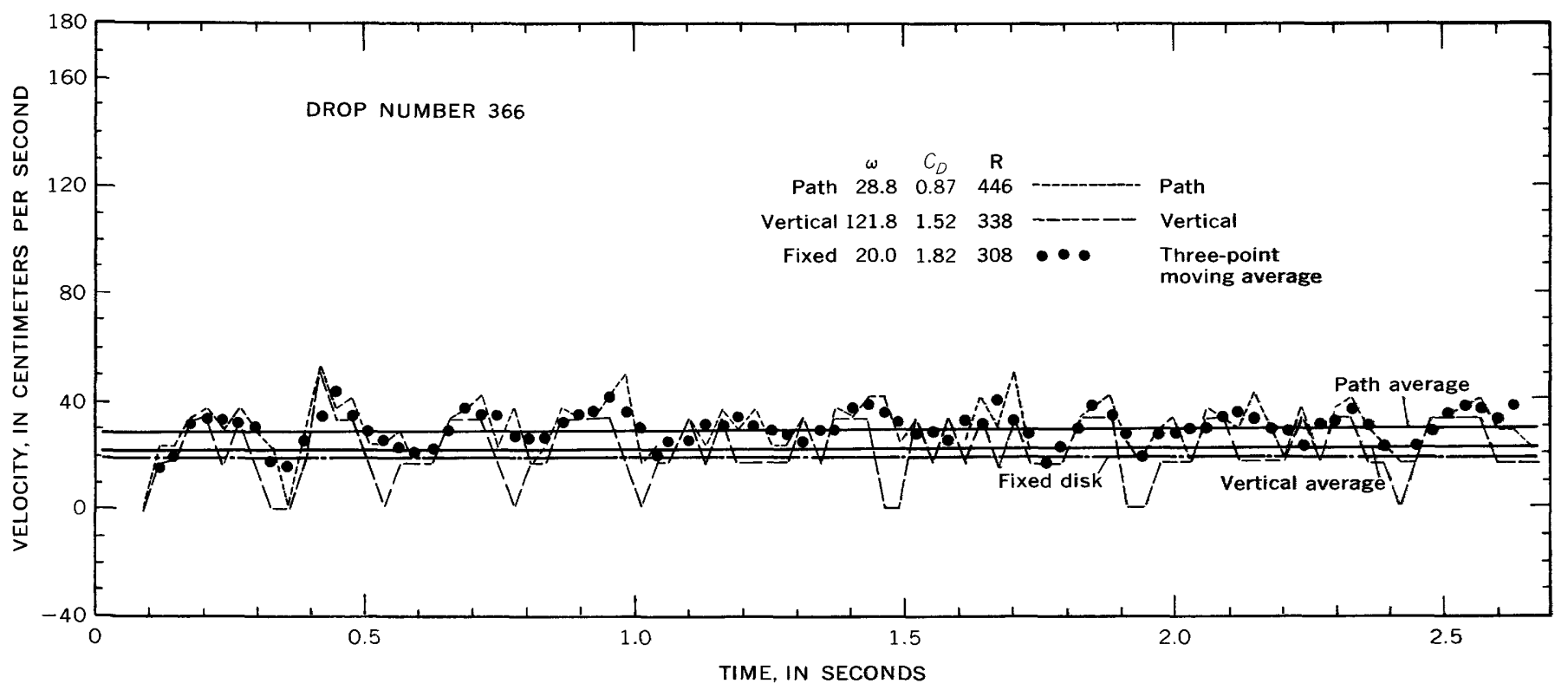

A

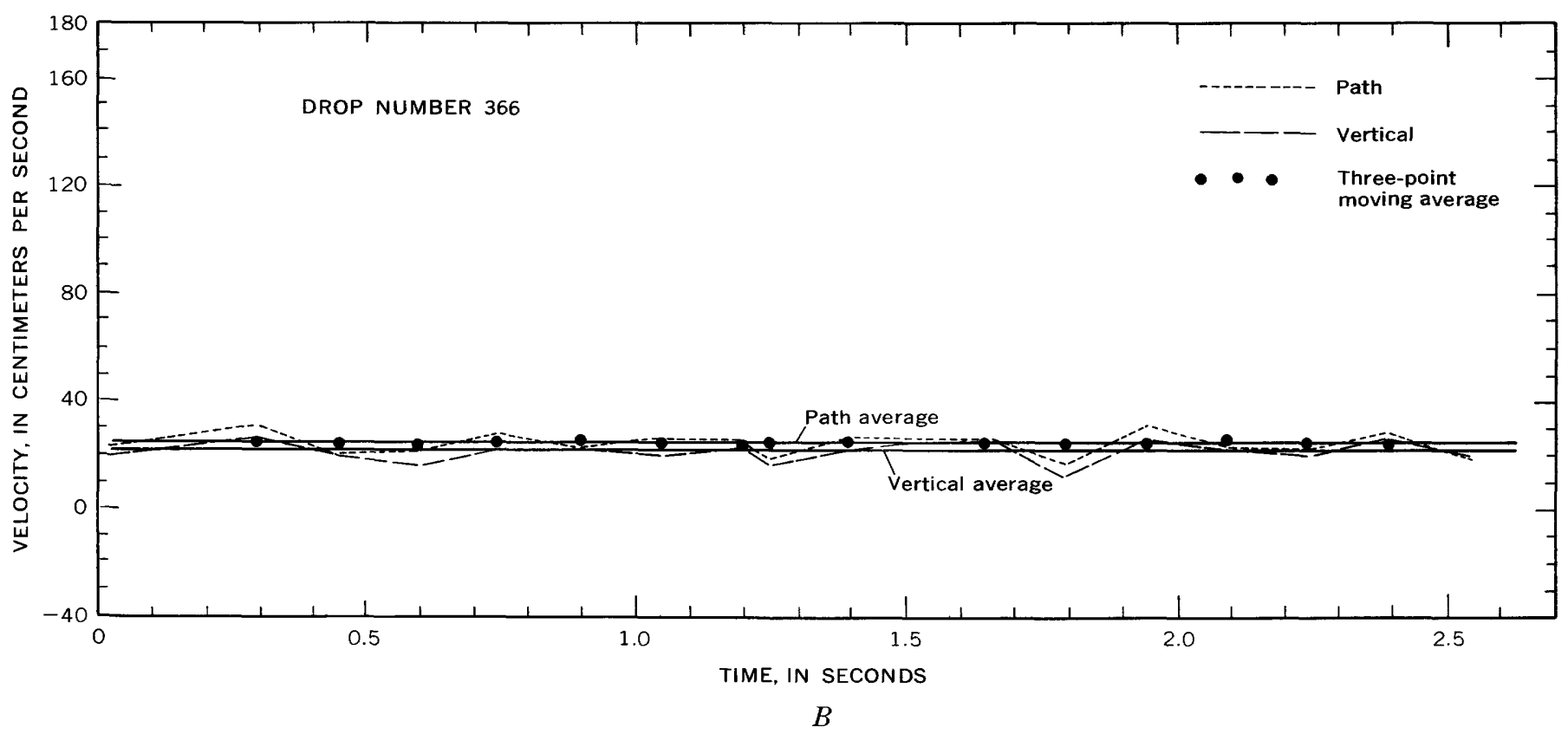

FrGURe 17.-Velocity-time relationship for a 2.54-cm aluminum disk falling in an oscillatory pattern. The time interval between successive position of the disk is five times longer in $(B)$ than in $(A)$.

proportional to the diameter of the disk and directly proportional to $\frac{\rho_{p}-\rho_{f}}{\rho_{f}}$. For example, the $3.81 \mathrm{~cm}$ (diameter) aluminum and lead disks falling in water at average vertical velocities of 50.2 and $67.5 \mathrm{~cm} / \mathrm{sec}$, had rotational frequencies of 0.6 and 2.9 revolutions per second, respectively. Table 7 summarizes the frequency of oscillation for each experimental drop.

\section{$C_{D}-\mathbf{R}$ curves and fall velocity}

Four diagrams (figs. 20, 21) present the $C_{D}-\mathbf{R}$ relationships for disks. Particle identity is maintained by use of different symbols as indicated in the legend. The stability number $\mathrm{I}$ and the frequency number $\theta$ appear beside each point in figures $20 \mathrm{~A}$ and $21 \mathrm{~A}$ where the disks were unsteady. 


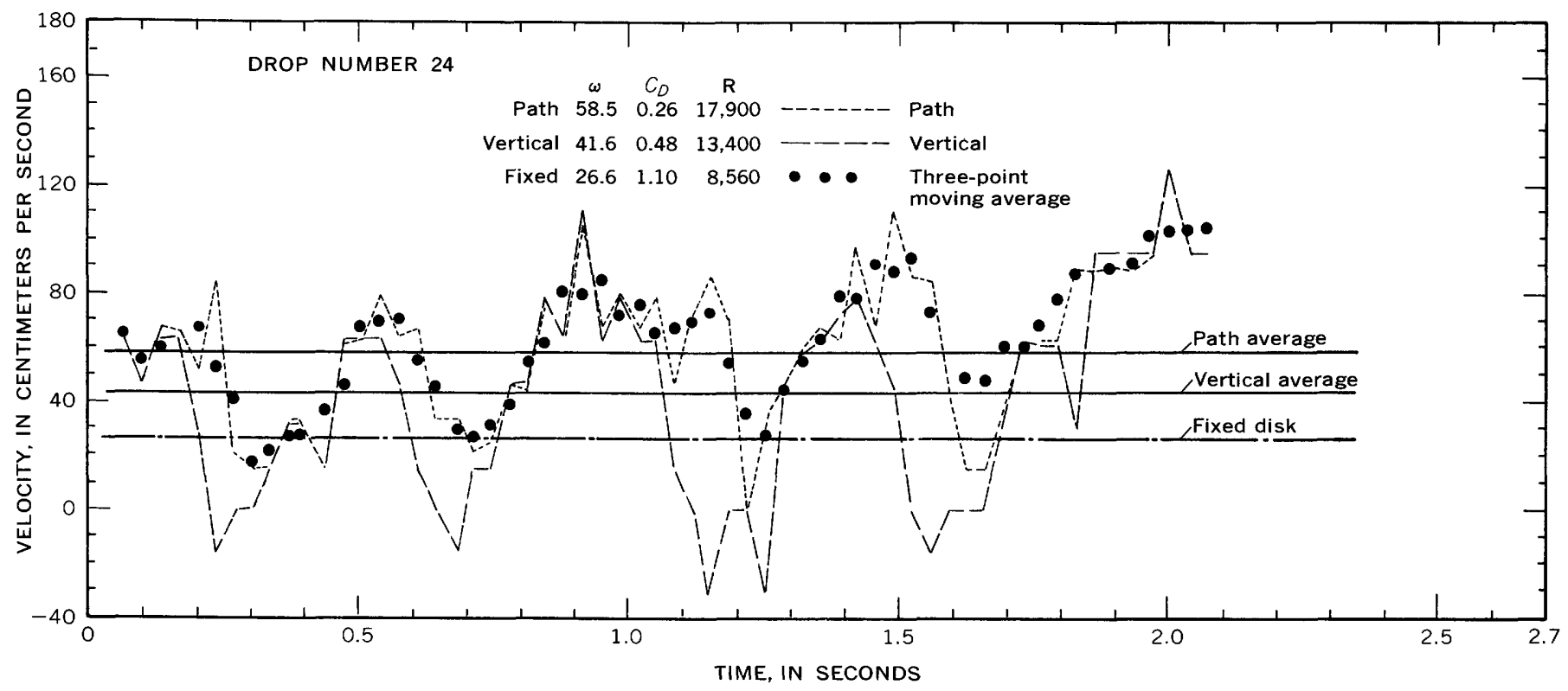

Figure 18.-Velocity-time relationship for a 2.54-cm aluminum disk falling in a glide-tumble pattern.

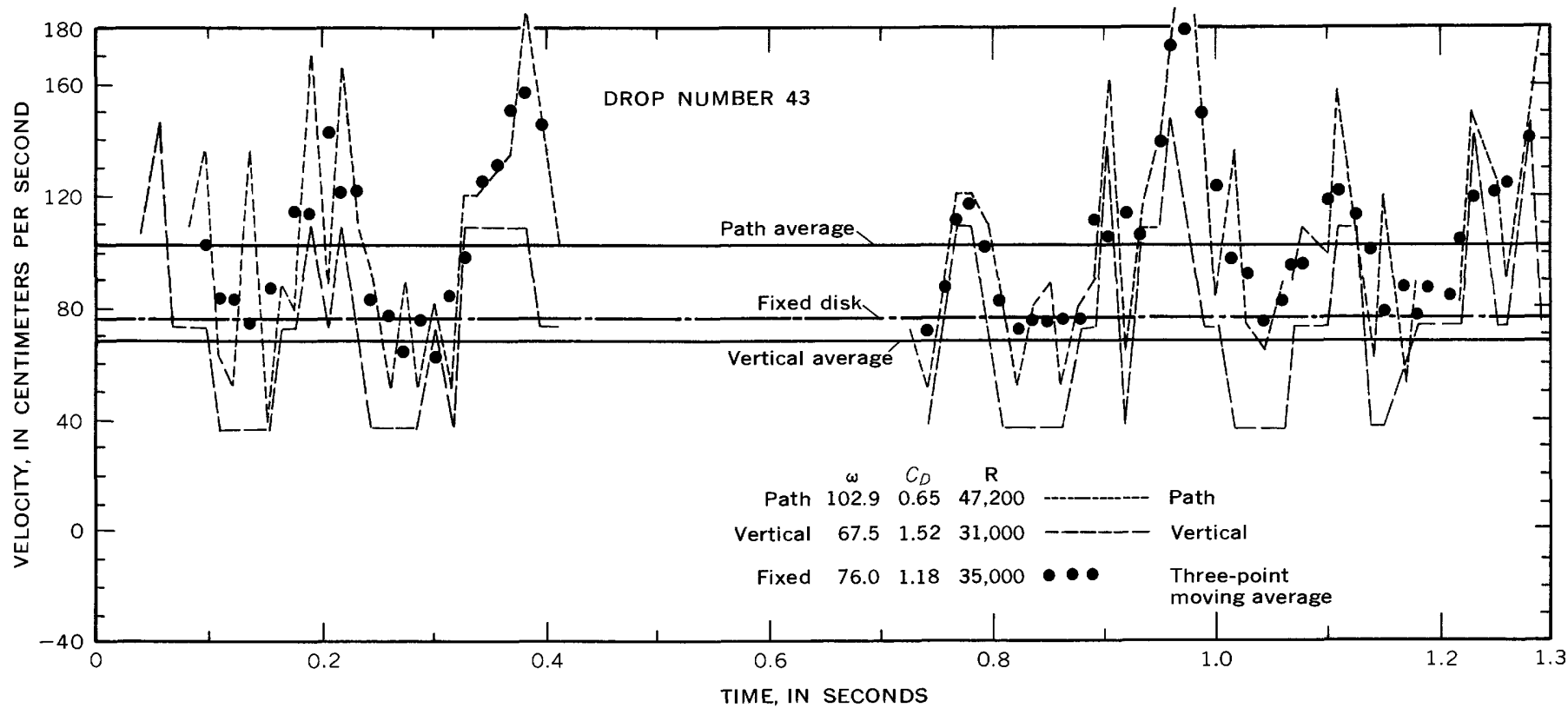

Figure 19.--Velocity-time relationship for a 3.81 -cm lead disk falling in a tumbling pattern. (Break in curve occurs where the disk fell down the wall of the column.)

When $10<\mathbf{R}<2,000$, the curve for the relationship of $C_{D}-\mathbf{R}$ for falling disks is approximately the same as the $C_{D}-\mathbf{R}$ relationship for fixed spheres (fig. 20A). For $10<\mathbf{R}<120$, the relationship is well established because the disks fell vertically, at a constant velocity without oscillation and with their maximum projected area perpendicular to the direction of fall. The relationship is not so well defined in the range between $120<\mathbf{R}<2,000$, where the disks were unsteady.
Here, the data are more sparse, the points scatter more, and the stability aud frequency number are beginning to influence the $C_{D}-\mathbf{R}$ relationship.

At $\mathbf{R}$ equal to about 10,000 for the given disks of this experiment, the $C_{D}-\mathbf{R}$ relationship is no longer unique, but has two values. The only difference between the disks used to develop the nonunique relationship is the density of the disks. The lead disks have a greater $C_{D}$ value for a given value of $\mathbf{R}$ than do 
TABLE 7.-Frequency of oscillation of unsteady particles falling in water-glycerine mixtures, in cycles per second

[Particles falling in mixtures of 94.24 percent or more of glycerine were always stable] A, aluminum; C, cylinder; D, disk; GT, glide tumble; L, lead; O, oscillation; OS, oblate spheriod; $\mathrm{PS}$, prolate spheroid; $\mathrm{R}$, rotation; $\mathrm{S}$, steady fall; $\mathrm{T}$, tumble; U undetermined.

\begin{tabular}{|c|c|c|c|c|}
\hline \multirow{2}{*}{$\begin{array}{l}\text { Particle material, shape, } \\
\text { and size }\end{array}$} & \multicolumn{4}{|c|}{ Percent glycerine } \\
\hline & 90.1 & 83.33 & 70.00 & 0.00 \\
\hline $\begin{array}{l}\mathrm{L}-\mathrm{D}-1.91 \\
\mathrm{~L}-\mathrm{D}-2.54 \\
\mathrm{~L}-\mathrm{D}-3.81 \\
\mathrm{~A}-\mathrm{D}-1.91 \\
\mathrm{~A}-\mathrm{D}-2.54 \\
\mathrm{~A}-\mathrm{D}-3.81 \\
\mathrm{~L}-\mathrm{OS}-1.91 \\
\mathrm{~L}-\mathrm{OS}-2.49 \\
\mathrm{~L}-\mathrm{OS}-3.85 \\
\mathrm{~A}-\mathrm{OS}-1.91 \\
\mathrm{~A}-\mathrm{OS}-2.50 \\
\mathrm{~A}-\mathrm{OS}-3.78\end{array}$ & $\begin{array}{l}\mathrm{S} \\
\mathrm{S} \\
2.3-\mathrm{GT} \\
\mathrm{S} \\
\mathrm{S} \\
\mathrm{S} \\
\mathrm{S} \\
\mathrm{S} \\
\mathrm{S} \\
\mathrm{S} \\
\mathrm{S} \\
\mathrm{S}\end{array}$ & $\begin{array}{l}4.0-\mathrm{O} \\
2.9-\mathrm{GT} \\
2.6-\mathrm{GT} \\
\mathrm{S} \\
\mathrm{S} \\
\mathrm{S} \\
\mathrm{S} \\
\mathrm{S} \\
\mathrm{S} \\
\mathrm{S} \\
\mathrm{S} \\
\mathrm{S}\end{array}$ & $\begin{array}{l}4.2-\mathrm{GT} \\
3.6-\mathrm{GT} \\
2.9-\mathrm{GT} \\
2.8-\mathrm{O} \\
2.2-\mathrm{O} \\
1.6-\mathrm{O} \\
\mathrm{S} \\
\mathrm{S} \\
\mathrm{S} \\
\mathrm{S} \\
\mathrm{S} \\
\mathrm{U}\end{array}$ & $\begin{array}{l}4.2-\mathrm{T} \\
3.9-\mathrm{T} \\
2.9-\mathrm{T} \\
1.4-\mathrm{GT} \\
1.2-\mathrm{GT} \\
.6-\mathrm{GT} \\
\mathrm{S} \\
\mathrm{S} \\
\mathrm{U} \\
4.6-\mathrm{T} \\
\mathrm{U} \\
2.66-\mathrm{O}\end{array}$ \\
\hline $\begin{array}{l}\text { L-PS-1.91 } \\
\text { L-PS-2.52 } \\
\text { L-PS-3.85 } \\
\text { A-PS-1.83 } \\
\text { A-PS-2.50 } \\
\text { A-PS-3.85 }\end{array}$ & $\begin{array}{l}\mathrm{S} \\
\mathbf{S} \\
\mathbf{S} \\
\mathbf{S} \\
\mathbf{S} \\
\mathbf{S}\end{array}$ & $\begin{array}{l}S \\
S \\
S \\
S \\
S \\
S \\
S\end{array}$ & $\begin{array}{l}S \\
S \\
S \\
S \\
S \\
S \\
S\end{array}$ & $\begin{array}{l}\mathrm{U} \\
4.81-\mathrm{OR} \\
4.0-\mathrm{OR} \\
3.5-\mathrm{O} \\
\mathrm{S} \\
2.69-\mathrm{O}\end{array}$ \\
\hline $\begin{array}{l}\mathrm{L}-\mathrm{C}-1.91 \\
\mathrm{~L}-\mathrm{C}-2.54 \\
\mathrm{~L}-\mathrm{C}-3.81 \\
\mathrm{~A}-\mathrm{C}-1.91 \\
\mathrm{~A}-\mathrm{C}-2.54 \\
\mathrm{~A}-\mathrm{C}-3.81\end{array}$ & $\begin{array}{l}\mathbf{S} \\
\mathbf{S} \\
\mathbf{S} \\
\mathbf{S} \\
\mathbf{S} \\
\mathbf{S}\end{array}$ & $\begin{array}{l}\mathrm{S} \\
\mathrm{S} \\
\mathbf{S} \\
\mathrm{S} \\
\mathrm{S} \\
\mathrm{S}\end{array}$ & $\begin{array}{l}3.2-\mathrm{O} \\
2.4-\mathrm{O} \\
2.0-\mathrm{O} \\
\mathrm{S} \\
\mathrm{S} \\
1.6-\mathrm{O}\end{array}$ & $\begin{array}{l}\mathrm{U} \\
2.0-\mathrm{OR} \\
2.0-\mathrm{OR} \\
2.3-\mathrm{O} \\
2.0-\mathrm{OR} \\
1.7-\mathrm{OR}\end{array}$ \\
\hline
\end{tabular}

the aluminum ones. Thus, somewhere between a Reynolds number of 2,000 and 10,000 , the resistance to motion for a disk becomes a function of the density ratio between it and the fluid as well as Reynolds number and shape factor. The division of the $C_{D}-\mathbf{R}$ relationship into two branches on the basis of the stability number I further emphasizes the importance of the density ratio between the disk and the fluid on the behavior of disks at certain values of $\mathbf{R}$.

The shape of the curve representing the $C_{D}-\mathbf{R}$ diagram is not affected by the choice of characteristic diameter used in the computations. The position of the curve $C_{D}-\mathbf{R}$ diagram, however, is the result of using different characteristic diameters (fig. 20).

Associated with the effect of $I$ on resistance to motion is the effect of the frequency number $\theta . C_{D}$ increases with $\theta$ independently of $\mathbf{R}$ (fig. 22). Thus, it is evident that the stability number $I$ and the frequency number $\theta$ are important parameters in describing the behavior of freely falling disks.

The solid lines in figures $22 A$ and $22 B$ represent the relationship for the glide-tumble and tumble patterns of fall. Insufficient data were available for the oscillating pattern of fall to establish a definite trend in the relation of $C_{D}$ to $\theta$; therefore, the broken lines, which represent that fall pattern, were arbitrarily drawn parallel to the solid ones. The position of the lines indicate, however, that the drag for a given frequency number is greater when the disk tumbles or glides than when it oscillates.

\section{OBLATE SPHEROIDS}

The fall pattern of the oblate spheroids was steady throughout most of the range of Reynolds numbers covered in the experiment. The only exceptions occurred for the aluminum and the largest lead spheroids falling in water. Of the aluminum spheroids, only the smallest one tumbled, whereas the largest one oscillated in a vertical plane about a horizontal diameter. The two smallest lead spheroids were perfectly steady while falling in the water. The middlesized aluminum particle and the largest lead one, for which the data were insufficient to make computations of $C_{D}$ and $\mathbf{R}$, had a tumbling pattern. The fact that the lead spheroids were steady whereas the aluminum ones were not, at least for the drops having valid data, is again evidence that the density ratio of the particle and fluid is an important parameter in particle behavior.

As expected, the oblate spheroids were steady over a larger range of Reynolds number than disks were.

When $10<\mathbf{R}<150$, the $C_{D}-\mathbf{R}$ relationship for oblate spheroids is almost identical to that for spheres (fig. 23). The divergence of the $C_{D}-\mathbf{R}$ relationships for spheres and oblate spheroids when $150<\mathbf{R}<5,000$ probably occurs because the pressure drag affects the fall of the oblate spheroid at smaller Reynolds numbers than it does the sphere. The divergence is not due to an unstable fall condition because the spheroids remain steady throughout their fall, but it was probably due to the earlier development of the pressure drag behind the spheroid. The development of the pressure drag occurs more rapidly for the spheroid than for a sphere because its shape induces separation and full development of the wake at smaller Reynolds numbers. When $5,000<\mathbf{R}<50,000$, the drag is independent of the Reynolds number.

\section{a cYland}

All cylinders fell with their maximum projected area perpendicular to the direction of fall for Reynolds numbers less than 400 . When $R>400$, the cylinders oscillated in a vertical plane about a horizontal axis normal to the major axis of the cylinder. At $\mathbf{R}>8,000$, another oscillation was superimposed on the first, an oscillation in a horizontal plane about a vertical axis. The frequencies of oscillation for cylinders are summarized in table 7 .

The curve representing the relationship of $C_{D}$ to $\mathbf{R}$ for cylinders is higher on the $C_{D}-\mathbf{R}$ diagram than for spheres (fig. 24). The two curves slowly diverge to $\mathbf{R} \approx 400$, after which the increased rate of divergence is coincidental with the increased oscillation in the 


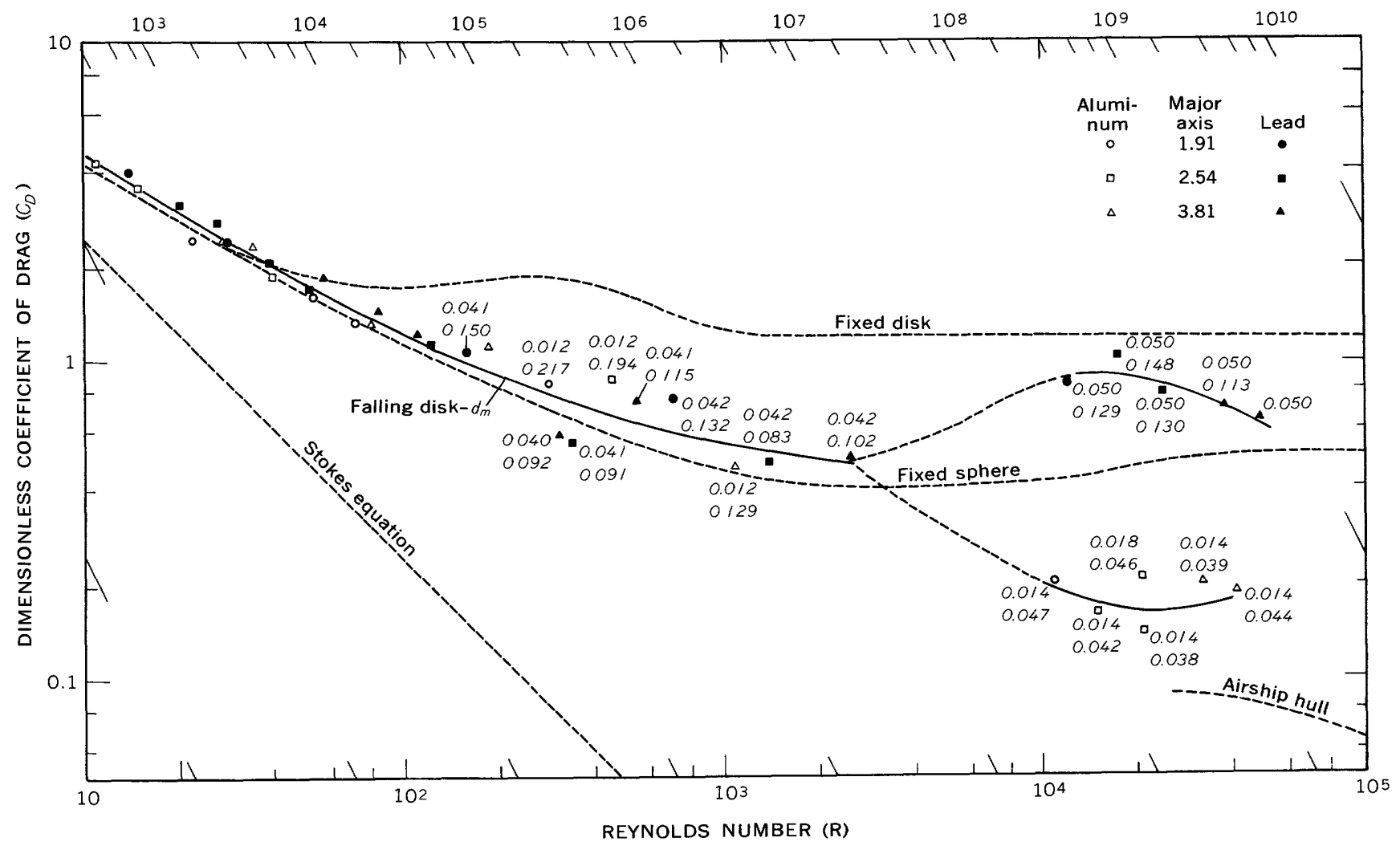

$A$

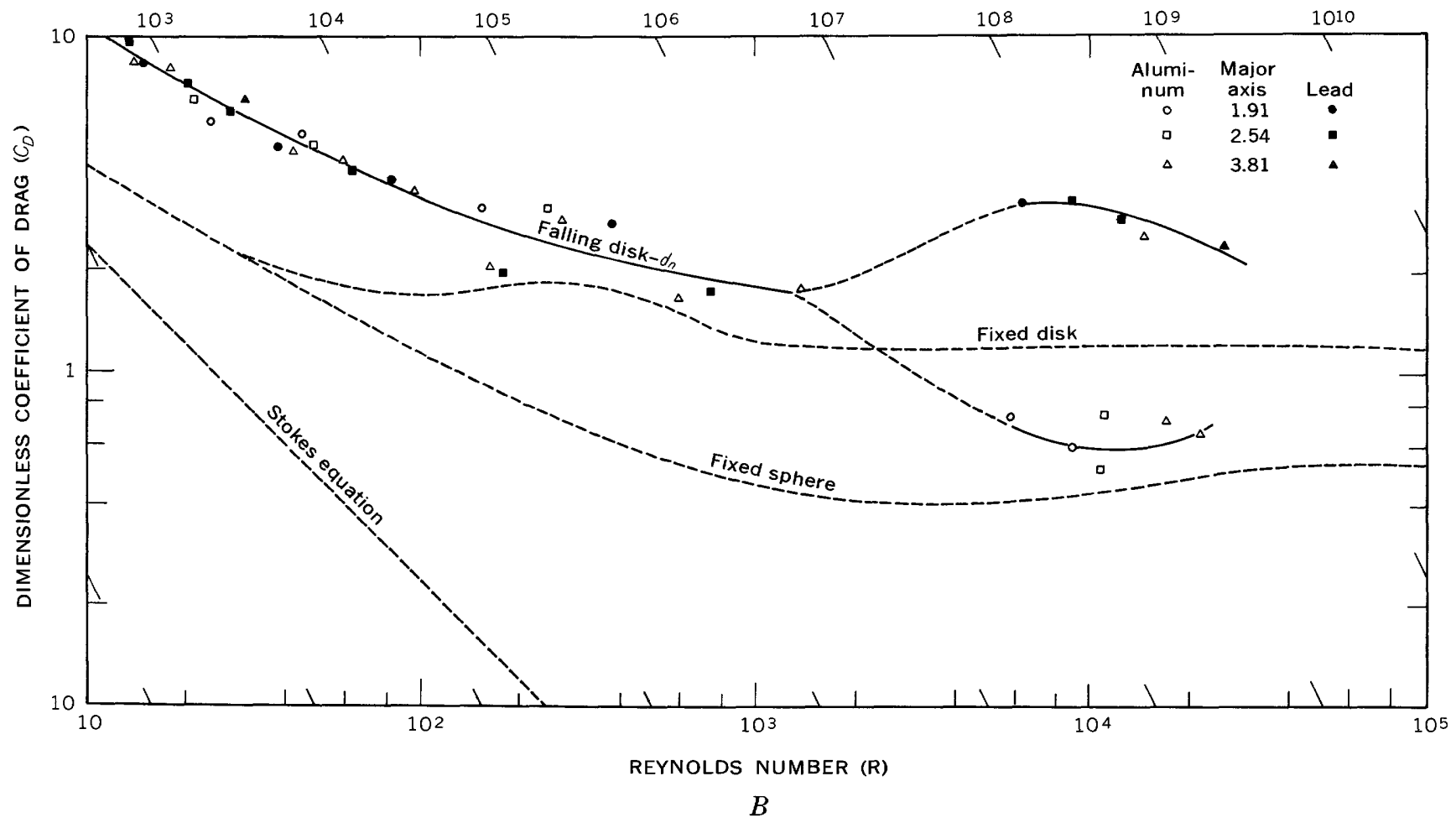

FIGURE 20.--Relationship of coefficient of drag and Reynolds number for falling disks having $S F_{c}=0.1 . A$, Computations are based on $d_{m}$ and path velocity. I and $\theta$ are given for points where disks were unsteady. $B$, Computations are based on $d_{n}$ and path velocity. 


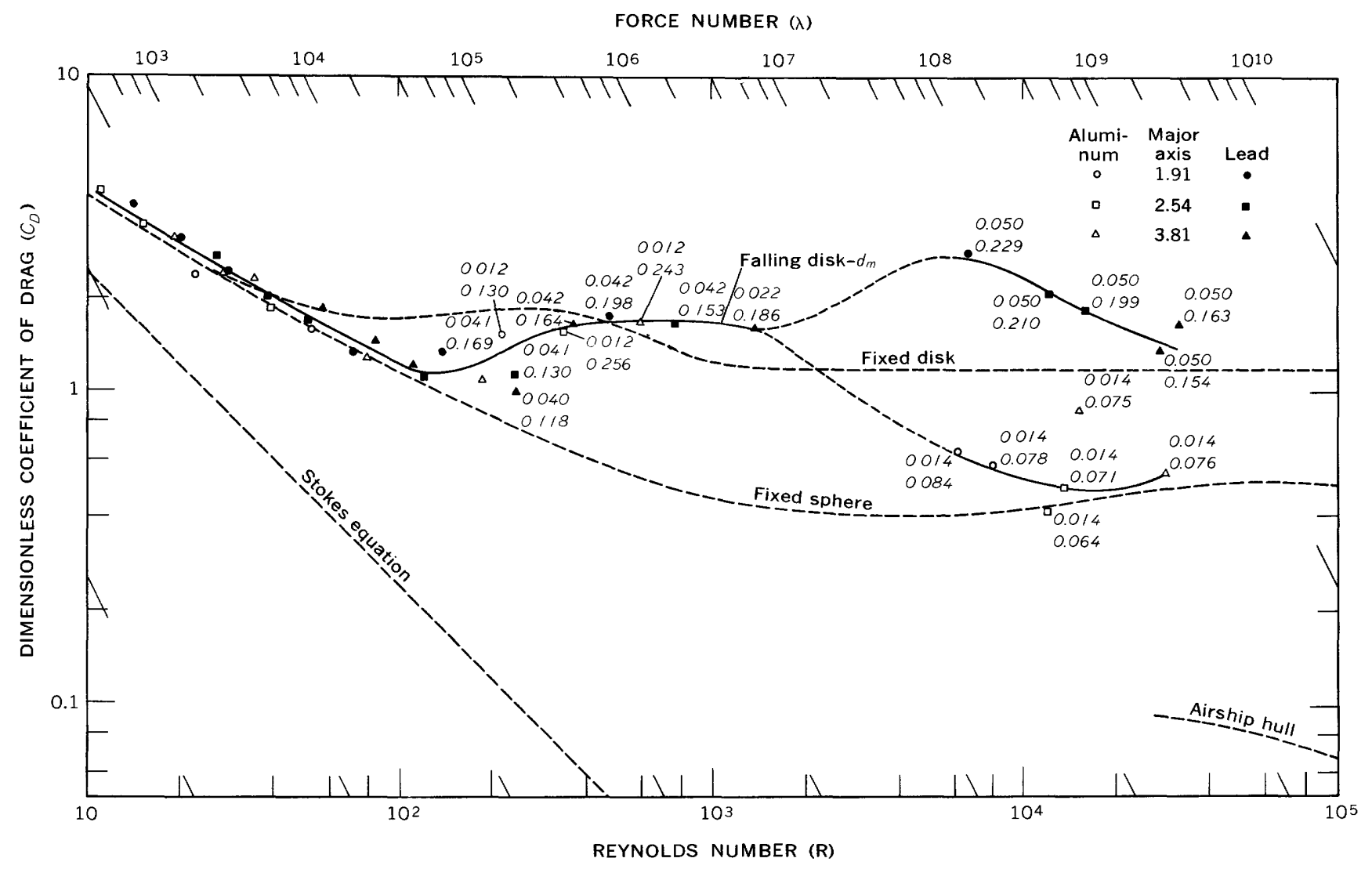

$A$

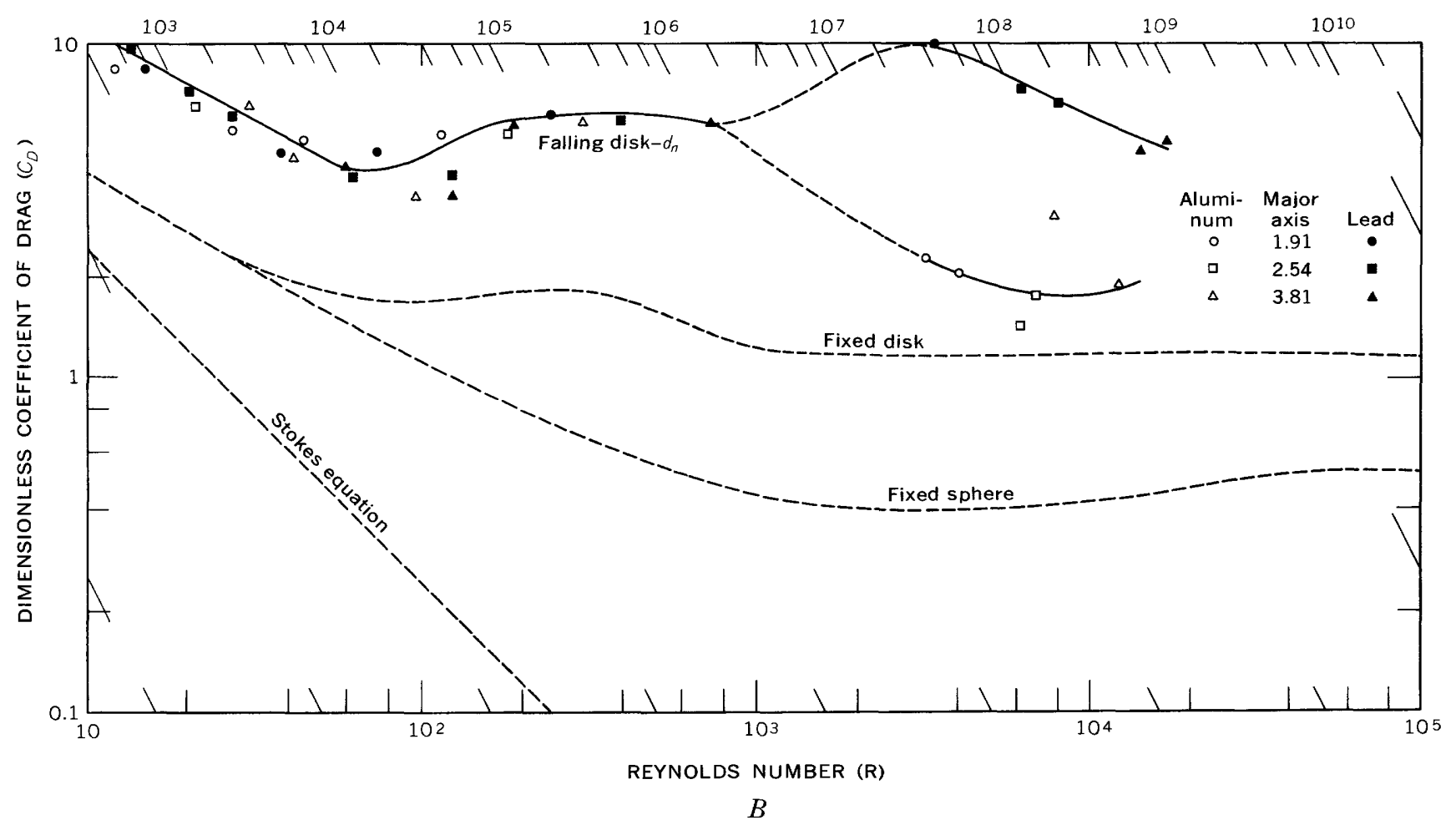

FIGURE 21.-Relationship of coefficient of drag and Reynolds number for falling disks having $S F_{c}=0.1 . A$, Computations are based on $d_{m}$ and vertical velocity. I and $\theta$ are given for points where disks were unsteady. $B$, Computations are based on $d_{n}$ and vertical velocity. 


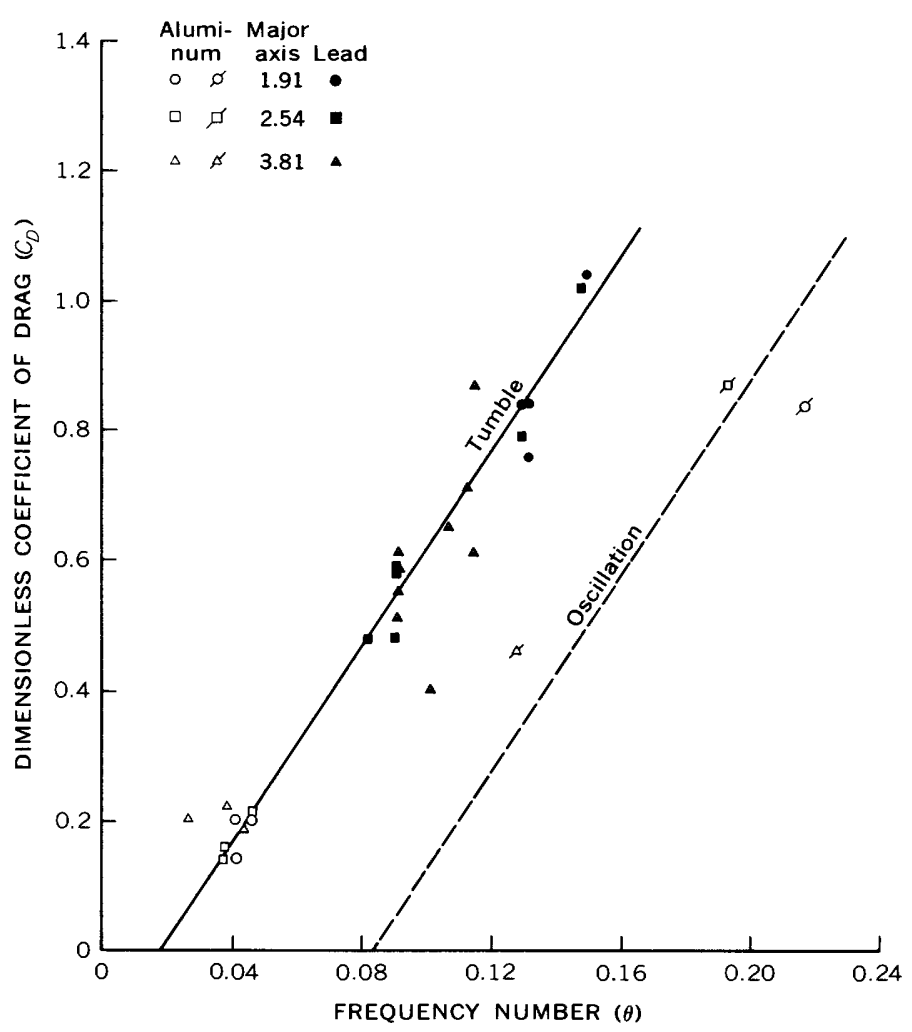

$A$

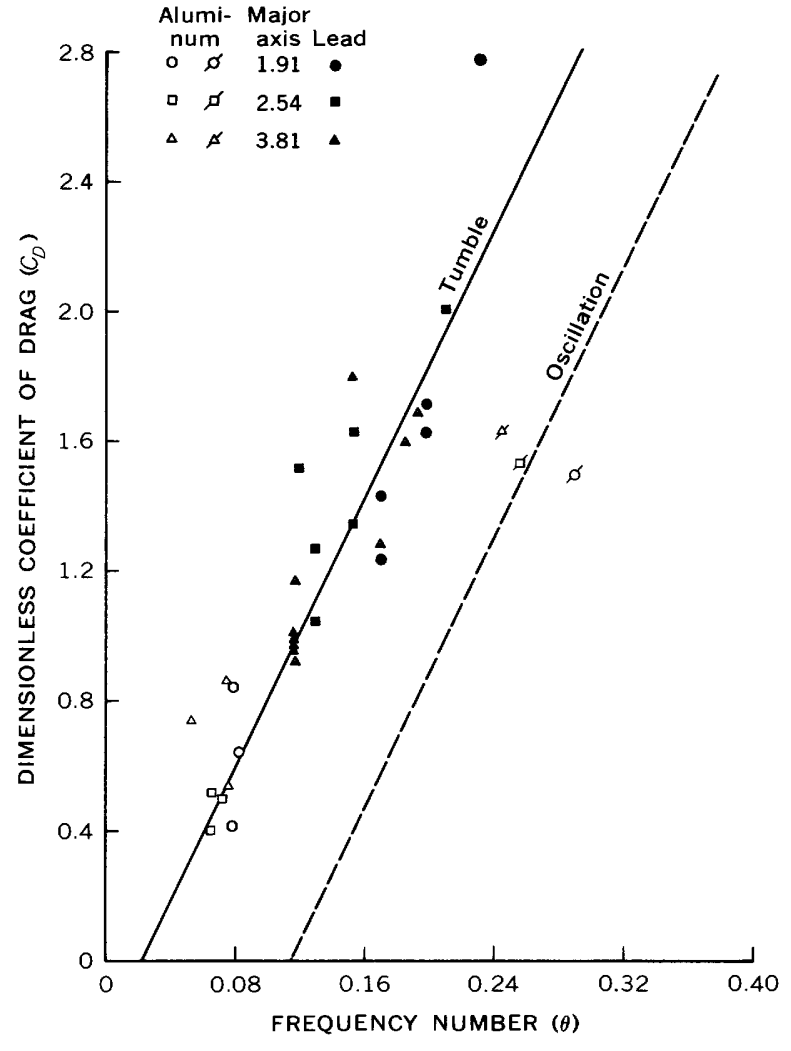

$B$

Figure 22.-Coefficient of drag as a function of frequency number for falling disks having $S F_{c}=0.1 . A$, Computations are based on $d_{m}$ and path velocity. $B$, Computations are based on $d_{m}$ and vertical velocity.

FigURE 23.-Coefficient of $\mathrm{drag}$ as a function at Reynolds number for falling oblate spheroids, $S F_{c}=0.5$. Computations are based on $d_{m}$ and path velocity. I and $\theta$ are given for points where the spheroids were unsteady. 


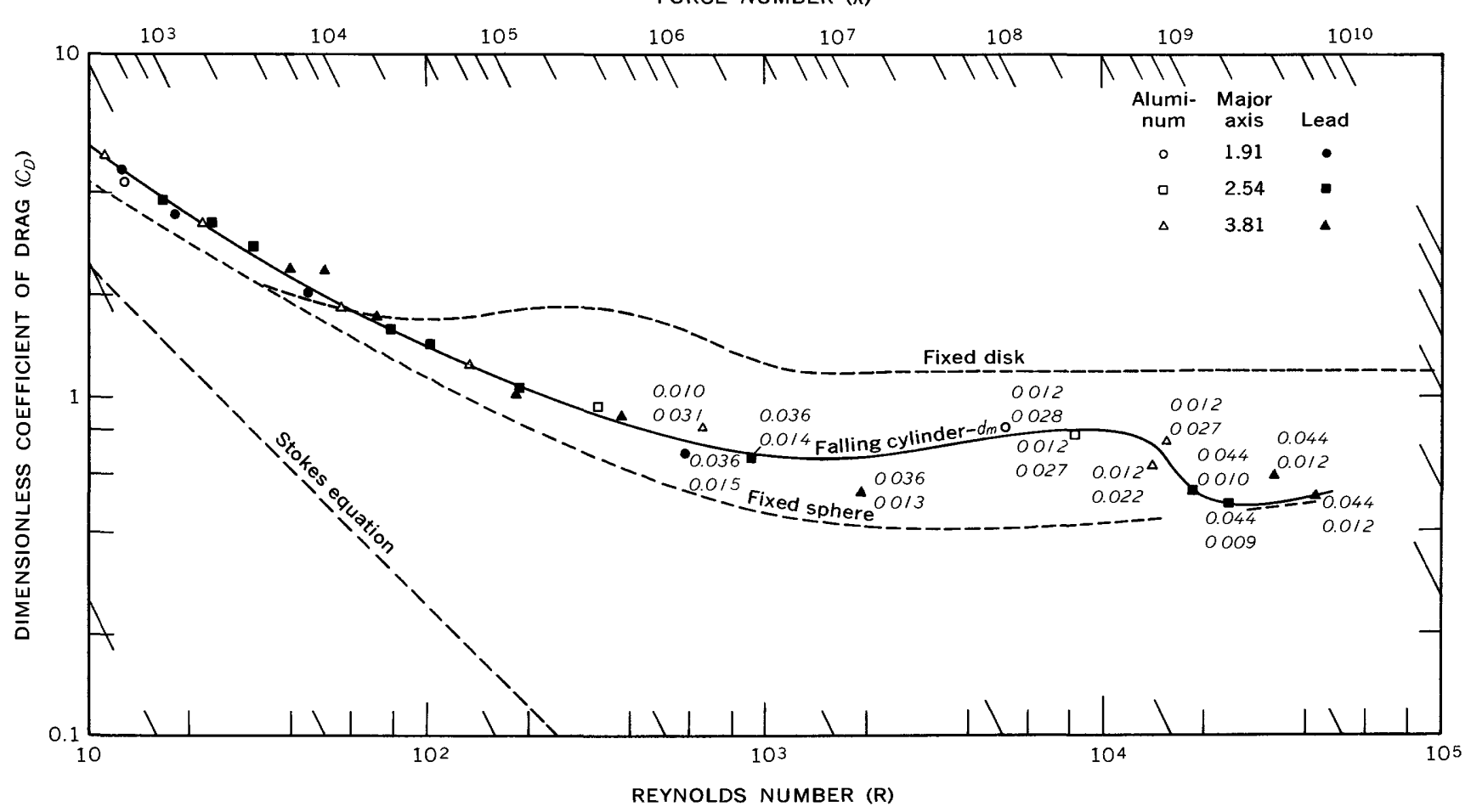

FIGURE 24.-Coefficient of drag as a function at Reynolds number for falling cylinders, $S F_{c}=0.5$. Computations are based on $d_{m}$ and path velocity. I and $\theta$ are given for points where cylinders were unsteady.

cylinder fall pattern. At $\mathbf{R} \approx 12,000$, the drag coefficient suddenly decreased.

In all instances where the cylinders were unsteady during fall, the increase in path length due to horizontal motion was small. The resulting increase in the path velocity over the vertical velocity was a maximum of 11 percent and a minimum of 1.6 percent. Average increase was 5.6 percent. As for disks, a strong relationship exists between $C_{D}$ and $\theta$, further evidence that resistance to motion increases as the degree of particle instability increases (fig. 25).

\section{PROLATE SPHEROIDS}

The prolate spheroids, a shape between the sphere and the cylinder, exhibited much the same patterns of fall as the cylinders. The first indication of instability was an oscillation in a vertical plane followed by an oscillation in both the horizontal and vertical planes as the Reynolds number increased. One particle, the 2.54 cm aluminum spheroid, exhibited a very slow rotation in the horizontal plane and no oscillation in the vertical plane. All particles were steady for Reynolds number ranging from 10 to 8,000 .

For $\mathbf{R}<200$, the $C_{D}-\mathbf{R}$ relationship for prolate spheroids is almost identical to that for spheres (fig. 26). Differences in path and vertical velocity were small. The path velocity was greater than the vertical velocity by a maximum of 5 percent and a minimum of 2.1 percent. The average increase was 3.3 percent.

\section{COMPARISON OF BEHAVIOR AMONG ALI PARTICLES}

When the $C_{D}-\mathbf{R}$ relationships for all particles computed by using $d_{m}$ and path velocity as characteristic parameters are compared, the relationships for spheres, oblate and prolate spheroids, and disks are almost identical in the range where $10<\mathbf{R}<400$ (fig. $27 A$ ). This consistancy in the relation of $C_{D}$ to $\mathbf{R}$ for spheres, oblate spheroids, and prolate spheroids indicates that the shape factor has only small effect on the fall velocity of a particle when $\mathbf{R}<400$. The coefficient of drag for cylinders is consistently higher when $10<\mathbf{R}<400$ than for the other four particles. The higher drag for cylinders is probably due to some characteristic not included in the shape factor. Perhaps the characteristic is the sharp corners which the cylinders have, but which the spheres and spheroids do not have. The sharp corners are part of the particle shape, but they are not included in the shape factor.

The effect of shape is more noticeable when $R>400$. The extreme shape of particles with small values of the Corey shape factor $S F_{c}$ causes separation of the flow and subsequent development of the pressure drag at smaller Reynolds numbers than for particles more uniformly shaped. The more rapid development of pressure drag of particles with small $S F_{c}$ causes the resistance to become independent of the Reynolds number at smaller values or $\mathbf{R}$ and larger values of $C_{D}$. 


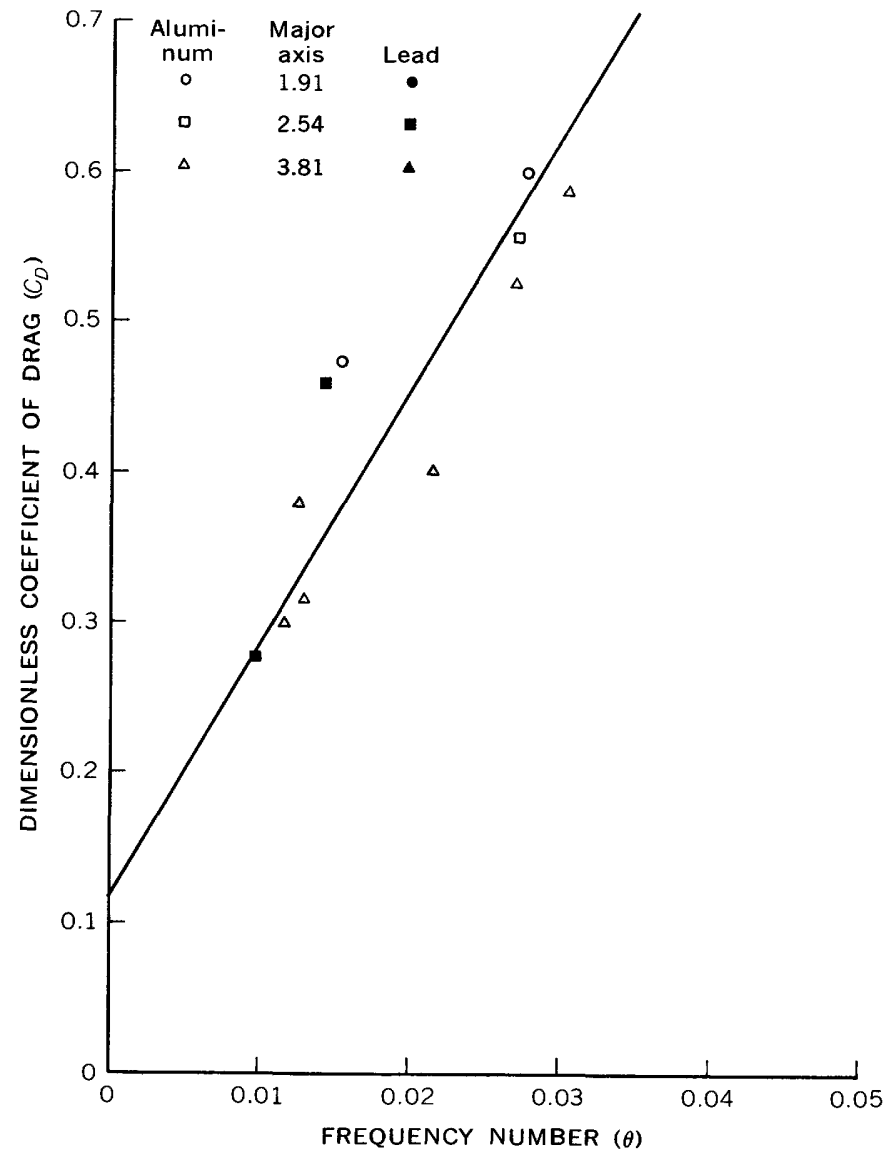

Figure 25.-Coefficient of drag as a function of frequency number for falling cylinders, $S F_{c}=\mathbf{0 . 5}$. Computations are based on $d_{m}$ and path velocity.

When $\mathbf{R}>10,000$, the $C_{D^{-}}-\mathbf{R}$ relationships for disks and cylinders, is not uniquely fixed by particle shape. It is a function of $\mathrm{I}, \theta$, and $\Phi$ as well.

When $\mathbf{R}<2,000$, the curves representing the relationship between $C_{D}$ and $\mathbf{R}$ are separated according to $S F_{c}$, except for cylinders and oblate spheroids, on the $C_{D}-\mathbf{R}$ diagram (fig. $27 B$ ). The cylinders and oblate spheroids have the same shape factor, but the relationships do not coincide. More will be said about the effect of particle shape in the section below.

\section{INTERPRETATION OF RESULTS}

The foregoing discussion presented experimental findings; the following interprets these findings.

\section{PARAMETRIC RELATIONSIIIPS}

The ratio between the maximum diameter $d_{m}$ and minimum diameter $d_{n}$ obviously is constant for all particles of one shape. Thus, when $d_{m}$ and $d_{n}$ are used to compute $C_{D}$ and $\mathbf{R}$, the constancy of the ratio of $d_{m}$ and $d_{n}$ preserves the "shape" of the curves representing the relationship of $C_{D}$ to $\mathbf{R}$ regardless of which characteristic diameter is used. Therefore, the shift in location of the respective curves on the $C_{D}-\mathbf{R}$ diagram is due to particle geometry, and the choice of diameter can be arbitrary as long as it is used consistently.

The difference found between the path and vertical velocities is a direct function of the effect of particle steadiness on the length of the fall path. The greater the degree of oscillation or rotation, the greater the difference between the velocities. Therefore, the $C_{D}-\mathbf{R}$ curves using the respective characteristic velocities in the computations for $C_{D}$ and $\mathbf{R}$, are the same as long as the particles are steady; they are different when the particles are unstable. Unlike the shift in the position of the $C_{D}-\mathbf{R}$ curve because of the change of characteristic diameter, the shift due to difference in velocity changes the shape of the curve. Probably much of the scatter in the data of other investigators is due to the change in vertical velocity brought about by the unstable condition of the particles during fall. All the given $C_{D}-\mathbf{R}$ diagrams that were based on the path velocity, except for the curve for disks when $R>10,000$, show a smooth curve, even when the particles oscillate and rotate. Hence, the fall velocity predicted from these $C_{D}-\mathbf{R}$ diagrams should be a close approximation of path velocity of the particle.

\section{PATTERNS OF FALI}

When the magnitude of the pressure drag on a particle approaches the weight of the particle, its pattern of fall is greatly influenced by small changes in the distribution of the pressure forces around it. Thus, the pattern of fall is a function of the steadiness of the center of pressure on the particle. Inasmuch as the pressure drag is dependent upon the degree of wake development, particle shape affects the pattern of fall to the degree that it affects the development and stability of the wake downstream from the particle.

If the wake stability is a function of the symmetry of the particle, then particles with a circular cross section should be more stable than ones with an elliptical cross section. Except for the disks, this was found to be true The oblate spheroids were more stable than either the prolate spheroids or the cylinders.

The fact that the disks were the most unstable indicates that extremeness in shape also affects the fall pattern. That is, extreme shape causes separation and wake development, and hence full development of pressure drag at smaller Reynolds numbers than for particles of more streamlined shapes, such as the oblate spheroids.

Apparently, the fall pattern of a particle becomes more steady (less oscillation and rotation and more vertical) as the Corey shape factor increases from numbers less than one to one. Also, the particle becomes 


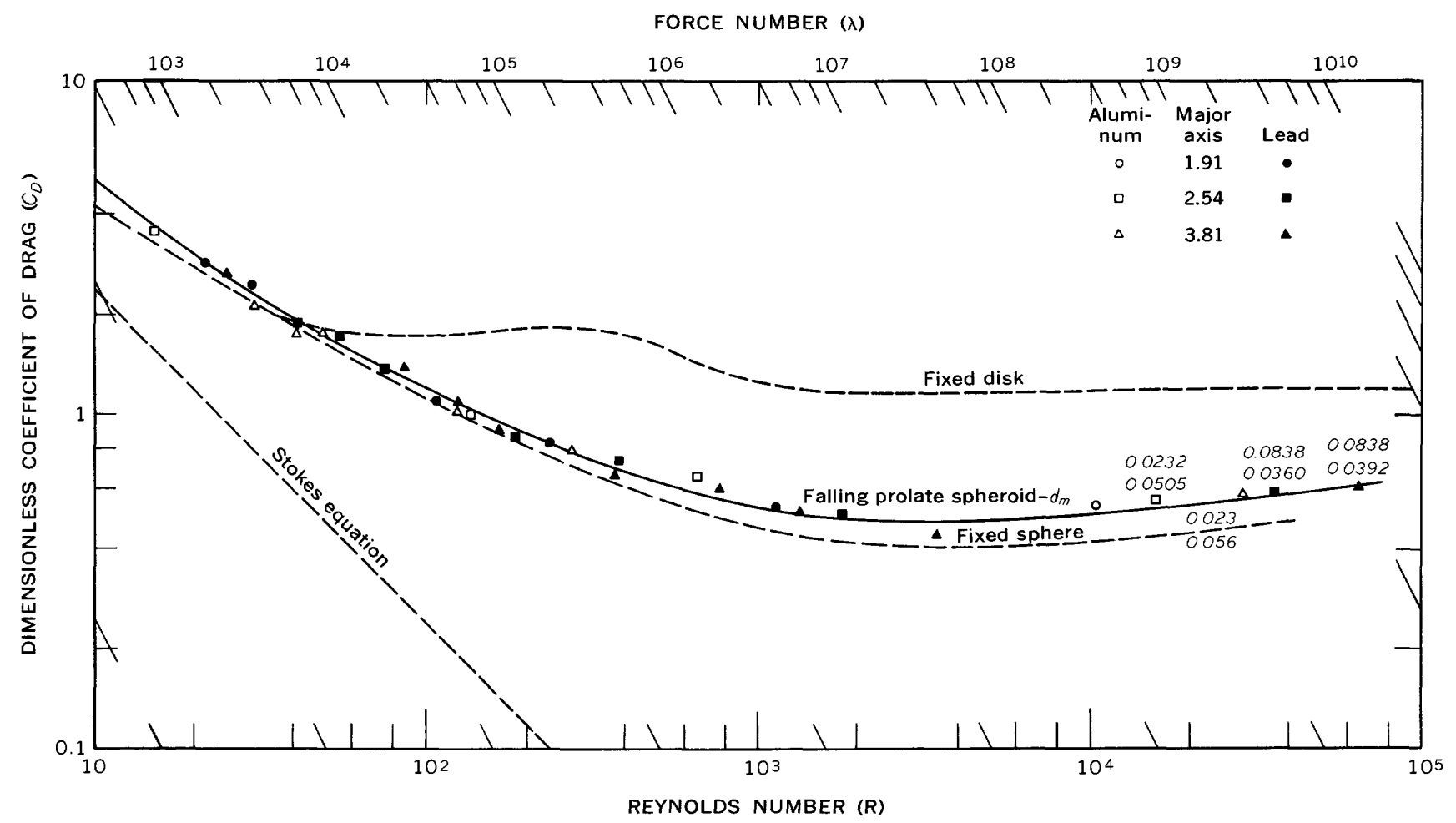

Figure 26.-Coefficient of drag as a function at Reynolds number for falling prolate spheroids, $S F_{c}=0.71$. Computations are based on $d_{m}$ and path velocity. I and $\theta$ are given for points where spheroids were unsteady.

more stable as $S F_{c}$ approaches one because of crosssectional changes from elliptical to circular. The effect of shape on the fall pattern of a particle is, therefore, a combination of the effects of the shape of the cross section and the extremeness of the overall shape or Corey shape factor $S F_{c}$.

The steadiness of the fall pattern of a particle has a marked effect on the ratio of path distance to vertical distance that the particle travels. The ratio increases as the degree of steadiness decreases. The degree of unsteadiness has a greater effect on the length of the path of nonspherical particles having a circular cross section than on those having elliptical cross sections. The path of travel for both disks and oblate spheroids was increased more by an unsteady fall pattern than it was for cylinders and prolate spheroids.

The separation of the curve into two parts in the $C_{D}-\mathbf{R}$ relationship was found only for disks. It is not known whether particle shapes other than disks will become sufficiently unsteady as a result of density differences for a similar division in the $C_{D}-\mathbf{R}$ relationship.

Two characteristics of an unsteady particle may reduce its fall velocity in turbulent natural flow from that obtained in a quiescent fluid. As previously noted, resistance to fall increases with the frequency of oscillation or rotation. If a particle, which has one fall pattern when falling in a quiescent fluid, were falling in a tur- bulent fluid, the turbulence may increase its oscillation, and hence its resistance to fall. The velocity of the particle would decrease a corresponding amount. The second characteristic is the increased length of the fall path as the particle becomes more unsteady. As the path of travel increases, the particle may be exposed to more turbulent eddies, which, in turn, would increase its unsteadiness. The net result would be a slower fall velocity than the same particle would experience in a quiescent fluid.

The turbulenece of a moving fluid may affect the behavior of a particle in another manner. Since resistance to motion is a function of $\omega^{2}$, squaring the mean velocity plus the velocity fluctuations will give a greater number to be used in equation 4 than the square of the mean velocity. The result will be a greater mean resistance to fall and a smaller mean fall velocity.

\section{SIIAPE FICTORS}

Of the three shape factors presented in the data (fig. $27 B$ ), the Corey shape factor $S F_{c}$ fits the $C_{D}-\mathbf{R}$ relationships in the most logical manner. It is still an inadequate measure because two curves having the same shape factor (cylinders and oblate spheroids) plot in quite different positions on the diagram. Alger's shape factor $S F_{c a}$, which modified $S F_{c}$ by accounting for surface area, fits the $C_{D}-\mathbf{R}$ curves (in fig. 27) except 

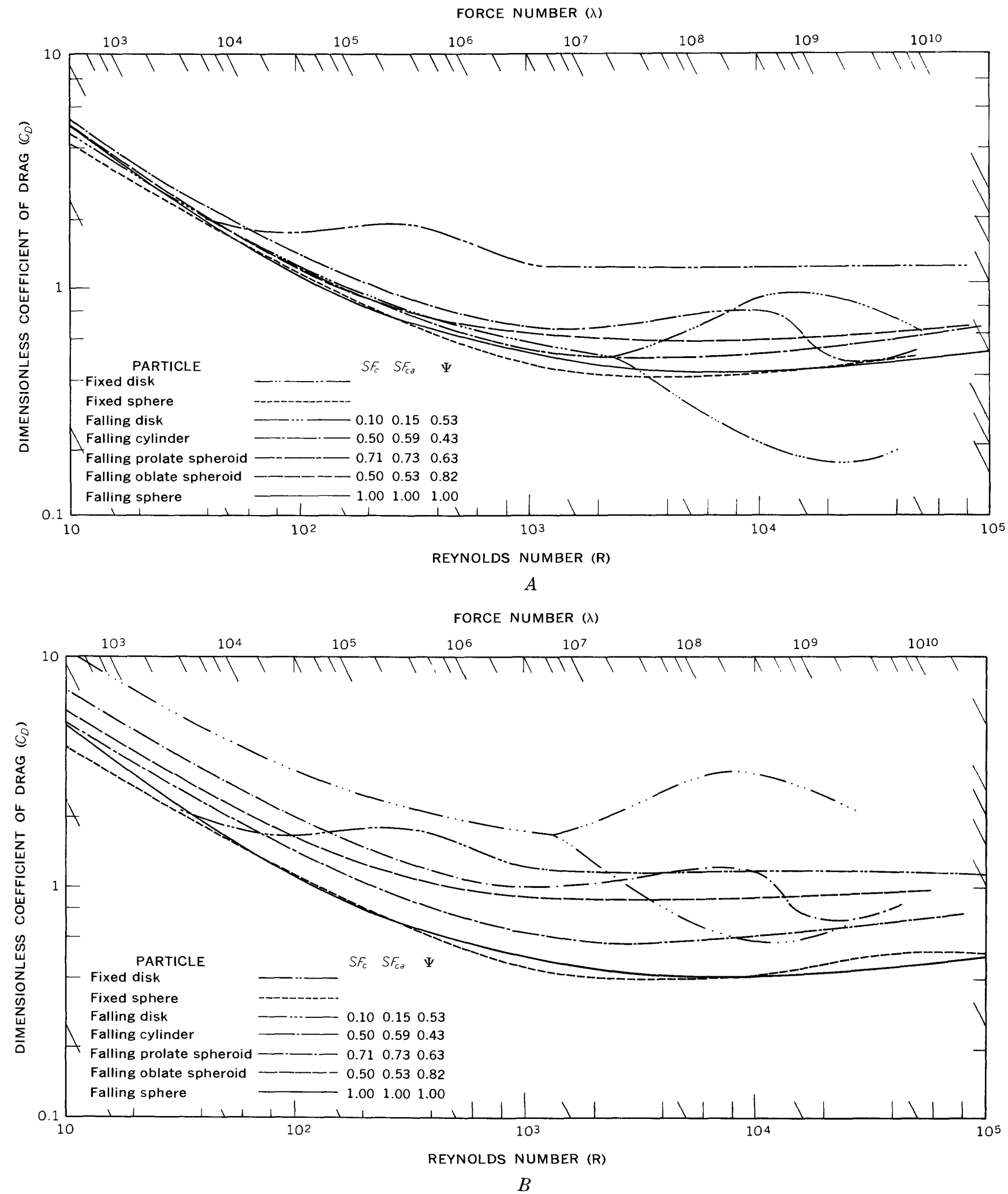

FiguRE 27.-Composite graphs of coefficient of drag as a function of Reynolds number for falling spheres, disks, oblate spheroids, cylinders, and prolate spheroids. $A$, Computations are based on $d_{m}$ and path velocity. $B$, Computations are based on $d_{n}$ and path velocity. 
for the cylinders and oblate spheroids. The larger value should be with the oblate spheroids rather than the cylinders to fit properly. Thus, the modification by Alger may overcompensate for some deficiencies of $S F_{c}$ for some particles. Wadell's sphericity parameter seems to be the least significant of the three shape factors.

Apparently, rough surfaces and sharp corners measurable increase the drag of falling particles. Comparisons of the curves representing the $C_{D}-\mathbf{R}$ relationship for crushed and naturally worn gravel particles have been made by Wilde (1952) and Colby (U.S. InterAgency Comm. Water Resources, 1957) for naturally worn sand and gravel. The curves for particles studied in the Wilde experiments indicate that roughness and roundness have as great an effect on particle fall velocity, if not greater, than the effects of shape.

Alger (1964) shows that the modification of $C_{D}$ and $S F_{c}$ by a factor proportional to the surface area of the particle is significant. By appropriate modification of $C_{D}$ and $S F_{\mathrm{c}}$ with the ratio $d_{A} / d_{n}$, Alger was able to predict the fall velocity of large concrete and steel cylinders from small aluminum models with an accuracy of about 2 percent. Alger assumed that $C_{D}$ was independent of $\mathbf{R}$ when $\mathbf{R}>2,000$. The relationship of $C_{D}$ to $\mathbf{R}$ for cylinders found in this study (fig. $27 \mathrm{~B}$ ) is not independent of $\mathbf{R}$ when $\mathbf{R}>2,000$. This appears to contradict Alger's findings.

\section{SUMMARY AND CONCLUSIONS}

The fall velocities of disks, cylinders, oblate and prolate spheroids, and spheres falling in quiescent fluids has been studied for the range of Reynolds numbers between 10 and 100,000. Curves that present the relationships between the coefficient of drag and the Reynolds number based on the path velocity, vertical velocity, maximum diameter, and nominal diameter as characteristic variables have been developed.

These characteristic variables are used to determine the coefficient of drag and the Reynolds number which are plotted on the $C_{D}-\mathbf{R}$ diagram. Individual particles, however, plot on lines of constant force number regardless of which parameters are used. Curves from points based on the nominal diameter and the maximum diameter of the particles are identical in shape when the path velocity is used in the $C_{D}-\mathbf{R}$ computations. The curves are also identical when the vertical velocity is used, but they are different from those for the path velocity. Curves using the path and vertical velocities are the same as long as the particles are steady, but deviate, depending on the degree of difference in velocity, when the particles become unsteady.

The falling spheres exhibited very little unsteadiness. The experimental curve based upon the data herein presented coincides with the curve for fixed spheres.
No rotation was apparent in any of the drops made with spheres except one that rotated through $45^{\circ}$ during its fall in the test section.

The disks were the least steady of all the particles tested. Unsteadiness first occurred in the form of oscillations in a vertical plane about a horizontal diameter at Reynolds numbers of approximately 100 . As the Reynolds number increases over its entire range, the results of the drops show a series of fall patterns ranging from a stable pattern of steady-flat fall where the disks fell vertically with their maximum projected area perpendicular to the direction of fall, to one of quasistable pattern of constant rotation. The patterns have been categorized in four general classifications which are, in turn, combined into three fall regimes as follows:

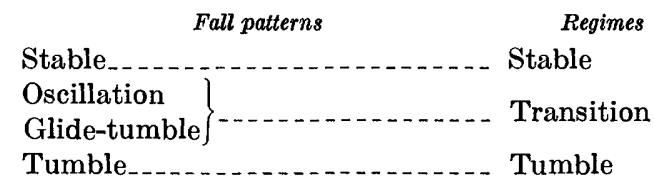

Boundaries of the suggested regimes are defined by $C_{D}, \mathbf{R}$, and $\mathrm{I}$.

The density ratio between the particles and the fluid affects fall velocity by virtue of its relation to the stability number I and to the frequency of oscillation. When $\mathbf{R}>10,000$, two branches of the $C_{D}-\mathbf{R}$ curve were defined for two different stability numbers of the disks. The stability number is greater for lead than aluminum disks, and the points for the lead disks plot higher on the $C_{D}-\mathbf{R}$ diagram than do the points for the aluminum ones. Since all variables of I are the same for all disks, including the thickness-diameter ratio, except the density ratio, the division in the curve must be due to particle density.

The coefficient of drag is a function of the frequency of oscillation as reflected by the linear relationship between $C_{D}$ and $\theta$. Thus, it can be concluded that both I and $\theta$ are important parameters in fall behavior studies.

The studies indicated that once oscillation began, disk unsteadiness was characterized by a rather uniform cyclic frequency. The oscillations were not random with respect to time.

The oblate spheroids were the most stable of the nonspherical particles. Reynolds numbers as great as 50,000 were obtained without indication of unsteadiness. When unsteadiness did develop, the patterns of fall were oscillation and tumble.

Prolate spheroids and cylinders had very similar patterns of fall, except that instability began at smaller Reynolds numbers for cylinders than for prolate spheroids. The general pattern of unsteady fall was that of oscillation in a vertical plane about a horizontal axis 
followed by the imposition of a horizontal oscillation about a vertical axis as Reynolds numbers increased.

When all curves based on the "path velocity" and the "maximum diameter" as characteristic parameters were plotted together, it was apparent that the shape of the particle had only a small effect on fall velocity for Reynolds numbers less than 400 . For $\mathbf{R}>400$, the particle shape had a more pronounced effect on the location of the $C_{D}-\mathbf{R}$ curves. Curves for particles with the smallest values of $S F_{c}$ became horizontal, or independent of $\mathbf{R}$, at lower Reynolds numbers than the curves for particles with larger $S F_{c}$ values.

When the fall patterns of all the particles were compared on the basis of shape, it was evident that the more extreme the shape, the greater the degree of instability. When extremes were not considered, it was apparent that particles with circular cross sections were more stable than particles with elliptical cross sections of the same $S F_{c}$.

This study indicates that more research is needed to investigate the various problems related to the behavior of large particles falling in quiescent fluids. The following studies would be helpful:

1. A systematic study of the effect of roughness and roundness on particle behavior. A comparison of these results with those of other investigations show that neglect of roughness and roundness may introduce errors of as much as 100 percent in estimating fall velocities.

2. A study to enlarge the concept of fall regimes to particles of shapes other than disks.

3. A more systematic study of the effect of the shape of the cross-sectional area needs to be made. The study herein reported appears to indicate that the $C_{D}-\mathbf{R}$ curve for particles with nearly circular cross section is not the same as the $C_{D}-\mathbf{R}$ curve for particles with elliptical or rectangular cross section even though the Corey shape factor is the same for both particles. Therefore, a study of particle behavior as the particle shape changes through progressive stages from an oblate spheroid to a sphere as compared to the particle behavior as the shape changes from a prolate spheroid to a sphere would be helpful.

4. The steadiness of a particle is important in its behavior. Therefore, a more detailed analysis of the equations of motion of a particle should be made.

\section{REFERENCES CITED}

Albertson, M. L., Barton, J. R., and Simons, D. B., 1960, Fluid mechanics for engineers: Englewood Cliffs, N.J., PrenticeHall, 561 p.
Alger, G. L., 1964, Terminal fall velocity of particles of irregular shapes as affected by surface area: Colorado State Univ., Ph. D. dissertation, $110 \mathrm{p}$.

Briggs, L. I., MeCullock, D. S., and Moser, F., 1962, The hydraulic shape of sand particles: Jour. Sed. Petrology, v. 32, no. 4, p. 645-656.

Brush, L. M., 1964, Accelerated motion of a sphere in a viscous fluid: Am. Soc. Civil Eng. Jour., v. 90, no. HY 1, p. 149-160.

Chatuthasry, N. C., 1961, Sedimentation diameter: SEATO Graduate School of Engineering, Bangkok, Thailand, M.S. thesis, $33 \mathrm{p}$.

Corey, A. T., 1949, Influence of shape on the fall velocity of sand grains: Colorado State Univ., M.S. thesis, 102 p.

Fahnestock, R. K., and Maddock, Thomas Jr., 1964, Preliminary report on bed forms and flow phenomena in the Rio Grande near El Paso, Texas, in Geological Survey research 1964, U.S. Geol. Survey Prof. Paper, 501-B, p. B140-B142.

Lamb, Horace, 1932, Hydrodynamics, New York, Dover Publications, $378 \mathrm{p}$.

MeNown, J. S., and Malaika, J., 1950, Effects of particle shape on settling velocity at low Reynolds numbers: Am. Geophys., Union Trans., v. 31, p. 74-82.

Odar, F., and Hamilton, W. S., 1964, Forces on a sphere accelerating in a viscous fluid: Jour. Fluid Mech., v. 18, pt. 2, p. 302-314.

Prandtl, L., and Tietjens, O. G., 1934, Applied hydro- and aeromechanics: New York, McGraw-Hill Book Co.

Rouse, H., 1946, Elementary mechanics of fluids: New York, John Wiley \& Sons, $376 \mathrm{p}$.

Rubey, W. W., 1933, Settling velocities of gravel, sand, and silt particles: Am. Jour. Sci., 5th ser., v. 25, p. 325-338.

Schulz, E. F., Wilde, R. H., and Albertson, M. L., 1954, Influence of shape on the fall velocity of sedimentary particles: Colorado State University and U.S. Army Corps of Engineers, MRD Sediment Ser., no. 5, $163 \mathrm{p}$.

Serr, E. F., 1948, A comparison of the sedimentation diameter and the sieve diameter for various types of natural sands: Colorado State Univ., M.S. thesis, $82 \mathrm{p}$.

Stelson, T. E., and Mavis, F. T., 1957, Virtual mass and acceleration in fluids: Am. Soc. Civil Eng. Trans., v. 122, p. 518-530.

Stringham, G. E., 1965, Behavior of geometric particles falling in quiescent viscous fluids: Colorado State Univ., $\mathrm{Ph}$. D. dissertation, $143 \mathrm{p}$.

U.S. Inter-Agency Committee on Water Resources, 1957, Some fundamentals of particle size analysis [prepared by B. C. Colby ***], in A study of methods used in measurement and analysis of sediment loads in streams: Washington, U.S. Govt Printing Office, Rept. 12, 55 p. [1958].

Wadell, H. A., 1932, Volume, space, and roundness of rock particles: Jour. Geology, v. 40, p. 443-451.

- 1933, Sphericity and roundness of rock particles: Jour. Geology, v. 41, p. 310-331.

- 1934, The coefficient of resistance as a function of Reynolds number for solids of various shapes: Franklin Inst. Jour., v. 217, no. 4, p. 459-490.

Wilde, R. H., 1952, Effect of shape on the fall-velocity of gravelsize particles: Colorado State Univ., M.S. thesis, 86 p.

Wilmarth, W. W., Hawk, N. E., and Harvey, R. L., 1964, Steady and unsteady motions and wakes of freely falling disks: Physics of Fluids, v. 7, no. 2, p. 197-208. 